\title{
The oleic acid-ozone heterogeneous reaction system: products, kinetics, secondary chemistry, and atmospheric implications of a model system - a review
}

\author{
J. Zahardis and G. A. Petrucci \\ Department of Chemistry, University of Vermont, Burlington, VT 05405-0125, USA \\ Received: 18 October 2006 - Published in Atmos. Chem. Phys. Discuss.: 9 November 2006 \\ Revised: 31 January 2007 - Accepted: 1 February 2007 - Published: 22 February 2007
}

\begin{abstract}
The heterogeneous processing of organic aerosols by trace oxidants has many implications to atmospheric chemistry and climate regulation. This review covers a model heterogeneous reaction system (HRS): the oleic acidozone HRS and other reaction systems featuring fatty acids, and their derivatives. The analysis of the commonly observed aldehyde and organic acid products of ozonolysis (azelaic acid, nonanoic acid, 9-oxononanoic acid, nonanal) is described. The relative product yields are noted and explained by the observation of secondary chemical reactions. The secondary reaction products arising from reactive Criegee intermediates are mainly peroxidic, notably secondary ozonides and $\alpha$-acyloxyalkyl hydroperoxide oligomers and polymers, and their formation is in accord with solution and liquidphase ozonolysis. These highly oxygenated products are of low volatility and hydrophilic which may enhance the ability of particles to act as cloud condensation nuclei (CCN). The kinetic description of this HRS is critically reviewed. Most kinetic studies suggest this oxidative processing is either a near surface reaction that is limited by the diffusion of ozone or a surface based reaction. Internally mixed particles and coatings represent the next stage in the progression towards more realistic proxies of tropospheric organic aerosols and a description of the products and the kinetics resulting from the ozonolysis of these proxies, which are based on fatty acids or their derivatives, is presented. Finally, the main atmospheric implications of oxidative processing of particulate containing fatty acids are presented. These implications include the extended lifetime of unsaturated species in the troposphere facilitated by the presence of solids, semi-solids or viscous phases, and an enhanced rate of ozone uptake by particulate unsaturates compared to corresponding gas-phase organics.
\end{abstract}

Correspondence to: G. A. Petrucci

(giuseppe.petrucci@uvm.edu)
Ozonolysis of oleic acid enhances its CCN activity, which implies that oxidatively processed particulate may contribute to indirect forcing of radiation.

\section{Introduction}

As of late the atmospheric chemistry and physics research community has been giving increasing attention to the role of organic aerosols $(\mathrm{OA})$ in the troposphere. This concern has initiated a number of recent reviews focusing on OA and addressing topics including: laboratory methodology (Rudich, 2003); the aging of OA (Rudich et al., 2007); the role of organic acids in forming CCN (Sun and Ariya, 2006; Yu, 2000); the role of bio-aerosols in forming CCN (Sun and Ariya, 2006); the role of OA in global climate modeling (Kanakidou et al., 2005); humic-like substances (HULIS) (Graber and Rudich, 2006); the significance of organic films at the air-aqueous interface (Donaldson and Vaida, 2006); as well as comprehensive works that span many of these disciplines (Jacobson et al., 2000) (Fuzzi et al., 2006). A common theme that echoes throughout many of these works is the importance of developing a better understanding of oxidative processing of $\mathrm{OA}$ and its implications to the troposphere.

It is clear that our understanding of the role of oxidative processing of OA is in its nascent stage. While typical OA in the troposphere has hundreds to thousands of components, we need to develop simple model systems to distill key features of oxidative processing of atmospheric OA. In this review we present an emerging reaction system, the oleic acidozone heterogeneous reaction system $\left(\mathrm{OL}-\mathrm{O}_{3}\right.$ HRS, oleic acid is cis-9-octadecenoic acid) that has become the benchmark for future experiments. As we discuss in Sect. 1.2, $\mathrm{OL}$ is a monounsaturated fatty acid found in tropospheric

Published by Copernicus GmbH on behalf of the European Geosciences Union. 
aerosols (Gill et al., 1983; Rogge et al., 1993c; Schauer et al., 1996; Stephanou and Stratigakis, 1993) and is employed as a tracer for cooking aerosols (Rogge et al., 1993c; Schauer et al., 1996; Stephanou and Stratigakis, 1993). We also discuss the very recent progression towards more complicated internally mixed $\mathrm{OA}$ and coatings that are more realistic proxies to tropospheric OA.

A recent workshop organized by the International Geosphere Biosphere Programme (IGBP) - International Global Atmospheric Chemistry Project (IGAC), Integrated Land Ecosystem Atmosphere Process Study (iLEAPS), and Surface Ocean-Lower Atmosphere Study (SOLAS) was held on atmospherically related phenomena and has been summarized (Fuzzi et al., 2006). In regards to OA four broad areas of concern were addressed: 1) sources; 2) formation and transformation; 3) physical and chemical state, and 4) atmospheric modeling.

Herein, we present a summary of experimental results and implications for the OL-O $\mathrm{O}_{3} \mathrm{HRS}$ and address points 2) and 3) above, with implications to 4). The results of these studies suggest that oxidatively processed OA may be good cloud condensation nuclei $(\mathrm{CCN})$ suggesting OA may play an important role in climate regulation by indirect aerosol effects.

\subsection{Scope of this review}

As we shall highlight in this review, it is clear that exposure to ozone has a strong effect on the chemical composition and physical properties of OL particles and has atmospheric implications. Therefore, there is a need to develop a better description of the oxidative processing of OA in the atmosphere. This includes a more detailed chemical and microphysical description of ozonolysis that includes reactive uptake, product description, and accounts for secondary reactions. Most importantly, correlation must be drawn between the roles of oxidative processing and the impact that OA has on atmospheric processes, such as indirect aerosol effects, where great uncertainty remains.

As of late, OL-O $\mathrm{O}_{3}$ HRS has emerged as a benchmark for studying the heterogeneous oxidation of unsaturated organics by ozone. In light of this, we present what has been learned about the OL-O $\mathrm{O}_{3}$ HRS in recent years. To set the stage we shall present a brief overview of sources of FA, including OL, to establish that it is ubiquitous in the troposphere and, importantly, highlight the interfacial role of FA in the troposphere. For more extensive details on the role of organic interfaces in general, the reader should consult the recent review by Donaldson and Vaida (2006). This will be followed by a concise summary of experimental methodologies. Emphasis will be placed on describing product formation of the OL-O ${ }_{3}$ HRS, most notably on the products of secondary chemistry. This is followed by a description of the resistor model of reactive uptake and a summary of the measurements of the reactive uptake of ozone by OL and related systems. Also discussed will be the kinetics of internally mixed particles and coatings, and the effects of phase equilibrium, morphology, and other factors on reactive uptake.

The discussion will focus on the broad tropospheric implications of oxidative processing of OA, from the perspective of what we have learned from this model system. Special attention will be given to the role of oxidized OA in acting as $\mathrm{CCN}$ and indirect aerosol effects.

\subsection{Sources of fatty acids and their role as surfactants in the} troposphere

Organic acids are ubiquitous in the troposphere and fatty acids (FA) make up a significant contribution to this fraction (Cheng et al., 2004; Duce et al., 1983; Hahn, 1980; Limbeck and Puxbaum, 1999). FA have both anthropogenic and biogenic sources, which we will briefly describe next. This is followed by an account of the important role of FA to act as organic surfactants in the troposphere and will also summarize some of the key experiments that have elucidated the importance of the FA and other organic interfaces in the troposphere.

Marine aerosols contribute significantly to the global organic aerosol load. Photosynthesis by marine organisms, especially autotrophic organisms such as phytoplankton, produces about 30-60 Pg of organic carbon annually (Duarte and Cebrián, 1996; Charpy-Roubaud and Sournia, 1990) including lipids. Typical total FA concentrations (dissolved plus particulate) in seawater range from $\sim 3-200 \mu \mathrm{gl}^{-1}$ (Marty et al., 1979). FA, along with $n$-alkanes and total hydrocarbons, are typically enriched on the microlayer (i.e. the air-sea interface) compared to the subsurface; for example, Marty et al. (1979) determined an enrichment of these chemical classes in the microlayer by a factor of $2-5$ in the northeastern Atlantic. The similarities between the ratios of the quantities of FA in the marine microlayer and in marine aerosols have long been noted (Barger and Garrett, 1970, 1976). These surface active agents are ejected into the marine troposphere by a bubble bursting mechanism (Blanchard, 1963, 1964; Barger and Garrett, 1970, 1976; Bezdek and Carlucci,

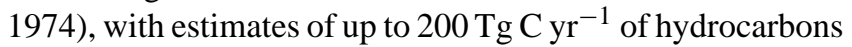
available for incorporation into marine OA proposed (Ellison et al., 1999). Organics comprise a significant fraction of marine aerosol, with estimates between $\sim 10-50 \%$ (wt/wt $\%$ ) (Maßling et al., 2003; Putaud et al., 2000) and may correlate with times of high biological activity (Mochida et al., 2002), notably plankton blooms (O’Dowd et al., 2004).

In the marine troposphere, C12-C19 FA are commonly observed, with the saturated FA being dominant (Mochida et al., 2002; Marty et al., 1979; Barger and Garrett, 1976; Quinn and Wade, 1972). They make a significant contribution to the organic coatings of sea salt particles (Tervahattu et al., 2002; Tervahattu and Juhanoja, 2002; Mochida et al., 2002). Unsaturated FA, including OL, have been observed (Mochida et al., 2002; Fang et al., 2002; Kawamura and Gagosian, 1987), and usually are at lower concentrations 
than saturated FA (Mochida et al., 2002; Fang et al., 2002; Kawamura and Gagosian, 1987). The detection of unsaturated FA in marine aerosols has been suggested to be indicative of recent biological origin (Fang et al., 2002), since they can me oxidized readily in the atmosphere. For example, Kawamura and Gagosian (1987)sampled remote marine aerosols on Enewetak Atoll 1 (Marshall Islands) and found stearic acid was $0.083 \mathrm{ng} \mathrm{m}^{-3}$, while the monounsaturated C18 (i.e., OL) was below the limit of detection. Similarly, in the North Pacific Ocean, stearic acid was detected at $0.21 \mathrm{ng} \mathrm{m}^{-3}$, while its monounsaturated analogue (e.g. OL) was $0.043 \mathrm{ng} \mathrm{m}^{-3}$ with other remote locations and fatty acid concentrations detailed in Table 1 of the report by Kawamura and Gagosian (1987). Similar trends were observed with the C16 saturated and monounsaturated FA (cf. palmitic and palmitoleic acid). Mochida et al. (2002) have also noted the lower abundance of unsaturated FA compared to saturated FA in aerosols in the marine boundary layer of the North Pacific. This study detected FA (C14-C32) and showed a positive correlation between C14-C19 FA with sea salt and biological activity. In this study, it was estimated that between $0.3-14 \%$ surface coverage for sea salt aerosols was due to C14-C19 saturated FA (Mochida et al., 2002).

In rural and remote continental locations, direct forest emissions, especially from vascular plants, are a significant biogenic source of FA (Cheng et al., 2004; Pio et al., 2001; Simoneit et al., 1988, 1991; Simoneit and Mazurek, 1982) including unsaturated FA. The unsaturated FA in these aerosols are often observed to be at lower concentrations than their saturated analogues due to oxidation. For example, in Harmattan aerosols of Nigeria, the ratio of saturated to unsaturated C18 FA generally favored the saturated species by factors of 0.6-230 (Simoneit et al., 1988). Similarly, this ratio was determined to be in the range 1.4-56 in aerosols in the western USA (Simoneit and Mazurek, 1982). The presence of unsaturated FA was considered to be a good indicator of recent biogenesis since they are rapidly oxidized (Simoneit et al., 1988).

There is a growing appreciation to the contribution bacteria (Ahern et al., 2006; Agranovski and Ristovski, 2005; Lee et al., 2007; Marks et al., 2001; Matthias-Maser and Jaenicke, 1995), pollen (Diehl et al., 2001, 2002; MatthiasMaser and Jaenicke, 1995), fungi (Elbert et al., 2006; Lee et al., 2007; Marks et al., 2001) and other microbial emissions from the biosphere make on the primary biogenic aerosol load. These primary biogenic emissions may have roles in acting as CCN (Sun and Ariya, 2006) and ice nuclei (Ahern et al., 2006; Diehl et al., 2001, 2002).

Gas and diesel powered vehicles contribute significant amounts of organics to the urban particulate load (Rogge et al., 1993a; Simoneit, 1985, 1986; Sodeman et al., 2005; Zheng et al., 2000; Huang et al., 2006; Hou et al., 2006; Fraser et al., 1999; Feng et al., 2006; Cheng et al., 2004). Rogge et al. (1993a) have shown that internal combustion engines burning gasoline and diesel contribute over $21 \%$ of the primary fine particulate organic carbon in Los Angeles. Similarly, Fraser et al. (1999) have shown that up to $19.1 \%$ of fine particulate organic material can be traced to motor vehicles during the morning traffic peak in Los Angeles. This fine particulate typically has more than 100 organic components and $n$-alkanoic acids, including saturated FA make up a considerable fraction of the total organic mass. Rogge et al. (1993a) found that for non-catalyst automobiles that the main portion of the identifiable organic mass $(61.2 \%)$ was polyaromatic hydrocarbons (including oxy-polyaromatic hydrocarbon classes); however, in contrast, in catalyst-equipped automobiles $n$-alkanoic acids, including saturated FA were the major component $(53.4 \%)$. In catalyst-equipped automobiles, palmitic acid was the most prevalent of the FA emissions, with an emission rate of $63.9 \mu \mathrm{g} / \mathrm{km}$ (Rogge et al., 1993a). Of unsaturated FA, OL was the most prevalent with an emission rate of $5.0 \mu \mathrm{g} / \mathrm{km}$ in the catalyst-equipped automobiles (Rogge et al., 1993a).

Cooking emissions are established as an important anthropogenic source of FA in urban environments (Zheng et al., 1997; Robinson et al., 2006; Rogge et al., 1991; Schauer et al., 1999). Very recently, a series of reports from China (Feng et al., 2006; Guo et al., 2003; He et al., 2004; Hou et al., 2006; Huang et al., 2006; Wang et al., 2006; Zhao et al., 2007) and Hong Kong (Sin et al., 2005; Zheng et al., 2000) have indicated that Chinese-style cooking can lead to significant FA emissions. Wang et al. (2006) studied organic aerosols in 14 coastal and inland mega-cities in China during the winter and summer 2003. The levels of fatty acids were very high, having an annual average of $769 \mathrm{ng} \mathrm{m}^{-3}$. Unsaturated FA (OL and palmitoleic acid) were found in all samples and had an annual total average concentration of $93.6 \mathrm{n} \mathrm{m} \mathrm{m}^{-3}$. Their concentration ratios compared to saturated FA (SA and C16) were $1.14 \pm 0.98$ in winter versus $0.43 \pm 0.09$ in summer, suggesting an enhanced photochemical degradation of the unsaturated FA during the summer (Wang et al., 2006; Kawamura and Gagosian, 1987). The high levels of FA in Chinese cities have been noted by others. Huang et al. (2006) reported a seasonal average concentration of FA at $260-483 \mathrm{ng} \mathrm{m}^{-3}$ in $\mathrm{PM}_{2.5}$ in Beijing, with unsaturated FA being present but at lower concentration than saturated FA. Zhao et al. (2007) studied four Chinese cooking styles in Guangzhou and determined that FA composed about $73-85 \%$ of the quantified particulate organic matter in $\mathrm{PM}_{2.5}$. This is similar to an earlier study on emissions of fine particulate from Chinese cooking in Shenzhen by He et al. (2004) that reported FA at over $90 \%$ in the quantified organic mass. In a study by Zheng et al. (2000)of solvent extractable organic compounds in $\mathrm{PM}_{2.5}$ of ambient aerosols in Hong Kong, FA were the major component at 46-80\% by weight. It should be noted that these authors considered the role of microbial and vascular plant emissions as well as cooking emissions (Zheng et al., 2000). A study in Mong Kok, Hong Kong by Sin et al. (2005) determined OL to be the predominant FA at $\sim 180 \mathrm{ng} \mathrm{m}^{-3}$ (our estimate from Fig. 5 
in their work) and attributed this to evaporation of cooking oils from the many "snack-bars/snack-counters" in that region that deep and stir fry foods in open kitchens in Mong Kok. As described in that work, OL was not the dominant FA in other sites in Hong Kong they monitored.

As noted in our discussion of marine aerosols, organics have been observed as coatings on sea salt particles (Tervahattu et al., 2002; Tervahattu and Juhanoja, 2002; Mochida et al., 2002) and there is recent, direct evidence that FA may be a more common coating on continental sulfate aerosols (Tervahattu et al., 2005) than has been previously suggested. These observations are helping to elucidate the importance of FA as organic surfactants in the troposphere. In prior works, organic surfactants had been hypothesized to reside on atmospheric particulate (Gill et al., 1983; Ellison et al., 1999; Finlayson-Pitts and Pitts Jr., 1999) and the transformation of these surfactants by oxidative processing had been suggested. Ellison et al. (1999) proposed a chemical model for the structure, composition and processing of organic particulate. Their model described organic aerosol in the form of an inverted micelle with an aqueous core and an organic surfactant coating, the latter being of biological origin. This model was important in that it suggested that the organic layer was transformed from an inert, hydrophobic film to a reactive, optically active hydrophilic layer via oxidation by atmospheric radicals. Subsequent studies have shown that these organic films are susceptible to oxidation by common tropospheric oxidants (Eliason et al., 2003, 2004; Asad et al., 2004; Mmereki and Donaldson, 2003; Moise and Rudich, 2001), with the oxidized films typically showing considerable change in composition and increased hydrophilicity (Asad et al., 2004; Demou et al., 2003; Moise and Rudich, 2001). Further details on how organic films at the air-aqueous boundary influence atmospheric processes are given in the recent review by Donaldson and Vaida (Donaldson and Vaida, 2006).

\section{Methodology}

Two main methodologies have been employed to study the OL-O $\mathrm{O}_{3}$ HRS: coated-flow tubes (CFT) and aerosol flow tubes (AFT). Both methodologies typically rely on mass spectral detection of chemical products. They differ in the way the organic-phase is presented to the trace oxidizing gas (cf. coating vs. particle); magnitudes of ozone exposure; as well as the chemical species that are monitored: in coated-wall studies of uptake, ozone decay is monitored while in the AFT studies the loss of the condensed-phase OL is typically monitored. Experiments employing CFT have a long tradition and therefore will be described only briefly in this report.

\subsection{Experiments with coatings and films}

The CFT method has been adapted to organic solid and liquid coatings, as well as mono-layers (Rudich, 2003) and semisolid coatings (Knopf et al., 2005). Typically, for liquid coating studies a wetted reactor is coated by placing a small volume of organic liquid within the reactor tube and rotating the reactor (de Gouw and Lovejoy, 1998; Moise and Rudich, 2000; Thornberry and Abbatt, 2004). With semi-solid coatings (Knopf et al., 2005), the preparative procedure affects the uptake of ozone as shall be discussed in detail later in this report. Ozone uptake is typically determined by monitoring the loss of $\mathrm{O}_{3}^{-}$that is generated by chemical ionization with $\mathrm{SF}_{6}^{-}$(de Gouw and Lovejoy, 1998; Knopf et al., 2005; Moise and Rudich, 2000; Thornberry and Abbatt, 2004).

Another means of assaying the oxidative processing of organic films employs quartz crystal microbalances. This method has been used to study the effects of ozone exposure on thin films of OL, including the way that oxidation can affect water uptake (Asad et al., 2004). A good description of this methodology as it is applied to organic thin films has been given by Demou et al. (2003). In CFT studies, the films are exposed to variable relative humidity ( $\mathrm{RH})$ while the oscillation frequency of a piezoelectric oscillator balance is monitored. As shall be discussed, recent studies employing this method show that water uptake is dramatically enhanced with OL after ozone exposure.

\subsection{Experiments with particles}

To date, aerosol-ozone studies of OL that have focused on kinetics, mechanism and/or product evolution have utilized pure OL particles (Hearn et al., 2005; Hearn and Smith, 2004b; LaFranchi et al., 2004; Morris et al., 2002; Smith et al., 2002; Zahardis et al., 2005, 2006a; Ziemann, 2005), internally mixed particles containing OL (Hearn et al., 2005; Hearn and Smith, 2004b, 2005; Katrib et al., 2005a; Ziemann, 2005; Mochida et al., 2006; Nash et al., 2006), and OL coatings on inert latex spheres (Katrib et al., 2004, 2005b). Very recently, complex OA such as meat-cooking (Hearn and Smith, 2006) and olive oil aerosols (Zahardis et al., 2006c), both with high OL content, have been evaluated. Both monodisperse and polydisperse aerosols have been interrogated. Kinetic studies on particulate OL typically monitor its decay directly and correlate it with the uptake of ozone. Most particle studies have employed AFT but environmental chambers have recently been used in the particle generation and reaction processes (Ziemann, 2005).

Motivation of OA studies in this size range include:

- The richness in organics of this range compared to that in the Aitken mode and in coarse particles (Hahn, 1980; Hoffman and Duce, 1977; Ketseridis and Eichmann, 1978) 
- The great uncertainty in magnitude of the impact of fine OA on radiative effects, with the greatest uncertainty on $\mathrm{CCN}$ mediated indirect aerosol effects

- The choice of this size range is in accord with particle dimensions that may have greatest impact on human health (Schwartz et al., 1996; Schwartz and Neas, 2000)

\subsubsection{Aerodyne aerosol mass spectrometry}

Morris et al. first employed an Aerodyne aerosol mass spectrometer (AMS) to study the OL-O 3 HRS (Morris et al., 2002). Numerous reports have appeared since on the use of the Aerodyne AMS to measure the loss of OL due to $\mathrm{O}_{3}$ uptake and reaction (Katrib et al., 2005a; Morris et al., 2002), determine stoichiometry (Katrib et al., 2004; Morris et al., 2002), identify chemical products (Katrib et al., 2004; Mochida et al., 2006), measure the volatility (Morris et al., 2002) of products formed by particles undergoing ozonolysis, observe changes in particle size (Katrib et al., 2005b) and morphology (Katrib et al., 2005a, b; Morris et al., 2002), and changes in particle density (Katrib et al., 2005b) due to ozonolysis. The Aerodyne AMS has been used to investigate particles with core-shell morphology (Katrib et al., 2004, 2005b) and has provided valuable information about changes in particle density, the O:C ratio and OL layer thickness as a function of ozone exposure. Very recently, Aerodyne AMS was utilized to determine the relative importance of competing pathways to high-molecular weight peroxides in the ozonolysis of mixed particle systems of methyl oleate (MOL) mixed with either dioctyl adipate (DOA) or myristic acid (C14) (Mochida et al., 2006).

\subsubsection{Chemical ionization mass spectrometry}

Chemical ionization mass spectrometry (CIMS) has been coupled to AFT-based experiments (Hearn et al., 2005; Hearn and Smith, 2004a, b, 2005) to measure the reactive uptake of ozone by OL, oleyl alcohol, linoleic acid, and 1octadecene. Particles are entrained in a jacketed flow tube, exposed to ozone with the aerosol's velocity determined by light scattering (Hearn and Smith, 2004a, b). Reacted particles are vaporized by a heated tube and chemical ionization of the vapor phase species is by proton exchange. Little fragmentation occurs with this soft-ionization process. Other methods of chemical ionization have been employed in these studies (Hearn and Smith, 2004a, b). The direct detection of the commonly observed products of ozonolysis (azelaic acid, nonanal, nonanoic acid, and 9-oxononanoic acid) and HMW species was reported for the ozonolysis of OL as well as relative product yields of some of these products (Hearn and Smith, 2004b) (Table 1). CIMS has also been applied to the study of internally mixed particles (Hearn et al., 2005; Hearn and Smith, 2004b, 2005) including complex particles such as meat-cooking aerosols (Hearn and Smith, 2006).

\subsubsection{Single-particle mass spectrometry}

Single-particle MS has shown applicability in the quantitative analysis of mixed particles, including OL and glycerol (Sykes et al., 2002), as well as measuring the uptake of ozone by OL (Smith et al., 2002). This method has recently been applied to the ozonolysis of mixed particles of $\mathrm{OL}$ and $\mathrm{C} 14$, revealing the presence of a solid surface layer and showing the effects of this surface layer on the reactive uptake of ozone (Nash et al., 2006). In these experiments, particles pass through an adjustable injector into a flow tube where they are reacted with ozone. Particle residence times are determined by light scattering. The OL decay is monitored by dual-laser, single-particle MS where an IR $\mathrm{CO}_{2}$ laser evaporates single particles and vacuum ultraviolet radiation is used to ionize the resultant molecular vapor. This decoupled scheme for vaporization and ionization has been used successfully to minimize molecular fragmentation and simplify product identification (Smith et al., 2002; Woods III et al., 2001, 2002) (Nash et al., 2005). The products observed and measured uptake coefficients of ozone by this method are summarized in Tables 1 and 2, respectively.

Similarly, experiments using synchrotron radiation in the vacuum ultraviolet range coupled with time-of-flight-MS (TOF-MS) are currently being adapted for real time analysis of OA including OL, and other FA (Mysak et al., 2005).

\subsubsection{Photoelectron resonance capture ionization aerosol mass spectrometry}

Photoelectron resonance capture ionization aerosol mass spectrometry (PERCI-AMS) (LaFranchi et al., 2004; Zahardis et al., 2005, 2006a, b) is a relatively new method to be applied to the OL-O ${ }_{3}$ HRS. Again, aerosol is sampled into a flow tube where it is reacted with ozone. Particles are then sampled with an aerodynamic lens into the ionization region of MS, where they are deposited onto a resistively heated wire. The resulting vapor is ionized with low-energy electrons and the gas-phase anions are monitored by TOF MS (LaFranchi and Petrucci, 2004; LaFranchi et al., 2004; LaFranchi and Petrucci, 2006). PERCI-AMS has been used for the direct and simultaneous measurement of all four of the commonly observed products of the ozonolysis of OL (LaFranchi et al., 2004; Zahardis et al., 2005), HMW peroxidic species (Zahardis et al., 2005) including polymers (Zahardis et al., 2006a), and has been applied to mixed particles (Zahardis et al., 2006b). Some of these products are summarized in Table 1. Recently this method has been applied to the analysis of the ozonolysis products of linolenic acid (LN) and olive oil (Zahardis et al., 2006c), a complex mixture of both saturated and unsaturated FA. 
Table 1. Products observed in the ozonolysis of OL particles and coatings.

\begin{tabular}{|c|c|c|c|c|c|c|c|c|c|c|c|c|c|c|c|}
\hline \multirow[b]{2}{*}{$\begin{array}{l}\text { OL dimension } \\
\text { (diameter or } \\
\text { thickness) }\end{array}$} & \multirow[b]{2}{*}{$\begin{array}{l}\mathrm{O}_{3} \text { conc } \\
\text { (molecules } \mathrm{cm}^{-3} \text { ) }\end{array}$} & \multicolumn{3}{|c|}{ Aerosol experiments } & \multirow[b]{2}{*}{$\begin{array}{l}\text { flow } \\
\left(\mathrm{cm}^{3} \mathrm{~s}^{-1}\right)\end{array}$} & \multirow[b]{2}{*}{$\begin{array}{l}\text { no. of molec } \\
\text { of OL }\end{array}$} & \multicolumn{2}{|c|}{ Coated-wall experiments } & \multirow[b]{2}{*}{$\begin{array}{l}\mathrm{O}_{3} \text { expos. } \\
\text { (atm s) }\end{array}$} & \multicolumn{5}{|c|}{ Carbon-based yield of products $(\%)$} & \multirow[b]{2}{*}{ Ref. } \\
\hline & & $\begin{array}{l}\text { reacn } \\
\text { time (s) }\end{array}$ & $\begin{array}{l}\text { OL conc } \\
\text { (molecules } \mathrm{cm}^{-3} \text { ) }\end{array}$ & $\begin{array}{l}\begin{array}{l}\text { OL conc } \\
\left(\text { (molecules }^{-1}\right. \\
\left.\text { particle }^{-1}\right)\end{array} \\
\end{array}$ & & & $\begin{array}{l}\text { no. of molecules of } \\
\mathrm{O}_{3} \text { (intg'd quan- } \\
\text { tity) }\end{array}$ & $\begin{array}{l}\text { molar ratio of } \\
\mathrm{O}_{3} \text { to } \mathrm{OL}\end{array}$ & & $\mathrm{NN}$ & OX & AA & $\mathrm{NA}$ & other & \\
\hline $200-600 \mathrm{~nm}$ & $2.5 \times 10^{14}$ & 7 & $<2 \times 10^{12 b}$ & $(8-200) \times 10^{6}$ & & & & $>10^{2}$ & $7 \times 10^{-5}$ & $\mathrm{n} / \mathrm{a}$ & $\mathrm{n} / \mathrm{a}$ & $\mathrm{n} / \mathrm{a}$ & $\mathrm{n} / \mathrm{a}$ & & $\begin{array}{l}\text { Morris } \\
\text { al. (2002) }\end{array}$ \\
\hline $10^{3} \mu \mathrm{m}$ & $1.0 \times 10^{14}$ & 0.1 & & & $50-200$ & $1.9 \times 10^{21}$ & $1.0 \times 10^{15}$ & $10^{-6}$ & $4 \times 10^{-7}$ & $25^{\mathrm{c}}$ & $\mathrm{n} / \mathrm{a}$ & $P$ & $P$ & & $\begin{array}{l}\text { Moise and } \\
\text { Rudich } \\
\text { (2000, 2002) }\end{array}$ \\
\hline $1.4-4.9 \mu \mathrm{m}$ & $3.4 \times 10^{15}$ & 8 & $<1 \times 10^{14 \mathrm{~d}}$ & $(3-100) \times 10^{9}$ & & & & $>30$ & $1 \times 10^{-3}$ & $\mathrm{n} / \mathrm{a}$ & $\mathrm{P}$ & $\mathrm{n} / \mathrm{a}$ & $\mathrm{n} / \mathrm{a}$ & & $\begin{array}{l}\text { Smith et } \\
\text { al. (2002) }\end{array}$ \\
\hline ca. $50 \mu \mathrm{m}$ & $10^{11}-10^{12}$ & $>0.1$ & & & 1.8 & $2 \times 10^{21}$ & $>2 \times 10^{10}$ & $>10^{-11}$ & $>10^{-9}$ & $25^{\mathrm{c}}$ & $\mathrm{n} / \mathrm{a}$ & $\mathrm{n} / \mathrm{a}$ & $\mathrm{n} / \mathrm{a}$ & & $\begin{array}{l}\text { Thornberry } \\
\text { and Abbatt } \\
(2004)\end{array}$ \\
\hline $2-30 \mathrm{~nm}$ & $2.5 \times 10^{14}$ & 3 & $3 \times 10^{18 \mathrm{e}}$ & $3 \times 10^{6 e}$ & & & & $10^{6}$ & $1 \times 10^{-5}$ & $0^{f}$ & $35^{\mathrm{e}}$ & $2^{\mathrm{e}}$ & $2^{\mathrm{e}}$ & $\begin{array}{l}35 \% \text { yield of } \mathrm{C}_{\mathrm{x}} \mathrm{H}_{\mathrm{y}} \mathrm{O}_{2} \text { prod- } \\
\text { ucts; } 25 \% \% \text { increase in parti- } \\
\text { cle density }\end{array}$ & $\begin{array}{l}\text { Katrib et } \\
\text { al. } \\
\text { 2005b) }\end{array}$ \\
\hline ca. $100 \mu \mathrm{m}$ & $10^{14}-10^{16}$ & 300 & & & 17 & $2.1 \times 10^{17}$ & $3 \times 10^{19 \mathrm{~g}}$ & $140^{\mathrm{g}}$ & $8 \times 10^{-2 g}$ & $\mathrm{n} / \mathrm{a}$ & $\mathrm{n} / \mathrm{a}$ & $\mathrm{n} / \mathrm{a}$ & $\mathrm{n} / \mathrm{a}$ & $\begin{array}{l}\text { increase in water uptake at } \\
95 \% \text { relative humidity }\end{array}$ & $\begin{array}{l}\text { Asad } \\
\text { al. (2004) }\end{array}$ et \\
\hline $0.6-1.0 \mu \mathrm{m}$ & $2.5 \times 10^{15}$ & 4 & $<5 \times 10^{13 \mathrm{~h}}$ & $5 \times 10^{8}$ & & & & $>50$ & $4 \times 10^{-4}$ & $42^{i, j}$ & $42^{\mathrm{i}}$ & 6 & $9^{\mathrm{i}}$ & $1 \%$ yield of $\mathrm{OOA}$ & $\begin{array}{l}\text { Hearn } \\
\text { and Smith } \\
\text { (2004b) }\end{array}$ \\
\hline $161 \mathrm{~nm}$ & $1.0 \times 10^{16}$ & 300 & $<4 \times 10^{10 \mathrm{~b}}$ & $4 \times 10^{6}$ & & & & $>2 \times 10^{5}$ & $4 \times 10^{-1}$ & $\mathrm{n} / \mathrm{a}$ & $\mathrm{n} / \mathrm{a}$ & $\mathrm{n} / \mathrm{a}$ & $\mathrm{n} / \mathrm{a}$ & $\begin{array}{l}\text { increase in CCN activity but } \\
\text { only for high ozone expo- } \\
\text { sure }\end{array}$ & $\begin{array}{l}\text { Broekhuizen } \\
\text { et al. (2004) }\end{array}$ \\
\hline $155 \mathrm{~nm}$ & $4.5 \times 10^{15}$ & 10 & $4 \times 10^{11}$ & $4 \times 10^{6}$ & & & & $1 \times 10^{4}$ & $2 \times 10^{-3}$ & $\mathrm{P}$ & $\mathrm{P}$ & $\mathrm{P}$ & $\mathrm{P}$ & $\begin{array}{l}\text { cyclic oxygenates having } \\
\text { oxygen-oxygen moieties, } \\
\text { including SO and cyclic } \\
\text { geminal diperoxides }\end{array}$ & $\begin{array}{l}\text { Zahardis et } \\
\text { al. (2005) }\end{array}$ \\
\hline $0.6-1.2 \mu \mathrm{m}$ & $\begin{array}{l}2.5 \times 10^{14} \text { to } \\
2.5 \times 10^{15}\end{array}$ & 4 & $<5 \times 10^{13 \mathrm{~h}, \mathrm{k}}$ & $5 \times 10^{8}$ & & & & $>50^{k}$ & $4 \times 10^{-4 j}$ & $\mathrm{n} / \mathrm{a}$ & $\mathrm{n} / \mathrm{a}$ & $\mathrm{n} / \mathrm{a}$ & $\mathrm{n} / \mathrm{a}$ & $\begin{array}{l}\text { uptake results suggest } 36 \% \\
\text { OL loss because of reac- } \\
\text { tions with CI }\end{array}$ & $\begin{array}{l}\text { Hearn } \\
\text { al. (2005) }\end{array}$ et \\
\hline $\begin{array}{l}\text { polydisperse, sub- } \\
\text { micron }\end{array}$ & $7.0 \times 10^{13}$ & 300 & $4 \times 10^{12}$ & $\mathrm{n} / \mathrm{a}$ & & & & 18 & $8 \times 10^{-4}$ & 0 & $28^{1}$ & $4^{1}$ & 0 & $\begin{array}{l}\text { major products include } \\
\text { AAHP, SO, other peroxides } \\
\text { and oxocarboxylic acids }\end{array}$ & $\begin{array}{l}\text { Ziemann } \\
(2005)\end{array}$ \\
\hline $0.5-3 \mathrm{~mm}$ & $7.5 \times 10^{15}$ & 2000 & & & 1.7 & $1.9 \times 10^{18}$ & $3 \times 10^{19}$ & 16 & 1 & $30^{\mathrm{f}}$ & 14 & 6 & 7 & $\begin{array}{l}\text { major yield of ester poly- } \\
\text { merization products of high } \\
\text { molecular weight (specifi- } \\
\text { cally,AAHP); } 1 \% \text { yield of } \\
\text { octanoic acid }\end{array}$ & $\begin{array}{l}\text { Hung } \\
\text { al. (2005) }\end{array}$ et \\
\hline
\end{tabular}

a The designation " $\mathrm{n} / \mathrm{a}$ " indicates that the analysis was not performed for these chemical species. "P" indicates the chemical species was present but its yield not quantified. Key: NN, nonanal; OX, 9-oxononanoic acid; AA, azelaic acid; NA, nonanoic acid. All other abbreviations correspond to the text and are compiled in Appendix A. ${ }^{\text {b }}$ Assumption is made of an upper-limit of $10^{4}$ particles $\mathrm{cm}^{-3}$ based on use of electrostatic classification of a polydisperse source. ${ }^{\mathrm{c}}$ Gas-phase NN. ${ }^{\mathrm{d}}$ Assumption is made of an upper-limit of $10^{3}$ particles $\mathrm{cm}^{-3}$ based upon use of vibrating orifice generator. ${ }^{\mathrm{e}}$ Results shown are for a $30 \mathrm{~nm}$ coating. ${ }^{\mathrm{f}}$ Condensed-phase NN. $\mathrm{g}$ A range of ozone concentrations was used. Results are summarized for $6.5 \times 10^{14}$ molecules of $\mathrm{O}_{3} \mathrm{~cm}^{-3}$. h Assumption is made of an upper-limit of $10^{5}$ particles cm ${ }^{-3}$ based upon use of a Meinhard TR-30-A1 polydisperse source. ${ }^{\mathrm{i}}$ These yields are tentative because relative detection sensitivities are assumed. See

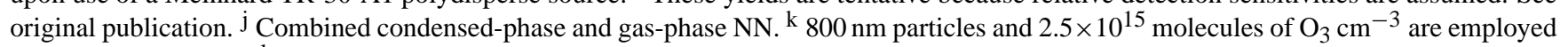
for these calculations. ${ }^{1}$ These yields are estimated mass percentages (Table adapted from Hung et al., 2005).

\subsubsection{Thermal desorption particle beam mass spectrometry}

The ozonolysis of pure OL particles or mixed particles of OL and a second organic (for example, dioctyl sebacate (DOS), hexadecanoic acid (C16, palmitic acid), or heptadecanoic acid (C17) have been studied in an environmental chamber using thermal desorption particle beam mass spectrometry (TDPBMS) (Ziemann, 2005). In these studies typically the OL is introduced by evaporation into an environmental chamber, after which particle formation proceeds via homogeneous nucleation. Mixed particles on the other hand are produced by nebulization of the appropriate solution. After reaction with ozone, the particles are analyzed in real-time by TDPBMS, collected and then vaporized by temperature programmed thermal desorption (TPTD) (Tobias and Ziemann, 1999), or their size distribution determined with a scanning mobility particle sizer, (SMPS). Vaporized particles are ionized by electron impact and mass analyzed by a quadrupole MS.

TDPBMS-TPTD has been utilized to measure the loss of $\mathrm{OL}$ due to $\mathrm{O}_{3}$ uptake and reaction in one-component and internally mixed particles, elucidation of mechanism, and the observation of many products of ozonolysis of OL, including HMW peroxidic species (Ziemann, 2005). These results are summarized in Tables 1 and 2. Recently TDPBMS has been applied to the heterogeneous reaction of $\mathrm{OL}$ with $\mathrm{NO}_{3}$ (Docherty and Ziemann, 2006) as well as the formation of SOA by reactions of this oxidant with linear alkenes (Gong et al., 2005).

\subsubsection{Field-induced droplet ionization mass spectrometry}

Field-induced droplet ionization (FIDI) is a new technique (Grimm and Beauchamp, 2003) that very recently has been applied to the study of interfacial chemistry (Grimm et al., 2006). One variation of FIDI involves the suspension of 1$2 \mathrm{~mm}$ droplets, from a capillary that can undergo a heterogeneous reaction between the liquid- and gas-phase species (Grimm et al., 2006). After a given reaction time, a high electric field induces FIDI into the droplets, forming fine jets of smaller progeny droplets that are characterized by mass spectrometry. The potential applicability of FIDI to the analysis of heterogeneous processing is demonstrated in the very recent investigation (Grimm et al., 2006) that included the 
Table 2. Reactive uptake of ozone by OL, other FA and related compounds, and select mixed particles and coatings.

\begin{tabular}{|c|c|c|c|c|c|c|c|c|c|}
\hline & Hearn and Smith (2004b) & Morris et al. (2002) & Smith et al. (2002) & Hearn et al. (2005) & Ziemann (2005) & Katrib et al. (2005a) & Knopf et al. (2005) & $\begin{array}{l}\text { Moise and Rudich } \\
(2002)\end{array}$ & $\begin{array}{l}\text { Thornberry and Ab- } \\
\text { batt (2004) }\end{array}$ \\
\hline Method & AFT & AFT & AFT & AFT & Env. Chamber & $\mathrm{AFT}$ & CFT & CFT & CFT \\
\hline Detection & CIMS & AMS & Single particle MS & CIMS & TDPBMS & AMS & $\operatorname{CIMS}\left(\mathrm{O}_{3}^{-}\right)$ & $\operatorname{CIMS}\left(\mathrm{O}_{3}^{-}\right)$ & $\operatorname{CIMS}\left(\mathrm{O}_{3}^{-}\right)$ \\
\hline $\mathrm{OL}$ & $(7.5 \pm 1.2) \times 10^{-4}$ & $(1.6 \pm 0.2) \times 10^{-3}$ & $\begin{array}{l}(0.99 \pm 0.09)- \\
(7.3 \pm 1.5) \times 10^{-3 c} \\
(5.8-9.8) \times 10^{-3 d}\end{array}$ & $\begin{array}{l}(1.38 \pm 0.06) \times 10^{-3} \\
(8.8 \pm 0.5) \times 10^{-4 \mathrm{e}}\end{array}$ & $(1.3 \pm 0.2) \times 10^{-3}$ & $(1.25 \pm 0.2) \times 10^{-3}$ & $\begin{array}{l}(0.64 \pm 0.05) \times 10^{-4} \mathrm{~s} \\
(7.9 \pm 0.3) \times 10^{-4} 1\end{array}$ & $\begin{array}{l}(8.3 \pm 0.02) \quad \mathrm{x} \\
10^{-4} l \\
(5.2 \pm 0.1) \times 10^{-5} \mathrm{~s}\end{array}$ & $(8.0 \pm 1.0) \times 10^{-4}$ \\
\hline LA & $(1.1 \pm 0.2) \times 10^{-3}$ & & & & & & & $\begin{array}{l}(1.2 \pm 0.2) \times 10^{-3} 1 \\
(1.4 \pm 0.1) \times 10^{-4} \mathrm{~s}\end{array}$ & $(1.3 \pm 0.1) \times 10^{-3}$ \\
\hline LN & & & & & & & & & $(1.8 \pm 0.2) \times 10^{-3}$ \\
\hline MOL & & & & $(1.23 \pm 0.10) \times 10^{-3}$ & & & & & \\
\hline $\mathrm{OL} / \mathrm{SA}$ & & & & & & $\begin{array}{l}(1.25 \pm 0.2)- \\
(0.6 \pm 0.15) \times 10^{-3 \mathrm{f}} \\
(0.15 \pm 0.1) \times 10^{-3 \mathrm{~g}}\end{array}$ & & & \\
\hline $\mathrm{OL} / \mathrm{C} 12$ & & & & & & & $\begin{array}{l}(4-7.2) \times 10^{-4} 1 \\
(0.2-1.7) \times 10^{-4} \mathrm{~s}-1\end{array}$ & & \\
\hline $\mathrm{OL} / \mathrm{C} 14$ & & & & & & & $\begin{array}{l}(4-7.2) \times 10^{-4} 1 \\
(0.2-1.7) \times 10^{-4} \mathrm{~s}-1\end{array}$ & & \\
\hline $\mathrm{OL} / \mathrm{C} 16$ & & & & & $(0.13 \pm 0.1) \times 10^{-3}$ & & & & \\
\hline Oleic/C17 & & & & & $(0.25 \pm 0.2) \times 10^{-3}$ & & & & \\
\hline Oleic/DOS & & & & & $(1.1 \pm 0.4) \times 10^{-3}$ & & & & \\
\hline $\begin{array}{l}\text { meat-cooking acids }{ }^{\mathrm{h}} \\
\mathrm{d}_{p}(\mu \mathrm{m})\end{array}$ & $0.8-1.5^{\text {a }}$ & $0.2-0.6$ & $0.340-1.22$ & $0.6-1.2(\mathrm{OL})$ & $0.02-0.5$ & 0.300 (mobility) & $(1.6-6.9) \times 10^{-5}$ & & $0.6 \mathrm{~mm}$ film (ave.) \\
\hline $\max _{\mathrm{b}} \mathrm{O}_{3}$ exp. (atm s) & $5 \times 10^{-4}$ & $\sim 1 \times 10^{-4}$ & $1 \times 10^{-3}$ & $\begin{array}{l}0.6-1.110(\mathrm{MOL}) \\
\sim 5 \times 10^{-4}\end{array}$ & $\sim 1.4 \times 10^{-3}$ & $3.00 \times 10^{-4}$ & $\sim 1.5 \times 10^{-8}$ & $\sim 2.4 \times 10^{-9}$ & $\sim 2.1 \times 10^{-8}(\mathrm{OL})$ \\
\hline
\end{tabular}

a Polydisperse aerosols with a mean diameter of $800 \mathrm{~nm} .{ }^{\mathrm{b}}$ The symbol $(\sim)$ indicates we estimated the maximum exposure of ozone from data presented in the original work. ${ }^{\mathrm{c}}$ This corresponds with a radii range of monodisperse particles respectively from $2.45 \mu \mathrm{m}$ to $680 \mathrm{~nm}$ with other values of $\gamma$ for different diameter particles given in the original work. ${ }^{\mathrm{d}}$ These are the corrected values of $\gamma$ accounting for the diffusion of OL; see original work for more details. ${ }^{\mathrm{e}}$ This is a corrected value accounting for OL loss via secondary chemistry; see the original work for more details. ${ }^{\mathrm{f}}$ These values correspond to OL/SA from 100/0 to 60/40, by weight. $\mathrm{g}$ This values correspond to OL/SA from $50 / 50$ to $0 / 100$ by weight. ${ }^{\mathrm{h}}$ See original work for details on the multicomponent coatings.

ozonolysis of single droplets of OL as well as oleyl-L- $\alpha$ lysophosphatidic acid. In this preliminary work, Grimm et al. were able to identify two of the frequently observed products of ozonolysis of OL. Although more work is needed to quantify product yields, this method appears promising for the study of heterogeneous reactions.

\section{Pathways and products in the ozonolysis of oleic acid}

OL is a monounsaturated fatty acid (FA) that is susceptible to oxidation from common gas-phase oxidants, most notably $\mathrm{OH}, \mathrm{NO}_{3}$, and $\mathrm{O}_{3}$ (Finlayson-Pitts and Pitts Jr., 1999; Seinfeld and Pandis, 1998), the last of which is the focus of this work. $\mathrm{OH}$ and $\mathrm{NO}_{3}$ add to the double bond of alkenes rather than abstracting a hydrogen atom, which is common with their reactions with alkanes (Finlayson-Pitts and Pitts Jr., 1999; Seinfeld and Pandis, 1998). There have been several studies of the heterogeneous processing of organic films by OH (Cooper and Abbatt, 1996; Bertram et al., 2001; Molina et al., 2004) and $\mathrm{NO}_{3}$ (Moise et al., 2002; Knopf et al., 2006) that acted as proxies of atmospheric OA. There are only a limited number of studies of the heterogeneous processing of OL particles by $\mathrm{NO}_{3}$ (Docherty and Ziemann, 2006; Hung et al., 2005), and to the best of our knowledge none with $\mathrm{OH}$. Docherty and Ziemann (Docherty and Ziemann, 2006) found the major products of the reaction of $\mathrm{NO}_{3}$ radicals with liquid $\mathrm{OL}$ aerosol particles in the presence of $\mathrm{NO}_{2}, \mathrm{~N}_{2} \mathrm{O}_{5}$, and $\mathrm{O}_{2}$ to be hydroxy nitrates, carbonyl nitrates, dinitrates, hydroxydinitrates, and more highly nitrated compounds. Hung et al. (2005) found that the heterogeneous oxidation of deposited, millimeter-sized OL droplets by the nitrate radical resulted in products with functional groups $-\mathrm{ONO}_{2},-\mathrm{O}_{2} \mathrm{NO}_{2}$, and $-\mathrm{NO}_{2}$ and high molecular weight products. More studies with $\mathrm{NO}_{3}$ and $\mathrm{OH}$ of both organic films and particles are needed for us to get a more accurate understanding of oxidative processing in the troposphere.

Ozonolysis is an oxidative reaction between ozone and the carbon-carbon double bond of an unsaturated compound. OL is an ideal model monounsaturated FA for studies of heterogeneous processing with ozone, being abundant and ubiquitous in the troposphere.

- It is the aim of researchers in this field to adapt the methods employed in the OL-O $\mathrm{O}_{3} \mathrm{HRS}$ to more complicated organics and, importantly, multicomponent mixtures that reflect naturally occurring $\mathrm{OA}$

A brief summary of ozonolysis is given below. While the emphasis of this review is on heterogeneous chemistry of tropospheric relevance, inference shall be drawn from mainly from ozonolysis of unsaturated organics in solution and to a lesser extent gas-phase ozonolysis.

\subsection{Overview of ozonolysis}

A simplified version of the ozonolysis of an unsaturated compound in solution is often described by the following three step mechanism (Fig. 1) (Bailey and Ferrell, 1978; Criegee, 1975; Harding and Goddard III, 1978; Hiberty, 1976; Murray, 1968): 
STEP 1:

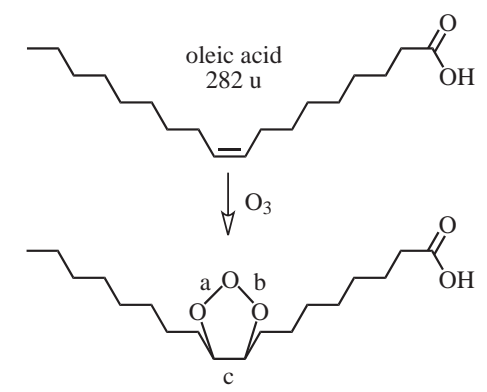

(primary ozonide, $330 \mathrm{u}$ )
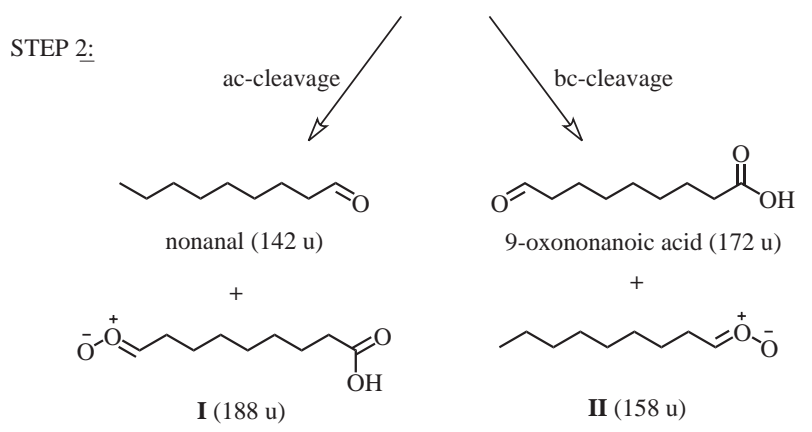

9-oxononanoic acid (172 u)

$+$

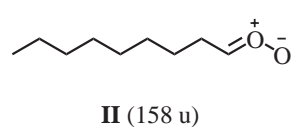

STEP 3:
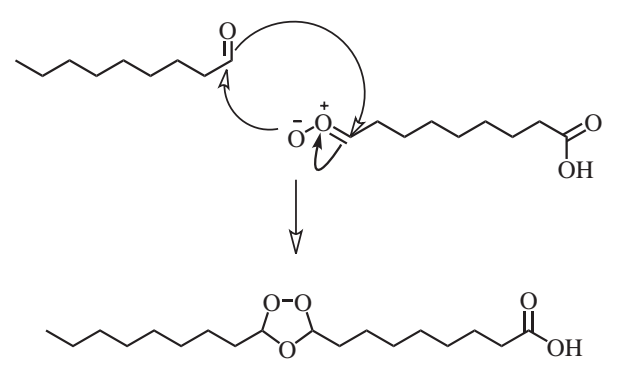

Secondary ozonide, $330 \mathrm{u}$

Fig. 1. Three-step reaction sequence of ozonolysis adapted to OL. Step 1: The formation of the PO; Step 2: Decomposition of the PO to nonanal, 9-oxononanoic acid and two stabilized CI; Step 3: An example of dipolar cycloaddition (for $a c$-cleavage route products) of CI (I) with nonanal.

\section{Step 1) formation of a primary ozonide (PO)}

Step 2) decomposition of the PO to aldehydes (or ketones) and carbonyl oxides (or Criegee intermediates, CI)

Step 3) recombination of the carbonyl oxide and the aldehyde (or ketone) to form secondary ozonides (SO)

In the ozonolysis of unsaturated species in solution, particularly at low temperature, SO are often observed and have been isolated in high yield (Bailey, 1978). As shall be discussed, the heterogeneous ozonolysis of OL and related compounds results in the formation of a medium rich in peroxides, including SO (LaFranchi et al., 2004; Zahardis et al.,
2005; Ziemann, 2005; Mochida et al., 2006) and other peroxidic products (Hung et al., 2005; Zahardis et al., 2005, 2006a; Ziemann, 2005; Hearn et al., 2005; Mochida et al., 2006; Nash et al., 2006). As will be explained, these products arise primarily from the reactivity of stabilized CI.

- "Secondary chemistry" will be defined as the reactions of the CI and aldehydes that arise from decomposition of the PO, as well as any subsequent reactions of the products of the aforementioned reaction

As will be evident throughout this review, the reactivity of the $\mathrm{CI}$ is of central importance in understanding the heterogeneous oxidative processing of $\mathrm{OL}$ and similar unsaturated species by ozone. Hence the following two sections dedicated to describing key features of the CI antecede the discussion of products of ozonolysis. The first of these sections summarizes important points on what is known about the electronic structure of the CI; the section following then distills notable differences between what is known about the gas- and liquid-phase reactivity of the CI.

\subsection{Criegee intermediates: electronic structure}

$\mathrm{CI}$ are depicted as both zwitterions and biradicals (a.k.a. diradicals) in the literature on the heterogeneous ozonolysis of OL. The discord in this description has its roots in part in the debate on the electronic structure of these intermediates that are extant in the organic chemistry literature (Bunnelle, 1991; Harding and Goddard III, 1978; Sander, 1990).

Criegee showed that for ozonolysis in solutions there was evidence indicating CI were zwitterionic (Criegee, 1975) based on reactivity trends (Criegee, 1975; Criegee and Wenner, 1949). On the other hand, as presented in a review by Bunnelle (1991), other researchers gave computational evidence that CI were singlet biradicals (Goddard III et al., 1973; Wadt and Goddard III, 1975). Revised considerations of some early calculations (Harding and Goddard III, 1978; Wadt and Goddard III, 1975) indicated the energy difference between the biradical and zwitterionic forms of the smallest CI were artificially large. Most subsequent computational studies focus on simple CI. Semiempirical calculations have been employed to investigate the effects of larger substituents on the electronic structure of CI and mostly indicate that substituted $\mathrm{CI}$ have significant biradical character (Bunnelle, 1991). The distilling conclusion of these investigations is that the $\mathrm{CI}$ electronic structure is best represented as a resonance between the biradical and the zwitterion.

More recent investigations have focused on substituted CI in solution. Density functional theory calculations indicate that the dipolar character is enhanced by progressive methylation (Selçuki and Aviyente, 1998). Solvent effects and resonance have also been considered (Parrondo et al., 1995) and it has been indicated that zwitterionic character was enhanced with increasing dielectric constant of the solution. 
In summary:

- CI most likely have zwitterionic and biradical resonances

- Computational work to date has primarily focused on smaller CI, especially $\mathrm{CH}_{2} \mathrm{OO}$

- We do not have an accurate description of the electronic state of CI generated in the ozonolysis of OL, let alone mixed OA. The electronic state of CI affects reactivity trends (Criegee, 1975; Criegee and Wenner, 1949); hence the predictions of product formation from ozonized OA will largely rely on empirical observations.

3.3 Criegee intermediates: gas-phase vs. liquid-phase reactivity trends

In regards to the fate of $\mathrm{CI}$ in the $\mathrm{OL}-\mathrm{O}_{3} \mathrm{HRS}$ there has been a question as to whether they react in a manner similar to what is observed in ozonolysis in the gas-phase or that in solution. In this section we will present a concise summary of the established reactivity of CI for these cases and in the following sections provide discussion that the CI react more in accord with solution chemistry. We will not present any details regarding a third experimental regime, namely investigations of $\mathrm{CI}$ in inert matrices under cryogenic conditions but interested readers can find several reviews (Bunnelle, 1991; Sander, 1990) that cover this topic of extensive research.

As noted by Neeb et al. (1998) regarding the differences in gas-phase and liquid-phase ozonolysis of ethene: "While the formation of the secondary ozonide is the most important reaction of the Criegee intermediate in the liquid-phase, its reaction pathways are quite different in the gas-phase, due to the generally much lower concentrations employed and the absence of solvent molecules." This statement is applicable towards the ozonolysis of most unsaturated compounds. A significant fraction of gas-phase CI undergoes unimolecular decomposition and these channels have been established for the simplest CI, $\mathrm{CH}_{2} \mathrm{OO}$ (Horie and Moortgat, 1991; Su et al., 1980; Herron and Huie, 1977). These products include $\mathrm{OH}$ and other free-radicals (Martinez et al., 1981; Neeb et al., 1998; Fenske et al., 2000; Gutbrod et al., 1997; Lewin et al., 2001; Aschmann et al., 2002; Ariya et al., 2000; Atkinson et al., 1995; Gutbrod et al., 1996).

As summarized by Neeb et al. (1998), in the gas-phase CI can undergo collisional stabilization and then can react with a variety of other species including aldehydes, $\mathrm{SO}_{2}, \mathrm{CO}$, water $\mathrm{NO}$, and $\mathrm{NO}_{2}$ as well as hydroxyl containing compounds (e.g. alcohols, organic acids) (Neeb et al., 1995, 1996).

In the gas-phase, CI can undergo spontaneous isomerization to a dioxirane, which by a 1, 2-hydrogen shift isomerizes to an acid (see review by Bunnelle, 1991). This acid is formed in a high energy state and may undergo dissociation if not quenched (Bunnelle, 1991; Herron et al., 1982). Numerous calculations summarized by Bunnelle (Bunnelle, 1991) indicate there is a considerable activation energy barrier between a thermally equilibrated CI and the dioxirane. For the channel of isomerization of the CI to the dioxirane to compete successfully against bimolecular channels the CI must be in a vibrationally excited state. As stated by Bunnelle (1991): "Depending on the excess energy between products, and further on the efficiency of collisional deactivation, the carbonyl oxides (i.e. CI) can be formed with sufficient internal energy to isomerize (to the dioxirane) spontaneously." These discussions focus, for the most part, on small CI, most notably, $\mathrm{CH}_{2} \mathrm{OO}$. Other fates of the $\mathrm{CI}$, such as ejection of atomic oxygen are considered by Bunnelle (1991).

The fate of CI in solutions is often quite different than in the gas-phase. As summarized by Bailey (1958) the CI has the following possible fates in solution:

1. The CI can undergo 1,3-dipolar cycloaddition with the carbonyl containing product that was formed from the decomposition of the PO. The products of these reactions are SO and polymeric ozonides

2. The CI can undergo 1,3-dipolar cycloaddition with other CI to form geminal diperoxides or polymeric peroxides

\section{The CI can undergo rearrangement}

4. The CI can react with protic solvents (e.g. alcohols, water, acids) and form hydroperoxides

While SO are often described as the major products of ozonolysis, there are some important exceptions. One of the most notable exceptions for this discussion is case (4) listed above; namely when the solvent is protic. In that case the CI may react with the protic species as or more efficiently than undergoing 1,3-dipolar cycloaddition with the carbonyl containing product formed from the decomposition of the PO (Bailey, 1958, 1978). This route may tend to favor hydroperoxide products (Bailey, 1958, 1978). This is of significance for the laboratory based observations that indicate that $\alpha$-acyloxyalkyl hydroperoxides are important products of the heterogeneous ozonolysis of OL and related unsaturated compounds (Zahardis et al., 2005, 2006a; Mochida et al., 2006; Ziemann, 2005; Hung et al., 2005; Hearn et al., 2005; Katrib et al., 2005a; Nash et al., 2006), and, as shall be discussed may be of significance in naturally occurring OA that contain water and other protic species.

As will be discussed, the results of these investigations on the $\mathrm{OL}-\mathrm{O}_{3} \mathrm{HRS}$ and related heterogeneous reaction systems are more in accord with solution chemistry than gas-phase ozonolysis. As will be described, in the OL-O 3 HRS, OL can be viewed as the solvent and appears to affect the product identity and yields in accord with solution chemistry. In subsequent sections we will make predictions on subsequent 
product types and yields relative to the $\mathrm{OL}_{-} \mathrm{O}_{3} \mathrm{HRS}$ for naturally occurring OA that can be admixtures of hundreds or more constituents that form the "solution". In light of this, the following solvent effects should be noted:

- Product distributions (i.e. the types and/or relative yields of products) in solutions that are treated by ozonolysis often depend on the solvent (Bailey, 1958, 1978; Greenwood, 1945; Pryde et al., 1968)

- The presence and types of peroxidic products appears especially sensitive to the type of solvent (Bailey et al., 1974; Fliszár et al., 1966; Murray, 1968; Zelikman et al., 1971; Bailey, 1958; Bernatek et al., 1967)

- Treatment of ozone-reacted mediums with acids (Bernatek et al., 1967; Bernatek and Ledaal, 1960; Bailey, 1978) may decompose ozonides and cause the formation of peroxyacids along with carbonyls. It is also well-established that bases can decompose ozonides and other peroxidic products of ozonolysis, forming ketones or aldehydes and carboxylic acids (Bailey, 1978). Ozonolysis in an aqueous medium can lead to the formation of $\alpha$-alkoxyalkyl hydroperoxides (Bailey, 1978), which can undergo decomposition (Pryde et al., 1968; Sturrock et al., 1963; Bailey, 1978)

3.4 Organic acid and aldehyde products of the ozonolysis of oleic acid

There are four commonly observed lower molecular weight (i.e. that is weigh less than OL) organic acid and aldehyde products observed in the heterogeneous ozonolysis of OL: azelaic acid, nonanal, nonanoic acid, and 9-oxononanoic acid. These products have been directly observed independently (Katrib et al., 2004; Moise and Rudich, 2002; Morris et al., 2002; Smith et al., 2002; Thornberry and Abbatt, 2004; Ziemann, 2005; Grimm et al., 2006) and simultaneously by researchers employing a variety of methodologies (Hearn and Smith, 2004b; Hung et al., 2005; LaFranchi et al., 2004; Zahardis et al., 2005). The yields of these products have been measured by some researchers and a recent compilation adapted from Hung et al. (2005) is given in Table 1.

In the following sections we will describe these four commonly observed aldehyde and organic acid products. These sections will concisely summarize under what conditions these products are observed and, when available, their yields. This is followed by a discussion of the secondary products of ozonolysis of OL and similar FA and their derivatives. These secondary products are mainly peroxides. This section antecedes a discussion which addresses the origin of the four commonly observed products and the likelihood that these products are, at least in part, third generation products arising from solvolysis of the peroxidic products.

\subsubsection{Azelaic acid}

Azelaic acid is a 9-carbon dicarboxylic acid that is a commonly observed product in the heterogeneous ozonolysis of OL. Azelaic acid has been independently measured at $6 \%$ by Hearn and Smith (2004b) and Hung et al. (2005) on the carbon-based yield scale (Hung et al., 2005). As summarized in Table 1, Hearn and Smith used CIMS to assay polydisperse aerosols with a mean diameter of $800 \mathrm{~nm}$, while Hung et al. oxidized OL as sub-millimeter to $\mathrm{mm}$ diameter droplets. Hung et al. had only a slightly larger number density of ozone compared to Hearn et al., but a much higher exposure due to the long time the droplets were exposed to the oxidant.

The yield of azelaic acid was also quantified by Katrib and coworkers in their studies of particles with core-shell morphology (Katrib et al., 2004) using an Aerodyne AMS. The yield was between $1-3 \%$ on the carbon-based yield scale for coatings between $2-30 \mathrm{~nm}$ in thickness. There appears to be a slight increase in azelaic acid yield with increasing thickness of OL.

Ziemann estimated that the mass fraction of azelaic acid is $\sim 4 \%$ for the reactions of submicron aerosols of OL in an environmental chamber as determined by TDPBMS (Ziemann, 2005).

As summarized on Table 1, other groups have detected, but not quantified, azelaic acid in the OL-O 3 HRS using AFT and CFT. Azelaic acid was also observed in the very recently reported heterogeneous ozonolysis of OL droplets by FIDI MS (Grimm et al., 2006).

- It should be noted that azelaic acid is often described in the literature as arising from the rearrangement of the CI that stems from the $a c$-route cleavage of OL (Hearn and Smith, 2004b; Katrib et al., 2004; Moise and Rudich, 2002; Rebrovic, 1992; Thornberry and Abbatt, 2004; Zahardis et al., 2005). As we discussed previously, the isomerization of a CI to the acid via a dioxirane is more typical of gas-phase reactivity than what is observed in solutions. There is strong experimental evidence that suggests this is may not be the case; rather that azelaic acid arises from the solvolysis of peroxidic products in accord with ozonolysis in solution (Mochida et al., 2006).

\subsubsection{Nonanal}

Nonanal is another commonly observed product of the heterogeneous ozonolysis of OL. This aldehyde can arise, at least in part, from the second step of ozonolysis by the $a c$ route cleavage of the PO. Nonanal is the most volatile of the four commonly observed products. In many cases, especially with the AFT based methodologies, this high volatility makes it difficult to measure nonanal. As shown in Table 1, Hearn and Smith (Hearn and Smith, 2004b) have measured a yield of $42 \%$ for this product on the carbon-based yield scale, 
with details provided by the authors of how they accounted for volatility losses. The authors assumed: a) the two $a c$ route products were azelaic acid and nonanal; $b$ ) these products were detected with equal efficiencies; c) a sum of moles of the products per mole of OL of this route is unity. The authors note that caution should be taken with these values since they are based on rather broad assumptions.

Hung and coworkers (Hung et al., 2005) reported a 30\% yield of nonanal on the carbon-based yield scale with their studies of OL droplets. This yield accounted for only nonanal in the condensed-phase, as opposed to Hearn and Smith, whose measure accounted for both the condensed- and gasphase nonanal. Furthermore, Hung and coworkers reported that $48 \pm 5 \%$ of the carbon was not detected. Indeed, the volatility of this species may be the cause for this discrepancy. Loss of nonanal by evaporation is in accord with the considerable loss of particulate mass measured in their experiments - upwards of $30 \%$ by carbon number. The radii of the droplets used by Hung et al. and the particles of OL used by Hearn and Smith were much larger than the coating thickness used by Katrib et al., which may account for the apparent difference in nonanal yield. Similarly, Ziemann did not observe nonanal with the ozonolysis of polydisperse submicron OL aerosol and attributed this to the high volatility of the aldehyde (Ziemann, 2005).

PERCI-AMS has been used for the detection of nonanal in the ozonolysis of submicron particulate (LaFranchi et al., 2004; Zahardis et al., 2006a, 2005). Although not quantified, the small relative signal intensity of nonanal compared to azelaic acid in these experiments (LaFranchi et al., 2004; Zahardis et al., 2006a, 2005) suggest that the former product may be lost to volatilization.

CFT based methods have been used to quantify the nonanal yield and studies to date report carbon-based yields of 25\% (Moise and Rudich, 2002; Thornberry and Abbatt, 2004). Thornberry and Abbatt detected the aldehyde product using CIMS with proton-transfer from $\mathrm{H}_{3} \mathrm{O}^{+}$(Thornberry and Abbatt, 2004). Only gas-phase species were detected in this study so no comparison to the yield of azelaic acid is possible. The authors note that the high volatility of nonanal caused some irreproducibility in their calibrations (Thornberry and Abbatt, 2004). A nonanal yield was reported by Moise and Rudich, with details of the mass spectral assignments given in the original article (Moise and Rudich, 2002) and details of the conditions given on Table 1. The yield of this aldehyde seems to be a function of temperature, with the yield decreasing from $296 \mathrm{~K}$ to $279 \mathrm{~K}$ with all other experimental conditions identical. Interestingly, the yield increases again if the temperature is decreased further (i.e., below 279 K). Similar behavior was observed with LA. Readers interested in further details on the temperature dependency of product evolution, ozone consumption, and its uptake by OL and related organic liquids, solids, and monolayers should consult the original works on these coated-wall reactor experiments (de Gouw and Lovejoy, 1998; Moise and Rudich,
2000, 2002; Thornberry and Abbatt, 2004).

In summary:

- The yield of nonanal is difficult to quantify due to volatilization losses

- Yields vary considerably between experiments probably due to differences in sizes of particles and droplets and thicknesses of coatings. Yields may be a function of temperature

\subsubsection{Nonanoic acid}

Nonanoic acid is a commonly observed product in the heterogeneous ozonolysis of OL. The yield of nonanoic acid has been quantified at $7 \%$ for droplets (Hung et al., 2005) and 9\% particles (Hearn and Smith, 2004b) and 2\% for coated particles (Katrib et al., 2004), with all values adjusted to the carbon-based yield scale. Hearn and Smith used aerosol CIMS; however, for this particular measure the reaction was performed offline, complicating comparison of yields from different routes. As summarized in Table 1, nonanoic has been detected in several other AFT experiments and in at least one CFT experiment, but in these cases the yield was not quantified. Ziemann did not observe nonanoic acid in his environmental chamber studies and attributed this to losses due to volatility (Ziemann, 2005).

- As was described previously for azelaic acid; nonanoic acid is often described in the literature as arising from the rearrangement of the $\mathrm{CI}$ that stems from the $b c$ route cleavage of OL (Hearn and Smith, 2004b; Katrib et al., 2004; Moise and Rudich, 2002; Rebrovic, 1992; Thornberry and Abbatt, 2004; Zahardis et al., 2005). As noted, there is strong experimental evidence that suggests this is may not be the case; rather that nonanoic acid may arise from the solvolysis of peroxidic products in accord with ozonolysis in solution (Mochida et al., 2006).

\subsubsection{9-oxononanoic acid}

9-Oxononanoic acid is another commonly observed product of the heterogeneous ozonolysis of OL and can arise, at least in part, from the second step of ozonolysis by the $b c$ route cleavage of the PO. Hearn and Smith (2004b) report a carbon-based yield of $42 \%$, while Hung et al. (2005) report a yield of $14 \%$ from their OL droplet experiments after a relatively long exposure time of $2000 \mathrm{~s}$. This product yield increases with ozone exposure as shown in the original work (Hung et al., 2005). Katrib et al. (2004) report a 35\% yield of 9-oxononanoic acid for $30 \mathrm{~nm}$ coatings of OL. Ziemann reported 9-oxononanoic acid at approximately $\sim 28 \%$ by mass in the reactions of submicron aerosols of OL in an environmental chamber as determined by TDPBMS (Ziemann, 2005). 


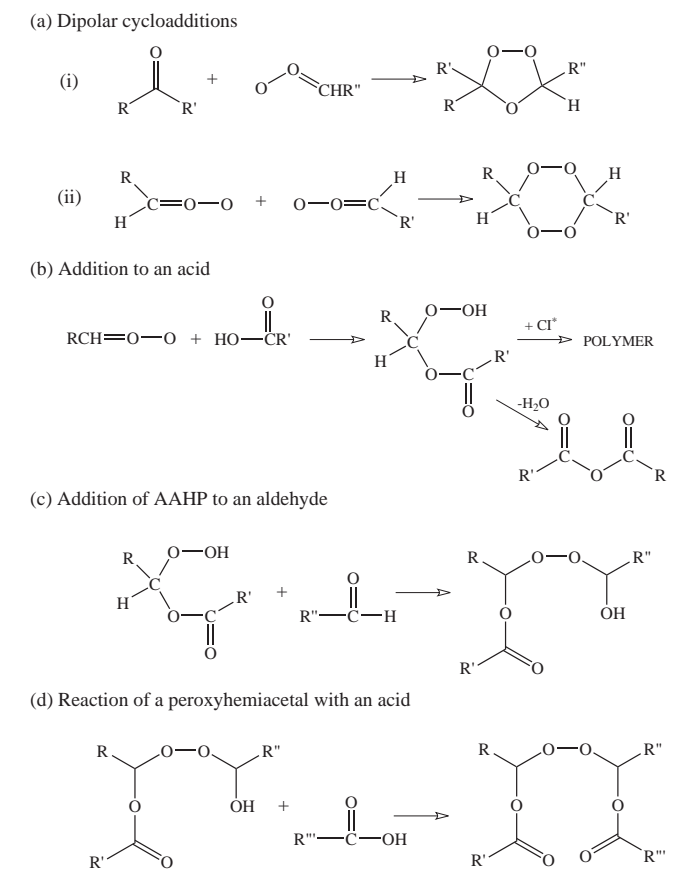

(e) ketone / aldehyde formation

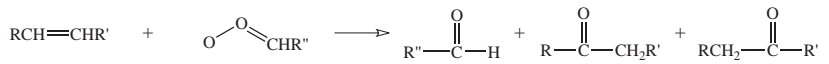

Fig. 2. Secondary chemistry arising from CI: (a) (i) Dipolar cycloaddition of CI with a carbonyl containing species forming a SO and (ii) Dipolar addition of two CI forming a cyclic geminal diperoxide (1, 2, 4-trioxolane); (b) Addition of CI to an organic acid leading to AAHP (when R or $\mathrm{R}^{\prime}$ contains a carbonyl group polymer propagation can occur); (c) Reaction of AAHP with an aldehyde forming a peroxyhemiacetal; (d) Further reaction of a peroxyhemiacetal with an organic acid forming a $\operatorname{bis}(\alpha$-acyloxy- $\alpha$-alkyl $)$ peroxide; (e) CI reaction with an unsaturated compound forming a ketone.

As summarized in Table 1, 9-oxononanoic acid has been detected by other AFT experiments but not quantified. Very recently, 9-oxononanoic acid was also detected FIDI MS (Grimm et al., 2006), but not quantified.

3.5 Products of secondary chemistry in the ozonolysis of oleic acid

A variety of products, mainly peroxidic in nature, have been observed in the heterogeneous ozonolysis of OL, other unsaturated FA, and their derivatives. These products have been attributed to the reactivity of the $\mathrm{CI}$ and are discussed in the following section. This is followed by an account of nonperoxidic products, namely ketones, which have been observed in the OL-O $\mathrm{O}_{3}$ HRS and in a related study with the methyl esters of FA.

\subsubsection{Peroxides and hydroperoxides}

The formation of peroxides, including hydroperoxides, is a key feature in the secondary chemistry of the OL-O $\mathrm{O}_{3} \mathrm{HRS}$. This is in accord with established observations of ozonolysis of unsaturated compounds in solution, where it has long been noted that $\mathrm{CI}$ can undergo dipolar cycloaddition with aldehydes and other $\mathrm{CI}$ forming SO and geminal diperoxides, respectively (Bailey, 1978; Criegee, 1975; Murray, 1968) or can react with solvents, for example reacting with carboxylic acids forming $\alpha$-acyloxyalkyl hydroperoxides (AAHP) (Bailey, 1978, 1958). An extensive compilation of this type of secondary chemistry is given elsewhere (Bailey, 1978, 1958).

As shown in Step 3 of Fig. 1, SO forms from the 1, 3dipolar cycloaddition of a CI with the carbonyl group of an aldehyde (or ketone), with both of these species arising from the decomposition of the PO. These SO can be formed by two main routes: a) the dipolar cycloaddition of the $\mathrm{CI}$ and the aldehyde that originate from the same route of decomposition of the PO; and, b) the dipolar cycloaddition of the $\mathrm{CI}$ and the aldehyde from opposite decomposition routes (Criegee, 1975). (Here we are ignoring the reaction with an aldehyde from an external source.) For simplicity, the former shall be referred to as the "conventional" SO and the latter as the "cross" SO, because the former appears to be the predominant type of SO formed in most studies in solution (Murray, 1968; Murray and Williams, 1969). Three geminal diperoxides are possible, two by the "conventional" route and one by "cross" cycloaddition. Two of these species were identified by Zahardis et al. (2005), with similarly weak signal intensity, though not quantified.

Recent work, in which organic peroxides were detected directly (Zahardis et al., 2005, 2006a; Ziemann, 2005; Hung et al., 2005; Mochida et al., 2006), suggests that organic peroxides may be a significant contributor to the $\mathrm{OL}-\mathrm{O}_{3} \mathrm{HRS}$. In one study it was estimated that the organic peroxides comprised $68 \%$ of the total aerosol product mass, while 9oxononanoic acid and azelaic acid were respectively only 28 and $4 \%$ (Ziemann, 2005). The classes of peroxidic products that have been detected include: $\alpha$-acyloxyalkyl hydroperoxides (AAHP), SO, $\alpha$-alkyloxyalkyl hydroperoxides, and oxocarboxylic acids. Figure 2 gives some illustrative examples of the reactions leading to some of these types of products. One of the assigned AAHP was proposed to be formed from either the reaction of 9-oxononanoic acid with a secondary $\mathrm{CI}$ or from an SO with the acid moiety of OL followed by oxidative cleavage about the double bond (Ziemann, 2005). The reactivity of AAHP has also been demonstrated by addition of octanal to the $\mathrm{OL}_{-} \mathrm{O}_{3}$ HRS after ozonolysis (Ziemann, 2005). This lead to the formation of a peroxyhemiacetal, which further reacted with 9-oxononanoic to form an observed bis ( $\alpha$-acyloxy - $\alpha$-alkyl) peroxide. Finally, the high degree of functionality of many of the measured reaction products implies the existence of numerous pathways leading to the formation of HMW products or oligomers. 


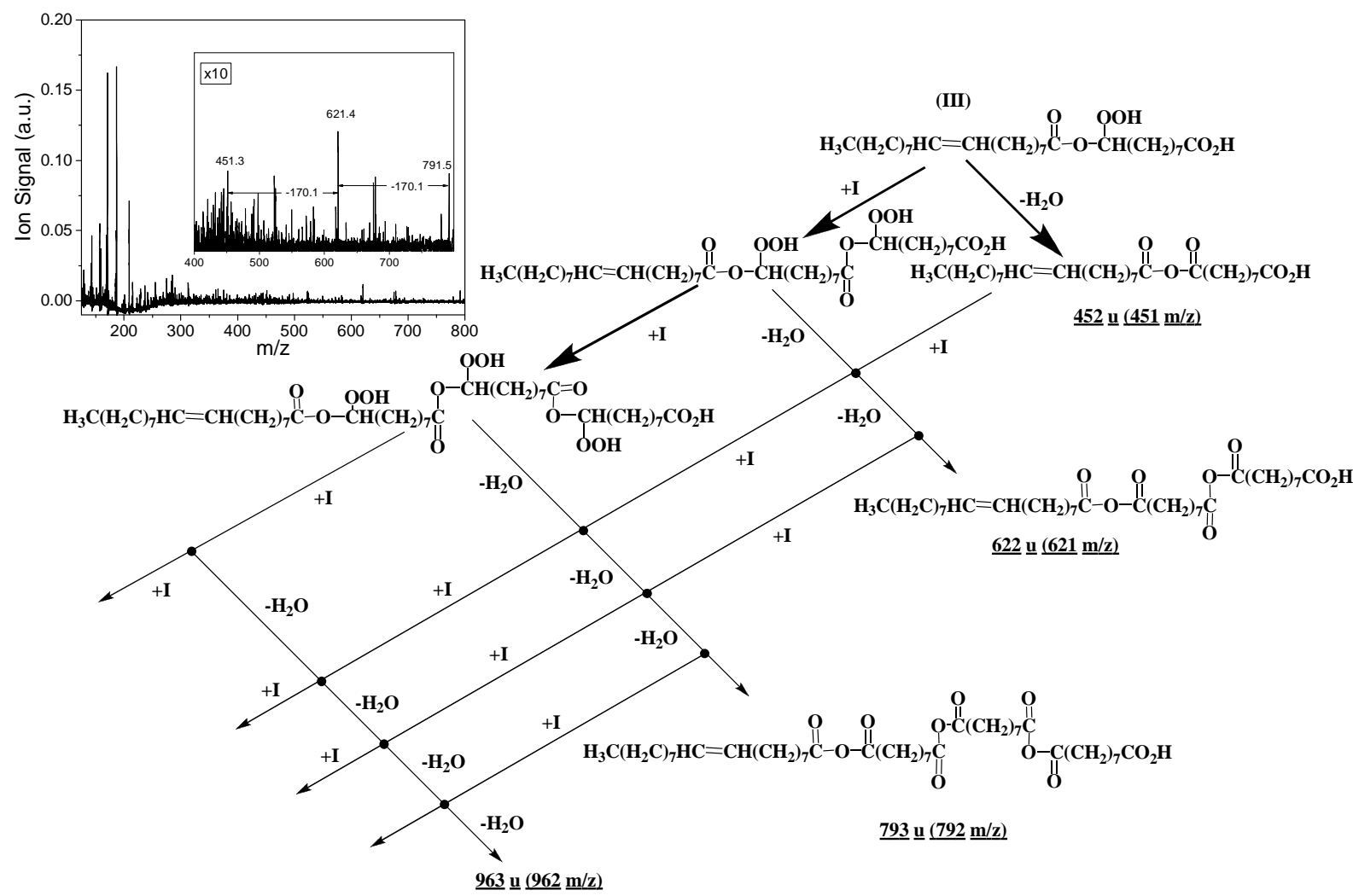

Fig. 3. The formation of peroxidic polymers (AAHP and corresponding polyanhydrides). Depicted are products arising from the addition of CI (I) (see Fig. 1) with OL. Underlined are the products directly observed in the PERCI mass spectrum shown in the inset (adapted from Zahardis et al., 2006a).

There is a growing body of evidence that the formation of AAHP is one of the most important secondary reactions of the $\mathrm{CI}$ in the $\mathrm{OL}-\mathrm{O}_{3}$ HRS. Hung and coworkers (Hung et al., 2005) have studied the reactions of mm-sized droplets of OL with ozone and a number of products observed by IR indicated the presence of ester groups. Theses HMW products were separated by masses corresponding to 9-oxononanoic acid and the azelaic acid CI, which, by their description, acted as polymerization propagators. In their description, this polymerization is quite general; the CI adding to OL, carboxylic acids, or aldehydes. The authors also depict other novel polymers that contain both AAHP motifs and SO moieties on the same polymeric backbone. There was also a discernable increase in viscosity of these droplets that could be attributed to the HMW polymers formed during ozonolysis. Zahardis and coworkers (Zahardis et al., 2006a) also observed polymer formation in the $\mathrm{OL}-\mathrm{O}_{3}$ HRS, with a series of products differing by $170 \mathrm{u}$ suggesting polymerization by a similar mechanism, namely the addition of an in situ generated CI to the carboxyl group of OL forming AAHP products (Fig. 3).

The recent work by Mochida et al. (2006) with particles of MOL mixed with DOA and C14 investigated the rela- tive importance of the pathways to peroxidic products including SO, diperoxides, monoperoxide oligomers, AAHP, $\alpha$-acyloxyalkyl hydroxyalkyl peroxides, and bis(acyloxy-1alkyl) peroxides (the combination of the latter three classes of compounds, in accord with the notation of the original work, we abbreviate as " $\alpha$ AAHP-type" compounds). Using Aerodyne AMS they identified two SO to be the major products of the ozonolysis of pure MOL as well as in mixed particles with an inert matrix of DOA, to a mole fraction as low as 0.04 for MOL. Conversely, ozonolysis of mixed particles of MOL and $\mathrm{C} 14$ formed $\alpha$ AAHP-type compounds in high yields for mole fractions of MOL of 0.5 or less. The authors suggested that the stabilized CI efficiently reacted with carboxylic acid functional group of $\mathrm{C} 14$ and therefore competed with the reactions of the stabilized CI with aldehydes to form SO, provided that both types of functionalities (stabilized CI and carboxylic acid) were present at significant concentrations (Mochida et al., 2006). This suggests that $\alpha$ AAHPtype compounds may be favored over SO in tropospheric OA that is rich in mono- and dicarboxylic acids. As shall be explained in the Discussion of this report, this has implications to atmospheric OA in that stabilized CI may help transform organic acids and other protic species to HMW peroxidic 
species that may have important ramifications to $\mathrm{CCN}$ properties (Shilling et al., 2007¹).

Polymerization of OL has also been observed in thin films (Asad et al., 2004), noting a concomitant increase in water uptake to OL film exposure to ozone. Chemical changes were monitored in the thin films by IR spectroscopy, with broad absorption features in the exposed film that "probably correspond to $\mathrm{OH}$ stretching transitions of the polymeric species and associated carboxylic acids, respectively" (Asad et al., 2004). By direct comparison to the IR spectrum of azelaic acid, Asad et al. concluded this species was not present in the condensed-phase and that the reacted medium was "a substance or mixture which was much more highly oxidized". Although not assigned in the original work, this IR spectrum suggests AAHP products (Colthup et al., 1975).

Several other studies have strongly suggested secondary chemistry involving $\mathrm{CI}$, and the formation of peroxidic products, primarily through uptake and kinetic measurements (Hearn et al., 2005; Nash et al., 2006; Katrib et al., 2005a) and shall be discussed in the upcoming sections on reactive uptake.

Some notable points regarding the richness of the secondary chemistry in the OL-O $\mathrm{O}_{3} \mathrm{HRS}$ include

- The yield of peroxidic products may be significant in the $\mathrm{OL}-\mathrm{O}_{3}$ and related HRS

- There are a variety of different reactions that can lead to peroxides, which can react further. Classes of products including $\alpha$ AAHP-type compounds and SO have been identified. These products are HMW, low volatility oxygenates, and notably include oligomers and polymers

This suggests

- Oxidative processing of OA that has unsaturated constituents, may show considerable peroxide formation that may enhance $\mathrm{CCN}$ ability

- Ozonolysis of unsaturated FA may play a role in HULIS formation in the troposphere

\subsubsection{Ketones}

One of the first products of secondary chemistry reported in the OL-O 3 HRS was 9-oxooctadecanoic acid (OOA) (298u) (Hearn and Smith, 2004b). This product was proposed to have been formed by the addition of the CI to the double bond of OL, which subsequently decomposes to OOA and either 9-oxononanoic acid or nonanal. The mechanism for this type of reaction had been proposed originally by Katrib et al. (2004), although this secondary product was not directly detected. The products formed can also be explained

\footnotetext{
${ }^{1}$ Shilling, J. E., King, S. M., Mochida, M., Worsnop, D. R., and Martin, S. T.: Mass spectral evidence that small changes in composition caused by oxidative aging processes alter aerosol CCN properties, J. Phys. Chem. A, submitted, 2007.
}

by the mechanism of partial cleavage (Bailey, 1978), which competes with the ozonolysis of unsaturated organics. In this mechanism only one atom of ozone reacts by electrophilic addition with the double bond of the unsaturated compound to give both epoxides and ketones and releases molecular oxygen. This reaction may compete efficiently with ozonolysis with unsaturated organics that have steric hindrance about the double bond, with many examples compiled by Bailey (1978).

Zahardis et al., have also reported ketone formation in the $\mathrm{OL}_{2} \mathrm{O}_{3}$ HRS as detected by PERCI-AMS (Zahardis et al., 2006a). Follow-up studies with related FA and methyl esters of FA (Zahardis et al., 2006b) showed that stearic acid, which is the saturated analogue of OL, did not undergo similar oxygenation when undergoing ozonolysis. Also the saturated methyl ester, methyl palmitate, showed no oxygenation after ozonolysis, while unsaturated methyl esters showed evidence of oxygenation, which the authors ascribed to the formation of ketones (Zahardis et al., 2006b).

The channel(s) to ketones, whether by the mechanism proposed by Katrib et al. (2004) or by the mechanism of partial cleavage(Bailey, 1978), is probably a minor pathway(s) compared to the other channels of secondary reactivity in $\mathrm{OL}-\mathrm{O}_{3}$ HRS and related unsaturated FA and their derivatives. The yield reported by Hearn and Smith was very small (Hearn and Smith, 2004b), $\sim 1 \%$ on the carbon-based yield scale. Similarly, with the study of unsaturated methyl esters, though not quantified, the signal associated with the ketone products was weak (Zahardis et al., 2006b). None of the aforementioned studies considered the possibility of the mechanism of partial cleavage so the case of epoxide formation (Bailey, 1978) in the OL-O 3 HRS and related systems has been ignored as of late by researchers in this field.

\subsection{Key features regarding pathways and product forma- tion}

The ozonolysis of OL, other FA and FA derivatives shows product formation in accord with liquid-phase or solution trends that are long established (Bailey, 1958, 1978)in synthetic organic chemistry, with the most notable of these trends being the formation of SO and $\alpha$ AAHP-type compounds.

There have been comparable studies of the ozonolysis of OL in solution that directly support the peroxidic products observed in the HRS. Ledea et al. (2003) carried out the ozonolysis of OL in hexane, water, carbon tetrachloride, ethanol and water and found in all cases that AAHP were formed as major products with all the solvents employed as determined by ${ }^{1} \mathrm{H}$ NMR. The ${ }^{1} \mathrm{H}$ NMR resonance studies reported by Rebrovic (1992) determined $\alpha$ AAHPtype compounds, SO and aldehydes as the major types of products in the ozonolysis of OL in carboxylic acid solutions. Very recently, Reynolds et al. (2006), using tandem MS, have identified a complex mixture of AAHP, SO, and 
cyclic diperoxides as major products for the ozonolysis of $\mathrm{OL}$ in ethyl acetate. The degree of oligomerization increased with reaction time. It should be noted that nonanal, nonanoic acid, 9-oxononanoic acid, and azelaic acid were also observed by negative ion electrospray ionization MS for the same reaction system. One of the important observations of this study was that ozonized OL samples showed clear evidence of oligomerization occurring after storage in ethyl acetate at $4^{\circ} \mathrm{C}$ in the dark. These samples were analyzed 1 week and 3 months after exposure to ozone and the oligomerization was attributed to alternative routes of oligomer formation, including decomposition and recombination of the smaller oligomers or the reaction of dissolved ozone with OL remaining in solution (Reynolds et al., 2006).

Many of the reports to date have drawn correlation between gas-phase ozonolysis of alkenes and the $\mathrm{OL}-\mathrm{O}_{3} \mathrm{HRS}$, most notably in attributing the formation of nonanoic acid and azelaic acid to the rearrangement of CI to the corresponding acid (Hearn and Smith, 2004b; Katrib et al., 2005a; Moise and Rudich, 2002; LaFranchi et al., 2004; Zahardis et al., 2005; Ziemann, 2005; Thornberry and Abbatt, 2004). As was very recently suggested (Martin, 2006b), this correlation is likely to be erroneous. As we discussed in Sect. 3.3, there is a high activation energy barrier between the CI and the dioxirane isomer that precedes formation of the acid, which to compete with bimolecular channels (e.g. cycloaddition to $\mathrm{SO})$ requires the $\mathrm{CI}$ to be in a vibrationally excited state. In solution, the unimolecular channel of isomerization of the CI to the carboxylic acid is not significant and probably just a minor channel to the formation of acidic products (e.g. azelaic and nonanoic acid in the OL-O 3 HRS), hence stabilization of the $\mathrm{CI}$ and subsequent bimolecular processes leading to peroxidic products is favored (Bailey, 1958, 1978).

The stabilization of the CI in the heterogeneous ozonolysis of liquid aerosols of unsaturated organics was recently demonstrated by Mochida et al. (2006). In their study, the ozonolysis of pure MOL resulted in a high yield of SO and the absence of $\alpha$ AAHP-type compounds, which has been observed in studies of bulk liquids of MOL (Nishikawa et al., 1995). These results suggested a low yield of nonanoic acid and azelaic acid monomethyl ester that would arise from the pathway of the $\mathrm{CI}$ rearrangement to the carboxylic acid. This implies that stabilization of the CI, rather than isomerization to the carboxylic acid, is the dominant fate of the CI (Mochida et al., 2006). This was also noted by Hung et al. (2005) in studies of OL droplets.

As was recently suggested (Martin, 2006a), the azelaic acid and nonanoic acid products observed in the OL-O ${ }_{3} \mathrm{HRS}$ likely arise, at least in part, from the decomposition of SO, i.e. third generation products. This is in accord with acidolysis in an acidic solution or solvolysis in the case of ozonolysis in a pure protic liquid. A detailed mechanism and description is given in Chapter VIII of Bailey's work on ozonolysis (Bailey, 1978) for acidolysis and solvolysis of peroxides. Other routes of decomposition of peroxides, including thermal, photolytic and base catalyzed are considered in Bailey (Bailey, 1978) as well. More investigations are needed to assess the role of decomposition of peroxidic products of ozonolysis and the aging of $\mathrm{OA}$ in the troposphere.

In summary:

- The products observed in the heterogeneous ozonolysis of OL, other unsaturated FA and derivatives are in accord with products observed in well-established reactions in solution, favoring products of bimolecular reactions i.e. peroxidic products

- Stabilized CI can react efficiently with protic species, such as carboxylic acids, to form $\alpha$ AAHP-type compounds.

- Lower molecular weight products may arise, in part, from decomposition of peroxidic products. Rearrangement of CI to carboxylic acids is probably a minor channel

\section{Reactive uptake of ozone: overview}

Atmospheric heterogeneous processing can be described as the transformation of one species on or close to a particulate's surface. Although this review focuses on the ozonolysis of OA, with emphasis on OL, much of the framework for describing heterogeneous processing comes from considerations of inorganic aerosols (namely water and sulfate) with trace gases. Much of the early work in this regard focused on the uptake of halogenated species by sulfuric acid aerosols (Abbatt and Nowak, 1997; Donaldson et al., 1997; Hanson, 1998; Hanson and Lovejoy, 1995; Hanson and Ravishankara, 1993; Hanson et al., 1996). The models developed for describing inorganic HRS were adapted to the uptake model used for OL and other organics.

Understanding uptake of ozone is central to describing the processing of OA and in the Discussion we will address the tropospheric implications based on insight gained from the $\mathrm{OL}_{-} \mathrm{O}_{3}$ HRS. We will try to apply these implications to some of the extant questions regarding the role of oxidative processing of OA by ozone in tropospheric chemistry:

- What effect does oxidative processing by ozone of unsaturated OA have on the atmospheric aging process of $\mathrm{OA}$ ?

- Can OA act as CCN after oxidative processing by ozone? Under what tropospheric conditions is this activation likely?

- Are there any other radiative effects associated with oxidative processing of OA by ozone that might impact the global radiation budget in the troposphere?

- How is the lifetime of an unsaturated species in OA affected by ozonolysis? Furthermore, how is this lifetime 


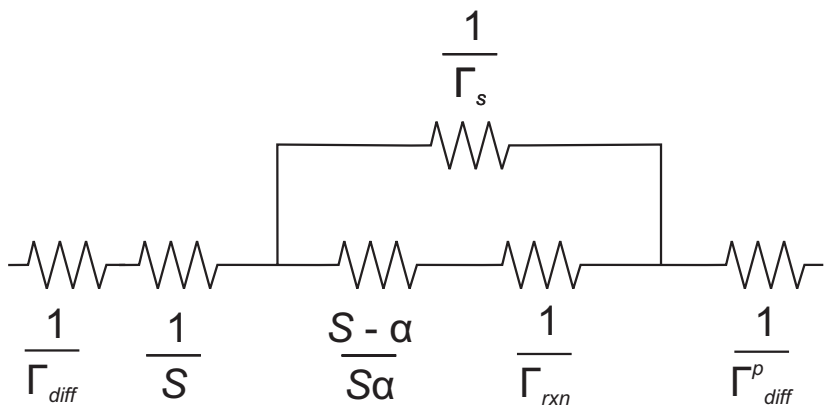

Fig. 4. The resistor model, an electric circuit analogue applied to reactive uptake microphysics of organic aerosols. In this model microphysical processes are represented as resistances, with gas-phase diffusion $\left(\Gamma_{\text {diff }}\right)$, surface reaction $\left(\Gamma_{s}\right)$, mass accommodation $(\alpha)$, chemical reaction within the particle $\left(\Gamma_{\text {rxn }}\right)$, diffusion-limited mixing within particle $\left(\Gamma_{\text {diff }}^{p}\right)$, and the adsorption coefficient $(S)$ depicted.

affected in real OA with many components and the possibility of different phases and phase separation?

We shall address some aspects of these questions in the Discussion after describing the experimental results on the determination of the reactive uptake of ozone by OL and related compounds, including internally mixed particles and coatings.

\subsection{Models of reactive uptake}

The formalism developed by Worsnop et al. (2002) adapts the model of uptake of gaseous species by liquids (Davidovits et al., 1991; Hanson, 1997; Hanson and Lovejoy, 1995; Kolb et al., 2002; Shi et al., 1999) to reactive transforms of the condensed-phase organic species because the particle MS methods monitor the loss of the organic substrate. In the $\mathrm{OL}_{-} \mathrm{O}_{3} \mathrm{HRS}$, this involves monitoring OL loss and using this loss to calculate the uptake coefficient, $\gamma$. We shall discuss and present uptake data garnered from AFT and CFT experiments, the latter of which typically monitor the loss of ozone. The latter method is well-established with a long tradition, hence we will only give the results employing this method and the interested reader is referred to the literature for details on the kinetics formalism (Lovejoy et al., 1995; Moise and Rudich, 2000; Thornberry and Abbatt, 2004; Utter et al., 1992).

We shall provide a summary of the formalism developed by Worsnop et al. (2002) and others (Smith et al., 2002) in regards to reactive uptake. Complete descriptions including the formal derivations are available to interested readers (Hearn et al., 2005; Smith et al., 2002; Worsnop et al., 2002). Figure 4 illustrates the key parameters invoked in the uptake of a trace gas by OL as it is described to date. One of the key parameters is the mass accommodation coefficient, $\alpha$ which is the probability of the trace gas entering the particle-phase:

$$
\alpha=\frac{\# \text { molecules entering particle phase }}{\# \text { molecules that collide with surface }}
$$

As described by Worsnop et al. (2002), in the absence of surface reactions the mass accommodation is directly proportional to the flux, $J_{x}$, of the trace gas, $x$, into the liquid

$J_{x}=\frac{n_{x} \bar{c} \alpha}{4}$

where $n_{x}$ is the number density of gas-phase ozone molecules $\left(\mathrm{cm}^{-3}\right)$ and $\bar{c}$ is the mean thermal velocity $\left(\mathrm{cm} \mathrm{s}^{-1}\right)$ of gas-phase ozone. Equation (2) is valid only when the trace gas has no surface reaction with other gaseous molecules at the surface, itself, or with the liquid- phase species.

In equilibrium systems there is no net uptake of the trace gas by the liquid. However, reactions of the solvated trace gas can act as a sink for that gaseous species and the flux is now proportional to the uptake coefficient, $\gamma$ :

$J_{x}=\frac{n_{x} \bar{c} \gamma}{4}$

The uptake coefficient is less than or equal to unity since the flux must be less than or equal to the collision frequency of the gas with the surface. In considering the $\mathrm{OL}_{-} \mathrm{O}_{3} \mathrm{HRS}$, if the stoichiometry of ozone loss and OL loss is the same, it can be shown that the particle-phase OL loss is given by:

$-\frac{d[\mathrm{OL}]}{d t}=\frac{3 n_{x} \bar{c} \gamma}{4 a}$

where " $a$ " is the particle radius and the ratio of 3 to $4 \mathrm{a}$ accounts for the surface to volume ratio of the particle. Analytical solutions to Eq. (4) are not known (Worsnop et al., 2002), so analysis proceeds by considering limiting regimes in a fashion developed by Crank (1975) and Danckwerts (1970). As of late, it has been shown that a general assumption of ozone loss and OL (or other unsaturated FA, or derivative) loss having the same stoichiometry is not valid, due to secondary reactivity. For example, as we discussed in Sect. 3.5.1, it now appears that in these HRS that CI react with carboxylic acids of OL forming AAHP (Mochida et al., 2006; Nash et al., 2006; Katrib et al., 2005a; Hearn et al., 2005; Zahardis et al., 2006a; Ziemann, 2005; Hung et al., 2005), and this acts as another channel of loss of the condensed-phase species. We shall discuss corrections to the resistor model in this regard as well as other kinetic methods employed to the $\mathrm{OL}_{-} \mathrm{O}_{3}$ and related HRS in the sections following a discussion the resistor model.

\subsection{The resistor model}

A model has been developed that attempts to decouple the measured uptake coefficient, $\gamma_{\text {meas }}$, into constituent chemical 
and physical processes (Fig. 4) including gas- and particlephase diffusion $\left(\Gamma_{\text {diff }}\right.$ and $\Gamma_{\text {diff }}^{p}$, respectively), mass accommodation $(\alpha)$, adsorption $(S)$ and reactivity term(s) $\left(\Gamma_{\mathrm{rxn}}\right)$ (Worsnop et al., 2002).

The loss of ozone to the particle can be described by Fick's second law, accounting for the chemical reactivity with the $\mathrm{k}\left[\mathrm{O}_{3}\right]$ term in Eq. (5), which is an expression for ozone loss:

$$
-\frac{\partial\left[\mathrm{O}_{3}\right]}{\partial t}=-D \nabla^{2}\left[\mathrm{O}_{3}\right]+k\left[\mathrm{O}_{3}\right]
$$

An assumption that OL diffuses rapidly is made to ensure that the OL concentration can be assumed to be uniform throughout the particle, especially near the surface. This allows for the pseudo-first order approximation to be made i.e. $\mathrm{k}=\mathrm{k}_{2}[\mathrm{OL}]$. The steady-state approximation is typically evoked (i.e., $\partial\left[\mathrm{O}_{3}\right] / \partial \mathrm{t}=0$ ), and, assuming only a radial dependency of $\left[\mathrm{O}_{3}\right]$, gives

$$
D \nabla^{2}\left[\mathrm{O}_{3}\right]=k\left[\mathrm{O}_{3}\right], \text { with } \nabla^{2}=\frac{1}{r^{2}} \frac{\partial}{\partial r}\left(r^{2} \frac{\partial}{\partial r}\right)
$$

It has been shown (Smith et al., 2002) that applying finite ozone boundary conditions at the origin and assuming its concentration at the surface to be constant that

$\left[\mathrm{O}_{3}\right]=\frac{H P_{\mathrm{O}_{3}} a \sinh (r / l)}{r \sinh (a / l)}$

In Eq. (7) $\mathrm{H}$ is Henry's law constant and $l$ is the diffusoreactive length and is effectively the length the ozone must diffuse into the particle to react. $\mathrm{P}_{\mathrm{O} 3}$ is the pressure of ozone (atm). The diffuso-reactive length is given by

$l=\left(\frac{D}{k}\right)^{1 / 2}$

where $D$ is the diffusion coefficient of ozone in the reactive matrix $\left(\mathrm{cm}^{2} \mathrm{~s}^{-1}\right)$ and $\mathrm{k}$ is the pseudo-first order rate constant $\left(\mathrm{s}^{-1}\right)$. The gradient and the flux of ozone through the gasparticle boundary can be derived from Eq. (7) (Smith et al., 2002) and normalization of the surface flux to the collision frequency with the surface, gives the uptake coefficient. Substitution of the uptake coefficient into Eq. (4) is used to derive a rate of change of OL in terms of key parameters and variables:

$$
\begin{aligned}
\frac{d[\mathrm{OL}]}{d t}= & \left(\frac{-3 P_{\mathrm{O}_{3}} H\left(k_{2} D[\mathrm{OL}]\right)^{1 / 2}}{a}\right) \\
& {\left[\operatorname{coth}\left(a\left(\frac{k_{2}[\mathrm{OL}]}{D}\right)^{1 / 2}\right)-\frac{1}{a}\left(\frac{D}{k_{2}[\mathrm{OL}]}\right)^{1 / 2}\right] }
\end{aligned}
$$

No general solution is known for Eq. (9); however, solutions have been found in four limiting regimes. These solutions have been derived previously (Smith et al., 2002; Worsnop et al., 2002) and we only present an outline of the methodology and physical assumptions.

\subsection{Limiting cases of reactive uptake}

The solutions to Eq. (9) for the four limiting regimes are summarized in Table 3 in terms of the ratio $[\mathrm{OL}] /[\mathrm{OL}]_{t=0}$, since particle-based methods measure the concentration of condensed-phase OL prior to and post reaction with ozone. In summary, these cases are:

Case 1: Rapid diffusion of ozone throughout the particle. In this case $l>a$ and the right hand factor in Eq. (9) is approximately equal to $\mathrm{a} / 3 l$ when $\mathrm{a} / l<1$ (Smith et al., 2002)

Case 2: Reaction limited by ozone diffusion or a near surface reaction. In this case $l<\mathrm{a} / 20$, and in Eq. (9) the factor $[\operatorname{coth}(\mathrm{a} / l)-\mathrm{a} / l]$ approaches unity (Smith et al., 2002)

Case 3: Reaction at the surface. This assumes the reaction of OL and ozone is at the surface and second order (Smith et al., 2002), with $\delta$ being the surface depth

Case 4: Uptake limited by OL diffusion. Notice in this case $\mathrm{D}_{\mathrm{OL}}$ is the diffusion coefficient of $\mathrm{OL}$ and should not be confused with $\mathrm{D}$, which is the diffusion coefficient of ozone in OL (Worsnop et al., 2002)

\subsection{Experimental determination of reactive uptake}

This section will begin with a summary of experiments that place emphasis on the measured uptake of ozone by OL, with the results of coated-wall studies presented first, and then the AFT studies. Secondly, the results from studies on related FA, internally mixed particles containing OL and/or other FA, and some other related organics will be presented. Emphasis will be placed on noting the approximations utilized in calculating the uptake coefficient, and all kinetic information that gives insight into the extent of secondary chemistry in these systems.

\subsubsection{Reactive uptake by one-component coatings}

Early measurements of the uptake of ozone by organic liquids on coated-wall reactors were performed by de Gouw and Lovejoy (de Gouw and Lovejoy, 1998). They measured the reactive probability (i.e. uptake coefficient) of ozone by a variety of organic liquids including canola oil, which is predominately OL (Mag, 1990). Employing a rotating wetted-wall reactor they determined an uptake coefficient of $\sim 8 \times 10^{-4}$. (A complete list of numerical values of reactive probability as a function of temperature was not provided in the original work; we estimated this value for $\sim 25^{\circ} \mathrm{C}$ by interpolation from the plot provided in the original work.)

Moise and Rudich (2002) employed a rotating wall flow reactor to measure uptake coefficients for liquid and frozen $\mathrm{OL}$ of $(8.3 \pm 0.2) \times 10^{-4}$ and $(5.2 \pm 0.1) \times 10^{-5}$, respectively. 
Table 3. The limiting cases of $\mathrm{O}_{3}$ uptake by particulate OL. Derivation of $\gamma$ for Cases $1-3$ is given in the original works (Worsnop et al., 2002; Smith et al., 2002) and details on Case 4 are given by Worsnop et al. (2002). An outline of the resistor model is given in Sect. 4.2 of this report; a summary of the approximations of these Cases is given in Sect. 4.3.

\begin{tabular}{lll}
\hline Limiting cases & {$[\mathrm{OL}] /[\mathrm{OL}]_{t=0}$} & $\gamma$ \\
\hline $\begin{array}{l}\text { Case 1: Rapid diffusion of ozone } \\
\text { throughout the particle }\end{array}$ & $\exp \left(-H k_{2} P_{\mathrm{O}_{3}} t\right)$ & $\frac{4 H R T r k_{2}[\mathrm{OL}]}{3 \bar{c}}$ \\
\hline $\begin{array}{l}\text { Case 2: Reaction limited by ozone dif- } \\
\text { fusion. (A near surface reaction.) }\end{array}$ & $\left(1-\frac{3 H\left(D k_{2}\right)^{1 / 2} P_{\mathrm{O}_{3}} t}{2 r([\mathrm{OL}])^{1 / 2}}\right)^{2}$ & $\frac{4 H R T\left(D k_{2}[\mathrm{OL}]\right)^{1 / 2}}{\bar{c}}$ \\
\hline $\begin{array}{l}\text { Case 3: Reaction at the surface } \\
\begin{array}{l}\text { Case 4: Uptake limited by OL diffu- } \\
\text { sion }\end{array}\end{array}$ & $\exp \left(\frac{-3 \delta^{2} H k_{2}^{\text {surf }} P_{\mathrm{O}_{3}} t}{r}\right)$ & $\frac{4 H R T \delta^{2} k_{2}^{\text {surf }}[\mathrm{OL}]}{\bar{c}}$ \\
\hline
\end{tabular}

The uptake coefficient for liquid-phase OL is in good agreement with the value of de Gouw and Lovejoy's for canola oil, despite the fact that most of the OL in canola oil is in the form of triacylglycerols (Mag, 1990). Comparable measurements were performed on LA, with the liquid and frozen phases having uptake coefficients of $(1.2 \pm 0.2) \times 10^{-3}$ and $(1.4 \pm 0.1) \times 10^{-4}$, respectively. LA has a considerably larger uptake coefficient compared to OL because the molecule contains two sites of unsaturation, effectively giving it twice the reactive capacity of OL.

Moise and Rudich (2002) suggested that for the liquidphases the reaction in the bulk of the medium may contribute significantly to the uptake of ozone. This suggestion was based in part on previous observations of uptake of ozone by alkenes and other reaction systems (Moise and Rudich, 2002; Moise et al., 2001) and similar conclusions could be drawn from studies employing monolayers and bulk liquids (Moise and Rudich, 2000).

As noted by Moise and Rudich (2002) for the liquid FA, if the reactivity towards ozone is proportional to the FA concentration and each carbon-carbon double bond reacts independently, then the ratio, $\mathrm{R}$, of uptake coefficients of OL to LA is given by

$R=\sqrt{\frac{2 \times \rho_{\mathrm{LA}} \times \mathrm{MW}_{\mathrm{OL}}}{\rho_{\mathrm{OL}} \times M W_{\mathrm{LA}}}}$

with $\rho$ denoting the density $\left(\mathrm{g} \mathrm{cm}^{-3}\right)$ of the respective FA. The theoretical value of $\mathrm{R}$ in this case is 1.43 . The experimental value calculated by Moise and Rudich for the liquids is $1.45 \pm 0.19$, which lead the authors to conclude that "the reactant activity is directly related to the concentration of double bonds, supporting the conclusion that the uptake has a dominant contribution from reaction in bulk" (Moise and Rudich, 2002).

Thornberry and Abbatt (2004) investigated the uptake of ozone by liquid-phase OL, LA and LN, in coated-wall tube experiments. In regards to $\mathrm{OL}$ and LA, their results were in accord with those of Moise and Rudich (2002); the uptake coefficient of ozone for OL was $(8.0 \pm 1.0) \times 10^{-4}$, for LA $(1.3 \pm 0.1) \times 10^{-3}$, and for LN $(1.8 \pm 0.2) \times 10^{-3}$. Again, the correlation between the uptake coefficient and degree of unsaturation is evident.

Key conclusions from these experiments are

$-\gamma$ has a value $\sim 8 \times 10^{-4}$ for the $\mathrm{OL}_{-} \mathrm{O}_{3} \mathrm{HRS}$

$-\gamma$ increases with degree of unsaturation

- The limiting case regime is probably Case 2 and/or 3

4.4.2 Reactive uptake of ozone by one-component particles

Since 2002, the results dedicated to the online analysis of the uptake of ozone by OL and other FA particulate have been presented to the atmospheric community. These methods include Aerodyne AMS, single-particle MS, CIMS, and TDPBMS and have directly monitored decay of the condensed-phase species (i.e. OL) to calculate the uptake coefficient of ozone. These new methods aim to monitor the reactions of condensed- phase species and determine $\gamma$ from their decay; however, since $\gamma$ is not measured by monitoring the decay of ozone directly, these results should initially be compared with those of coated-wall reactor methods.

4.4.2.1 Reactive uptake: aerodyne aerosol mass spectrometry

The Aerodyne AMS methodology has been applied to study the uptake of ozone by size-selected particles of OL (Morris et al., 2002). Based on the measured gas-phase diffusion uptake coefficient ( 0.30 to 2.0$)$ compared to the uptake coefficient determined by others $\left(\sim 10^{-3}\right)$, the authors used Case 2 as the limiting regime. They calculated the diffusoreactive length, $l$, to be approximately $5 \mathrm{~nm}$ by Eq. (8), using $\mathrm{D} \sim 10^{-6} \mathrm{~cm}^{2} \mathrm{~s}^{-1}$ and $\mathrm{k}_{2} \sim 10^{6} \mathrm{M}^{-1} \mathrm{~s}^{-1}$ and treating [OL] 
as the initial concentration of OL, $3.15 \mathrm{M}$. The radius of the OL particle was assumed constant, and the product $P_{O_{3}} t$ was taken as an experimental variable. The curves were then fit by adjusting two parameters: $\mathrm{H}\left(\mathrm{Dk}_{2}\right)^{1 / 2}$ and $\tau$. (The latter is a correction for the mixing time of ozone into the particle beam (Morris et al., 2002)) and an uptake coefficient of $(1.6 \pm 0.2) \times 10^{-3}$ was calculated for a maximum $\mathrm{O}_{3}$ exposure of $\sim 10^{-4} \mathrm{~atm} \mathrm{~s}$.

\subsubsection{Reactive uptake: single-particle mass spectrometry}

The uptake of ozone has also been measured by singleparticle MS (Smith et al., 2002) with particles with radii from $680 \mathrm{~nm}$ to $2.45 \mu \mathrm{m}$. The diffuso-reactive length was estimated to be $20 \mathrm{~nm}$ as described previously, with the only difference in the calculation being the diffusion constant of ozone in OL, which in this case was estimated to be $10^{-5} \mathrm{~cm}^{2} \mathrm{~s}^{-1}$ (as opposed to $10^{-6} \mathrm{~cm}^{2} \mathrm{~s}^{-1}$ ). Figure 5 shows decay curves of OL determined by this method. Two limiting cases of reactive uptake, namely Cases 2 and 3, were suggested and as noted by the authors "it is possible that the $\mathrm{O}_{3}$ reacts at both the surface and the bulk of the particle, but it is difficult to estimate the relative contributions of the two cases without accurate knowledge of $k_{2}, k_{2}^{\text {surf }}, \mathrm{H}$ and D." The authors noted further that Case 2 fit the data better when all particle sizes were considered and was used for the calculations with $\mathrm{H}\left(\mathrm{Dk}_{2}\right)^{1 / 2}$ estimated as previously described. The uptake coefficient ranged from $(0.99 \pm 0.09) \times 10^{-3}$ to $(7.3 \pm 1.5) \times 10^{-3}$ for particles with radii ranging, respectively, from $2.45 \mu \mathrm{m}$ to $680 \mathrm{~nm}$ with a maximum ozone exposure on the order of $10^{-3} \mathrm{~atm} \mathrm{~s}$.

Careful consideration of the data in Fig. 5 shows an anomaly noted by the authors: although Case 2 has no explicit dependency of $\gamma$ on the particle radius, there is a clear linear dependence when $\gamma$ is plotted as a function of the particle radius. The authors acknowledge that the model does provide a good fit for the data; however "(the model) does not describe our data adequately" (Smith et al., 2002). The authors suggest the decrease in $\gamma$ with increasing particle radius may stem from the diffusion of OL, with this effect more pronounced in larger particles. The authors estimated that the value of the uptake coefficient would be about (5.8$9.8) \times 10^{-3}$ for small particles, where this OL diffusion is not the limiting factor in uptake. They then numerically solved a coupled set of reaction-diffusion equations for $\left[\mathrm{O}_{3}\right]$ and $[\mathrm{OL}]$, without making the steady-state assumption for ozone or assuming rapid diffusion of OL. The value of the selfdiffusion constant of $\mathrm{OL}, \mathrm{D}_{O L}$, was varied and it was found that Case 2 was applicable when $D_{\mathrm{OL}}=3 \times 10^{-7} \mathrm{~cm}^{2} \mathrm{~s}^{-1}$. It was reasoned that as ozonolysis of OL proceeds, the formation of reaction products and the loss of OL near the surface may slow the diffusion of OL to that region. They found that only by lowering the value $\mathrm{D}_{\mathrm{OL}}$ to between (410) $\times 10^{-10} \mathrm{~cm}^{2} \mathrm{~s}^{-1}$, as a function of the particle size, could
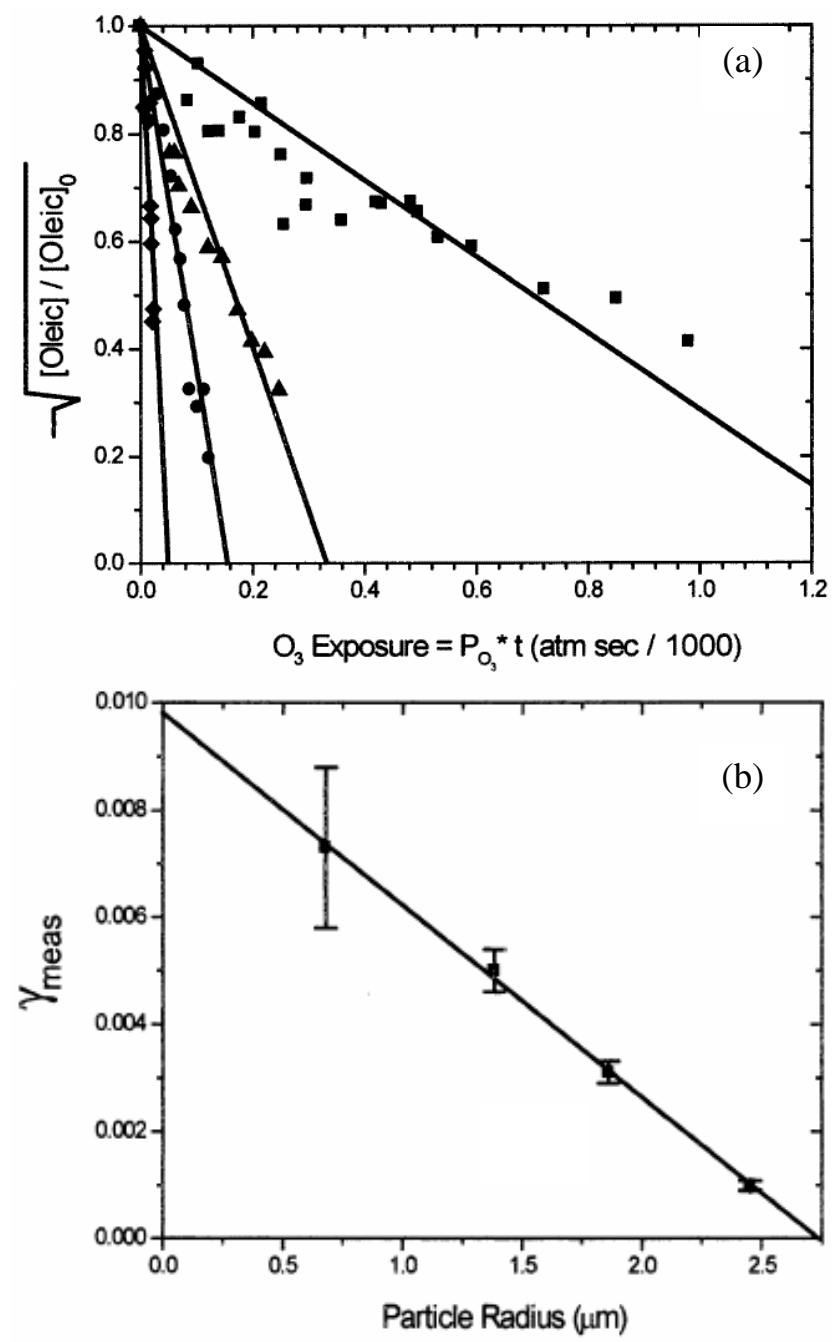

Fig. 5. OL decay profiles as measured by single-particle MS. (a) Decay profiles of four particle sizes: $(\diamond) 680 \mathrm{~nm},(\bullet) 1.38 \mu \mathrm{m},(\boldsymbol{\Delta})$ $1.86 \mu \mathrm{m}$, (ם) $2.45 \mu \mathrm{m}$. (b) Radial dependence evidenced in reactive uptake coefficients, although no radial dependency is predicted by Case 2 (from Smith et al. , 2002).

they fit the numerical solutions for [OL] to all their experimental data(Smith et al., 2002).

In summary

- The value of $\gamma$ is dependent on particle radius with values of $(0.99 \pm 0.09) \times 10^{-3}$ to $(7.3 \pm 1.5) \times 10^{-3}$ for particles with radii ranging, respectively, from $2.45 \mu \mathrm{m}$ to $680 \mathrm{~nm}$

- OL diffuses more slowly in the particles than is predicted by its self-diffusion coefficient 


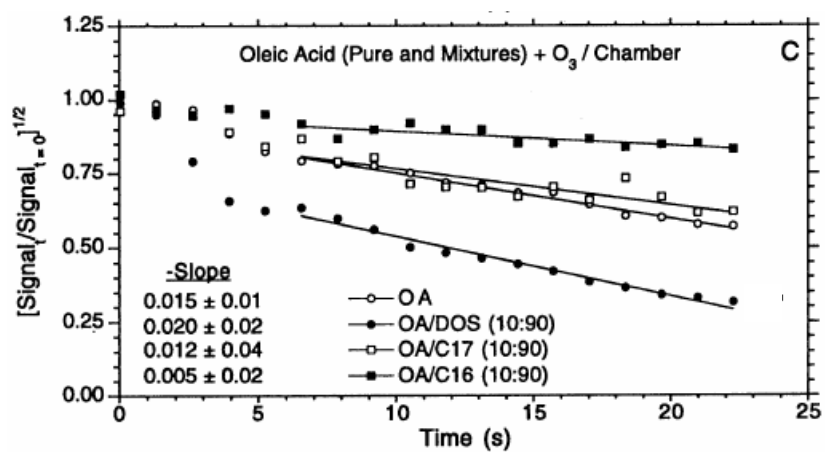

Fig. 6. Real-time TDPBMS signal of oleic acid (oleic acid is denoted OA in figure, while DOS, C17 and C16 correspond to our notation) decay for pure and mixed particles undergoing ozonolysis. Longer times of reaction are shown in Fig. 10 of the original work (adapted from Ziemann, 2005).

This suggests

- The formation of HMW products, such as polymers, from ozonolysis, can have a considerable effect on subsequent uptake

4.4.2.3 Reactive uptake: chemical ionization mass spectrometry

Hearn and Smith applied aerosol CIMS methodology to polydisperse particles of OL (Hearn and Smith, 2004b). In light of previous results (Moise and Rudich, 2002; Morris et al., 2002; Smith et al., 2002), they assumed kinetics governed by the limiting Case 2 . The polydisperse OL decay data was fit in a similar fashion as described previously. The best fit of $\gamma$ for polydisperse OL with an average diameter of $800 \mathrm{~nm}$ was $(7.5 \pm 1.2) \times 10^{-4}$. Polydisperse particles with other average diameters, namely 1.20 and $1.50 \mu \mathrm{m}$ were assayed with $\gamma$ determined to be $7.2 \times 10^{-4}$ and $7.3 \times 10^{-4}$, respectively. The authors noted that their results were in good agreement with those from coated-wall experiments (Moise and Rudich, 2002; Thornberry and Abbatt, 2004) but were lower than the results for the other two previously mentioned aerosol-based methods(Morris et al., 2002; Smith et al., 2002).

By a similar method, Hearn and Smith (Hearn and Smith, 2004b) determined the uptake coefficient of polydisperse LA with a mean diameter of $800 \mathrm{~nm}$ to be $(1.1 \pm 0.2) \times 10^{-3}$. Two other single component polydisperse particles were studied: oleyl alcohol and 1-octadecene (Hearn and Smith, 2004b). The former is the alcohol analogue of OL and had the identical value for the uptake coefficient as OL: $7.5 \times 10^{-4}$ for particles with an $800 \mathrm{~nm}$ average diameter. The value of $\gamma$ for 1-octadecene was considerably smaller than that of OL, only $2.4 \times 10^{-4}$ for polydisperse particles with an $800 \mathrm{~nm}$ average diameter, possibly due to the position of the double bond, or inhibited solubility or diffusion of ozone within the alkene (Hearn and Smith, 2004b).
In summary

- CIMS gave a value of $\sim 7 \times 10^{-4}$ for polydisperse OL particles assuming Case 2, a value in better agreement with coated-wall reactor measures than other particle based methods

- This method appears very convenient for measuring polydisperse particles, but the radial dependency on $\gamma$ is not readily extracted

Additional studies with CIMS have been conducted with monodisperse OL, but analysis of the results involved insight from the mixed particle studies, so we will refrain from discussing these results until Sect. 4.4.3.1.

4.4.2.4 Reactive uptake: thermal desorption particle beam mass spectrometry

The TDPBMS method has also been applied to study the ozonolysis of submicron $(\sim 0.02-0.5 \mu \mathrm{m}$ diameter $)$ OL particles assuming Case 2 kinetics. Figure 6 shows a typical kinetic plot, with the slopes giving the value of $\mathrm{H}\left(\mathrm{Dk}_{2}\right)^{1 / 2}$. An uptake coefficient of $(1.3 \pm 0.2) \times 10^{-3}$ was calculated for pure OL particles. Interestingly, this study, which is the only one to date employing an environmental chamber, gave results similar to those with the CFT and AFT.

4.4.3 Reactive uptake by internally mixed particles and coatings

Organic particles in the troposphere are mixed particles (Alves et al., 2001; Duce et al., 1983; Guo et al., 2003; Hahn, 1980; Huang et al., 2006; Pio et al., 2001; Simoneit et al., 1988; Simoneit, 1986). Recently, a succession of papers has appeared in the literature reporting on the application of instrumental methods and models developed for the OL-O 3 HRS to examine the kinetics and/or products of ozonolysis of internally mixed particles (Hearn et al., 2005; Hearn and Smith, 2004b, 2005, 2006; Katrib et al., 2005a; Zahardis et al., 2006b, c; Ziemann, 2005; Mochida et al., 2006; Nash et al., 2006) and multicomponent organic coatings (Knopf et al., 2005) that are more complex than this model system and more closely approximate real OA.

4.4.3.1 Reactive uptake of mixed particles: chemical ionization mass spectrometry

Hearn and Smith (2004b) have also measured the uptake coefficient of mixed particles of LA and OL with CIMS (Table 2). They found that the ratio of the uptake coefficients in the mixed particles of LA vs. OL is 1.37 , which is slightly smaller than the theoretical value of 1.42 anticipated for doubling $k_{2}$, and smaller than the ratio they measured for pure OL and LA particles (1.47) (Hearn and Smith, 2004b). As they note, this may indicate enhanced solubility and/or diffusion of $\mathrm{O}_{3}$ in pure LA particles (Hearn and Smith, 2004b). 
CIMS was applied to internally mixed, monodisperse particles of OL and MOL (Hearn et al., 2005). For $650 \mathrm{~nm}$ OL particles, the authors noted that all the cases that had exponential solutions for decay, namely Cases 1,3 and 4, fit the data well. The authors eliminated Case 4 because the decay showed a dependence on the partial pressure of ozone, no dependency on the inverse square of the particle radius, and they assumed that OL diffusion was sufficiently fast to maintain a constant concentration throughout the particle. They eliminated Case 1 by noting that there is clearly a linear dependence of OL decay on the inverse of the particle radius. They concluded that the particle decay was given by Case 3 , a surface reaction. This contradicts the prior studies, which indicated that this reaction was limited by ozone diffusion (Case 2) (Moise and Rudich, 2002; Morris et al., 2002; Smith et al., 2002). The authors calculated the uptake coefficient to be $(1.38 \pm 0.06) \times 10^{-3}$ for monodisperse OL from 600 $1200 \mathrm{~nm}$ that had to be adjusted to account for secondary reactivity in the system as shall be described.

The uptake of ozone by MOL was investigated to try to evaluate the extent of secondary reactivity (Hearn et al., 2005) in the ozonolysis of OL, namely the formation of AAHP by CI via reaction with OL. Since this reaction proceeds through the addition of a CI to the carboxyl group it would result in an additive loss to OL but would not deplete MOL. All loss of MOL would be via oxidative cleavage by ozone (Hearn et al., 2005). The best fit for $600-1100 \mathrm{~nm}$ MOL particles were given by Case 2 and $\gamma$ was calculated to be $(1.23 \pm 0.10) \times 10^{-3}$. Although the values of $\gamma$ were similar for pure OL and MOL, this does not explicitly imply that the uptake of the two particles is identical: "It is possible that $\mathrm{O}_{3}$ solubility and/or diffusion are larger in the (MOL) particles than in (OL) particles and that this enhancement offsets an increased (OL) loss due to secondary reactions." (Hearn et al., 2005).

The authors employed internally mixed particles of OL and MOL to investigate the extent of secondary reactions in the OL-O $\mathrm{O}_{3} \mathrm{HRS}$ by eliminating possible differences in ozone solubility and diffusion. By changing the $[\mathrm{MOL}] /[\mathrm{OL}]$ ratio, they were able to change the $[\mathrm{CI}] /[\mathrm{OL}]$ ratio, interrogating the extent of AAHP formation. Figure 7 emphasizes the key results from these experiments. Without assuming a limiting case regime, the initial rates of reaction of $\mathrm{OL}$ and $\mathrm{MOL}$ for internally mixed particles are plotted as a function of the mole fraction of $\mathrm{OL}, \chi$. While the initial rate of reaction rose substantially for OL with decreasing $\chi$, this was much less so with MOL. Figure 7 also presents the results of an analogous experiment using internally mixed particles of OL and $n$-hexadecane, the latter is a saturated organic that is nonreactive towards ozonolysis, showing that the initial rate of decay of OL is approximately constant. This suggests that the increase in the initial rate of reaction of OL with decreasing $\chi$ was not simply due to a decrease in OL, but rather due to an increase in the $[\mathrm{CI}] /[\mathrm{OL}]$ ratio. Figure 8 is the appearance curve of a CI rearrangement product, 9-methoxy-

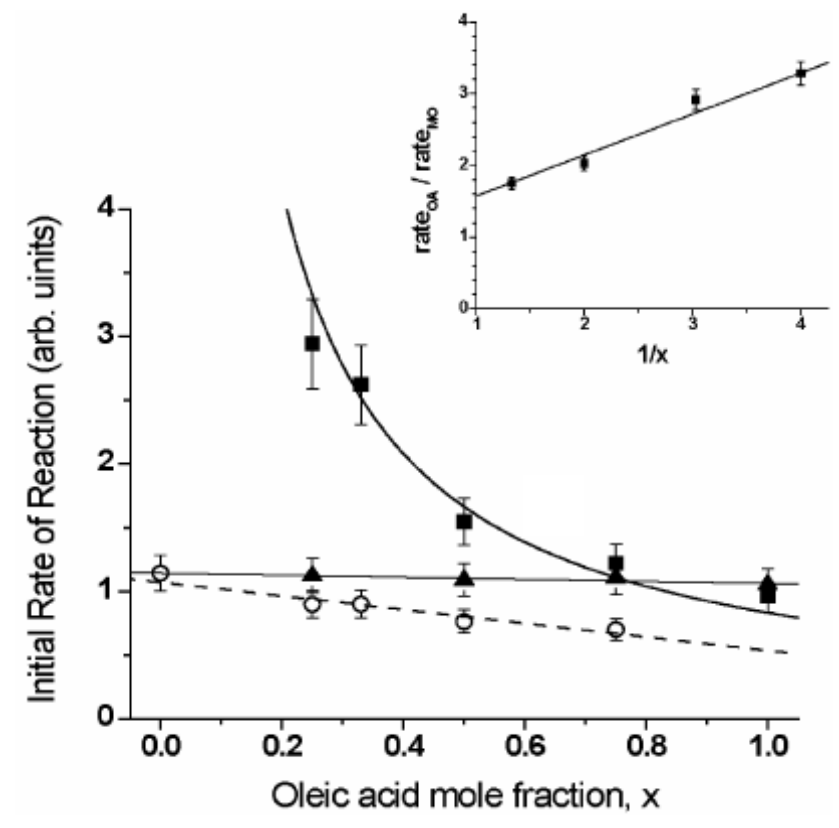

Fig. 7. Initial rates of reaction for internally mixed particles of OL (घ) and MOL (O). These initial rates are normalized to the rate of pure OL particles. Rates of internally mixed OL $/ n$-hexadecane (A) are shown for comparison. The increase in the OL decay rate at lower mole fractions of OL results from greater contributions to OL loss from reactions with CI. The inset shows the ratio of the rates (with OA denoting oleic acid and MO denoting methyl oleate), and the fit indicates that $36 \%$ of the measured loss of OL is attributed to secondary chemistry (from Hearn et al., 2005).

9-oxononanoic acid $(\mathrm{MW}=202 \mathrm{u})$, a stable carboxylic acid resulting from ozonolysis of MOL. The yield of this species is significantly lower in the mixed particle compared to pure MOL because the CI can react rapidly with OL. This effect is considerable; particles with a MOL: OL ratio of 3:1 show a reduction by a factor of 2 compared to the pure MOL particles.

Hearn et al. (2005) present further arguments that could account for the differences in the changes in the initial rate of reactions for OL and MOL with changing $\chi$. One argument involves phase separation, where an OL shell forms around an MOL core. Subsequently, a faster reaction would occur with the MOL as opposed to OL; however, this morphology would cause a delay in the reaction time of MOL as a function of shell thickness which was not observed. One of the most significant results of this experiment (Hearn et al., 2005 ) is the estimate of the extent of reaction between the CI and OL. The key assumption in this calculation is that the rates of reaction of OL and MOL are equal in the same particle (with other assumptions given by the authors). The authors suggested that the linearity shown in Fig. 7 is consistent with the reaction of the CI with OL and they used the slope of the curve to calculate that $36 \%( \pm 4 \%)$ of the OL lost is due to the reaction with the CI. The authors also 


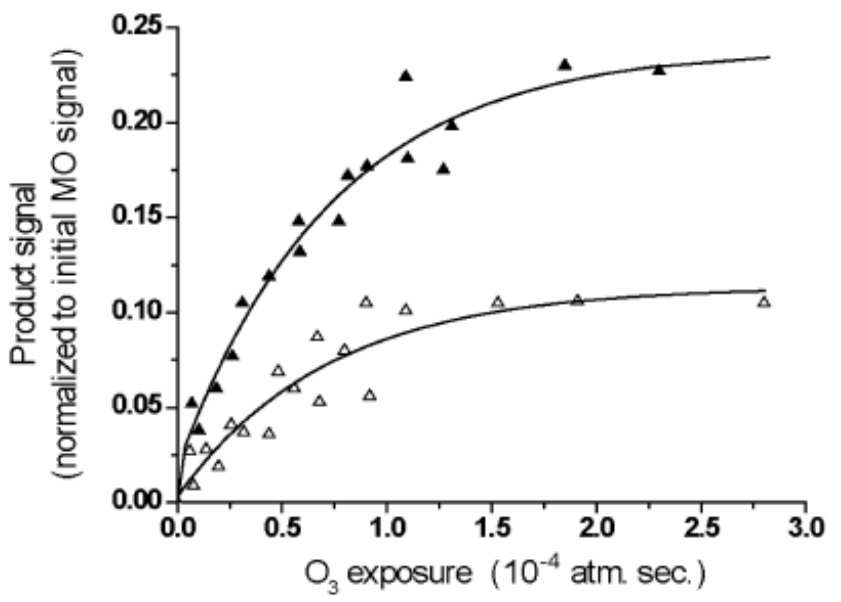

Fig. 8. Appearance of CI rearrangement products (9-methoxy-9oxononanoic acid) with progressive ozone exposure. The yield is lower in mixed OL/MOL particles $(\triangle)$ (methyl oleate is denoted MO on this figure) than pure MOL particles $(\boldsymbol{\Delta})$, indicating a sizable reaction between CI and OL. Lines are to guide the eye and do not represent fits to the data (from Hearn et al., 2005).

stated that "the linearity of this plot indicates that other secondary reactions involving (OL) and (MOL) must be negligible" (Hearn et al., 2005). The loss of OL to CI was used as a correction for $\gamma$ : the resulting corrected value of $\gamma$ of $(8.8 \pm 0.5) \times 10^{-4}$ is in good agreement with the coated-wall studies (Moise and Rudich, 2002; Thornberry and Abbatt, 2004). It is also slightly lower than the value of the uptake coefficient of MOL, which the authors suggest is due to an enhanced solubility or diffusion of ozone in MOL compared to OL. They attribute this to the lower degree of order in MOL compared to OL. Under ambient conditions OL is an ordered liquid (Iwahashi et al., 2000, 1995, 1991) (Fig. 9), while MOL is probably an isotropic liquid under these conditions. Hearn et al. have proposed that this ordered liquid has a high density of carbon-carbon double bonds at the surface and therefore "reduces the rate of $\mathrm{O}_{3}$ diffusion into the bulk and results in a surface-dominated reaction between $\mathrm{O}_{3}$ and the double bonds of (OL)." Most or all of the ozonolysis occurs in the first monolayer of the ordered liquid OL by this model. In contrast, the low-ordered MOL has deeper diffusion of ozone and less surface reactions and follows Case 2 kinetics.

Key results and conclusions of the CIMS studies on mixed particles include

- Loss of CI to OL may be a significant loss route, with AAHP the dominant products

- Secondary reactions of CI can consume OL and this should be accounted for in uptake calculations

- Accounting for these secondary reactions gives a value of $\gamma$ similar to coated-wall reactor based measurements

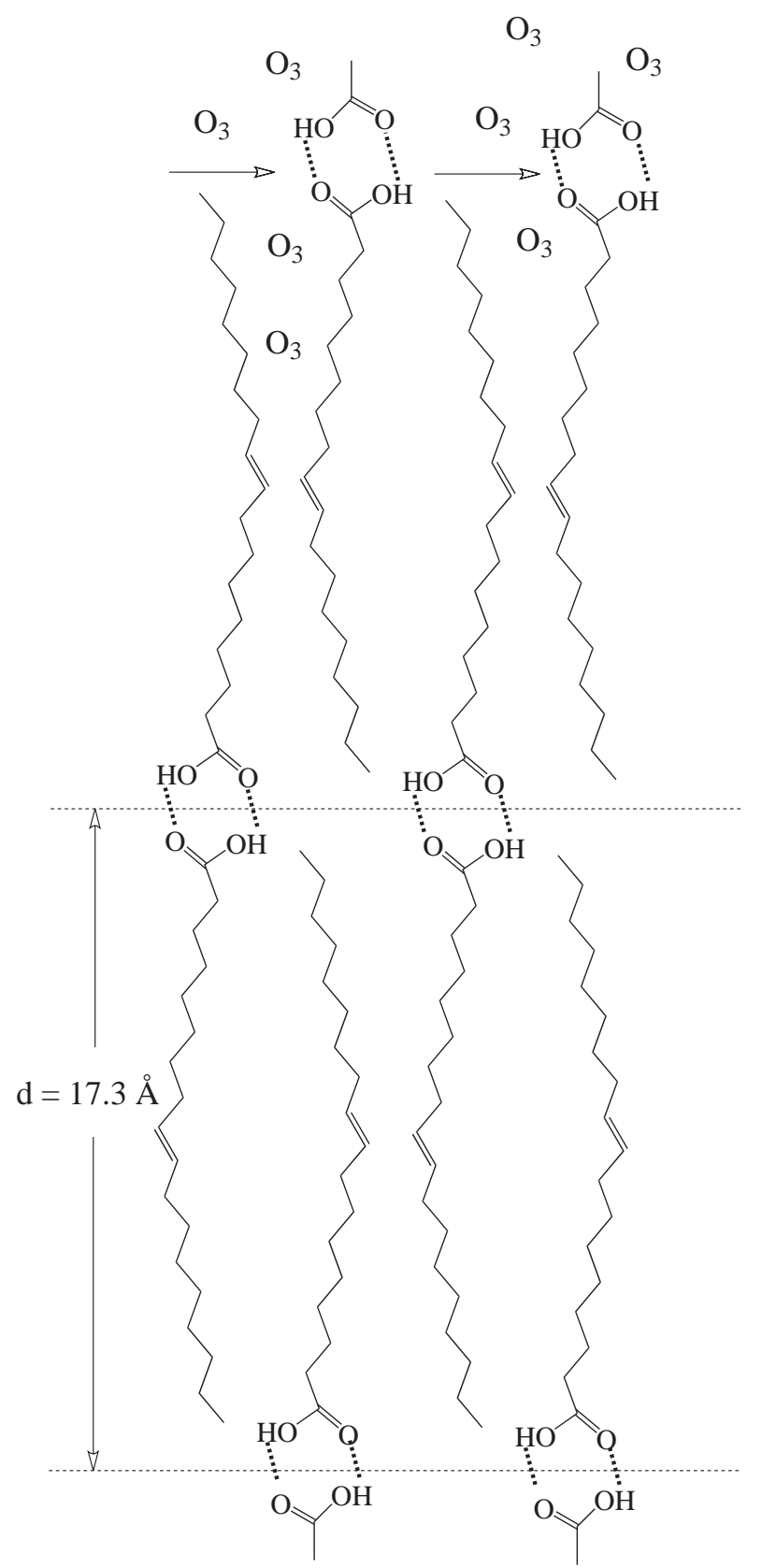

Fig. 9. Quasi-smectic condensed-phase structure of OL dimers stabilized by hydrogen bonding. As suggested by Hearn et al. (2005), the alkyl chains will be more mobile than the rigid double bonds and form an $\mathrm{O}_{3}$ "funnel" directing the $\mathrm{O}_{3}$ towards the double bonds while inhibiting diffusion past them. This has been proposed to be the basis of the surface reactivity of this system evidenced by Hearn et al. (2005). The spacing indicated on the figure has been determined by Iwahashi et al. (1991) (adapted from Hearn et al., 2005).

where ozone loss is measured directly. Other particlebased methods that do not account for secondary chemistry may have an artificially large value for $\gamma$ 
4.4.3.2 Reactive uptake of mixed particles: Aerodyne aerosol mass spectrometry

Katrib et al. (2005a) studied the uptake of ozone by internally mixed particles of OL and SA. An Aerodyne AMS was used to study nearly monodisperse $300 \mathrm{~nm}$ particles with OL concentration ranging from $0 \%$ to $100 \%$ relative to $\mathrm{SA}$. SA is the saturated analogue to OL so it does not undergo direct oxidative processing by ozone. Figure 10 shows the decay profile of SA in particles with different OL:SA ratios as a function of ozone exposure. The authors proposed that the increase in SA decay with ozone exposure and OL concentration is due to the secondary chemistry facilitated by stabilized CI that are formed by ozonolysis of OL. They proposed that the CI reacts with the carboxylic acid of the SA forming AAHP. They also noted that the decay profiles of SA and OL are very similar for 90/10 (OL: SA), 75/25 and 60/40 particles; however, with SA content greater than $50 \%$ the decay behavior of OL and SA differs.

The applicable limiting case for these mixed particles was not clear. This stems, in part, from our limited description of the phase behavior of binary FA mixed particles; which are well-described in bulk mixtures (Inoue et al., 2004a, b, c, 1992; Iwahashi et al., 2004). It was noted that classification of the reactive uptake for a mixed particle that may contain some solid- phase (SA) of uncertain morphology was an even more complex issue than for the simpler system of pure OL, for which there exists still a degree of uncertainty. The authors therefore opted for a data driven approach over the model driven approach (Katrib et al., 2005a) to determine the reactive uptake. The data-driven approach applies the steady-state assumption to the concentration of dissolved ozone in the particle, such that further ozone uptake is driven by chemical reaction and it is assumed that monitoring the loss of volume-averaged ozone is equal to measuring the rate of reaction of OL. The authors acknowledge that the second assumption has inherent inaccuracies since some of the OL is consumed by CI generated in ozonolysis.

The authors applied this method to non-spherical particles, such as those with SA (which was inferred from microscopy), then further adapted the expression for $\gamma$ for the Aerodyne AMS method that measures the mass of an aerosol population. This approach yielded:

$\gamma=\frac{-d m_{\mathrm{OL}} / d t}{\left(P_{\mathrm{O}_{3}} \bar{c} / 4 R T\right)\left(M W_{\mathrm{OL}} N A\right)}$

Here $m_{\mathrm{OL}}$ is the aerosol mass of $\mathrm{OL}, \mathrm{N}$ is the number concentration of particles, and $A$ is the particle surface area. Because $[\mathrm{OL}]$ and $\gamma$ both decrease over time, the authors extrapolated their decay data to zero time and calculated and initial uptake coefficient, $\gamma_{o}$. The pressure of ozone was varied at a fixed exposure time and $\mathrm{d} m_{\mathrm{OL}} / \mathrm{dt}$ was approximated as $\Delta m_{\mathrm{OL}} /(\Delta \mathrm{t})$, with $\mathrm{A}$ calculated for a known diameter particle, giving an upper-limit estimate of $\gamma_{o}$ by Eq. (11). This process was repeated for other ozone pressures, with further

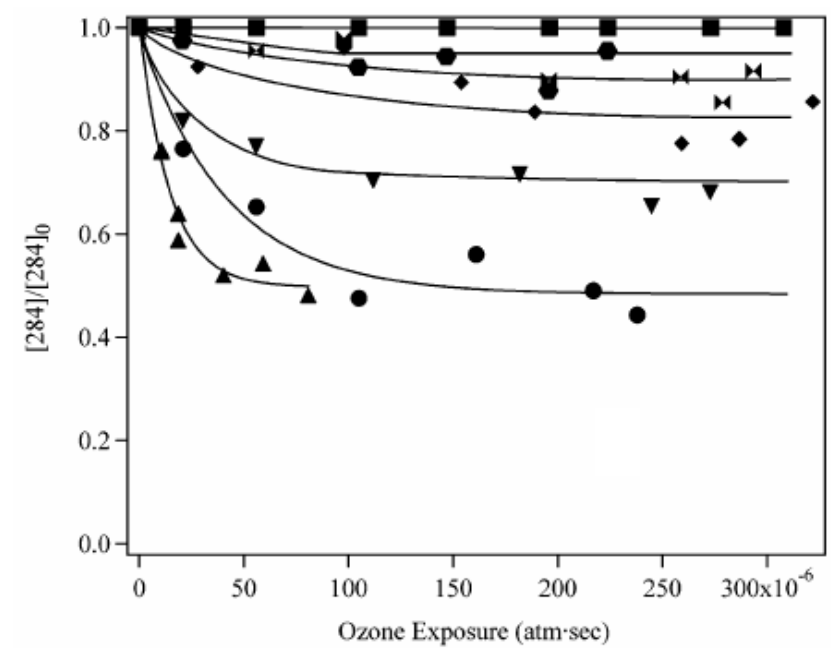

Fig. 10. Decay of $\mathrm{SA}$ from increasing $\mathrm{O}_{3}$ exposure for OL/SA mixed particles as determined by Aerodyne AMS. (SA is denoted

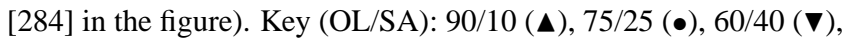
$50 / 50(\checkmark), 30 / 70(\bowtie)$ 10/90 ( $\neg), 0 / 100(\boldsymbol{\square})$. Lines are to guide the eye and do not represent a fit to the data (from Katrib et al., 2005a).

considerations given by the authors, and then averaged, giving $\gamma_{o}$ for a given OL/SA composition. This method gave $(1.25 \pm 0.2) \times 10^{-3}$ for pure OL, which is in good agreement with the prior Aerodyne AMS study (Katrib et al., 2004) that was model driven.

The authors consider the uptake coefficient reported as the upper-limit, since there was no accounting for the loss of OL to secondary reactions with CI. If a correction in accord to Hearn et al. (2005) is made, the value of $\gamma\left(\sim 8 \times 10^{-4}\right)$ is in good agreement with that of Hearn et al $\left(\sim 9 \times 10^{-4}\right)$. Katrib et al. found that the upper-limit value of $\gamma_{o}$ decreased linearly from OL/SA $100 / 0$ to $60 / 40$, from $(1.25 \pm 0.2) \times 10^{-3}$ to $(0.60 \pm 0.15) \times 10^{-3}$; however, at OL/SA $50 / 50$ the authors noted an abrupt drop in the upper-limit value of $\gamma_{o}$ to $(0.15 \pm 0.1) \times 10^{-3}$ which remained approximately constant toward higher particle content of SA. Similar decreases have been observed by Knopf et al. (2005) for alkanoic acid/ oleic acid mixtures, as shall be discussed in Sect. 4.4.3.5.

Katrib et al. (2005a) compared the results of the parameters of their Aerodyne AMS experiments: unreacted OL and SA at high ozone exposure, the initial uptake coefficient, and particle beam width and discerned there were three distinct composition regions that have different effects on these parameters (Fig. 11). In the first region, the linear increase in SA corresponds with a linear trend in the parameters. In region 2 there is an abrupt change in all the parameters, though the change appears monotonic. In the third composition region, there are no changes in the parameters or the change is minimal with increasing SA content

The authors suggest three postulates to explain the trends in the parameters, all of which relate to morphological changes in the particles: 


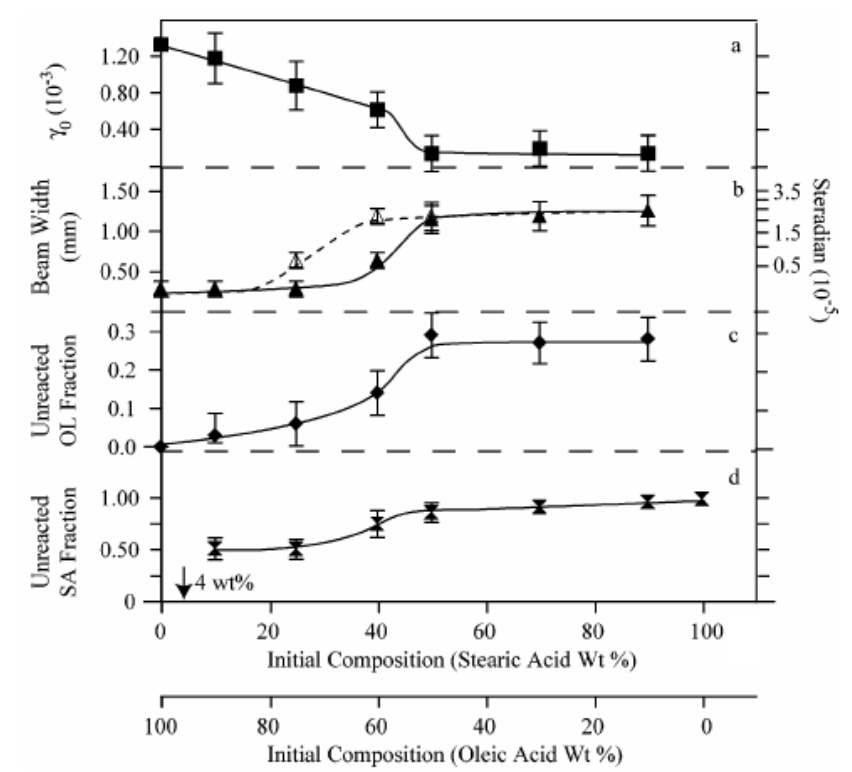

Fig. 11. Summary of results for increasing SA composition in OL/SA mixed particles: (a) initial reactive uptake coefficient $\left(\gamma_{o}\right)$; (b) beam width before $(\boldsymbol{\Delta})$ and after $(\triangle)$ ozone exposure $\left(300 \times 10^{-6}\right.$ atm s $\left.\mathrm{O}_{3}\right)$; (c) unreacted OL fraction after ozone exposure; (d) unreacted SA fraction after ozone exposure. Quantities are shown for increasing SA weight percent composition, with the balance being OL. Lines are to guide the eye and do not represent a model fit. The amount $4 \mathrm{wt} \%$ indicates the composition of a liquid with pure, solid SA at $298 \mathrm{~K}$ (Inoue et al., 2004b) (from Katrib et al., 2005a).

\section{- Supersaturation}

- SA binding OL as an impurity in its crystal lattice

- Formation of semi-permeable gels of SA that contain some liquid OL

The authors noted (Katrib et al., 2005a), in regards to OL: "For all compositions having SA content greater than 90/10, the reaction kinetics appear to have a two-step behavior, showing an initial fast decay for low ozone exposure followed by an apparent absence of further reaction at high ozone exposure." Similar kinetic effects have been observed in other mixed particle studies (Hearn and Smith, 2005; Ziemann, 2005), as noted by the authors.

In summary:

- A data driven approach was used to determine $\gamma \sim 1 \times 10^{-3}$ for OL, similar to other particle-based methods that do not correct for secondary chemistry

- Secondary chemistry via CI was indicated including reactions with a saturated FA (SA) that is not susceptible to direct ozonolysis

- Nonlinearity in $\gamma$ and other parameters may arise from morphological changes in the particle
4.4.3.3 Reactive uptake of mixed particles: thermal desorption particle beam mass spectrometry

Ziemann applied TDPBMS to mixed particles (Ziemann, 2005) employing an environmental chamber. The internally mixed particles included 10/90 (OL) mixtures with nonvolatile components: DOS, C17 and C16. None of these species are susceptible to oxidative cleavage by ozone, allowing for assessment of how liquids and solids affect reactive uptake.

Figure 6 shows the decay profiles of pure OL and the three internally mixed particles. Case 2 of the resistor model was applied, assuming a thin diffuso-reactive layer relative to the particle diameter. The kinetics of pure OL and DOS/OL are seen to be very similar, reacting essentially completely with ozone within $2-3 \mathrm{~min}$. It was noted by the author that the reaction of the mixtures containing the alkanoic acids, $\mathrm{C} 16$ and $\mathrm{C} 17$, are "initially almost as fast (as pure OL), but then slow down dramatically within $\sim 2$ min such that $\sim 65 \%$ and $\sim 80 \%$ of the OL has reacted after $\sim 8$ min." These effects are attributed to the phase equilibria. In the particles with $\mathrm{C} 16$ and $\mathrm{C} 17$, the fast and slow regimes may be due to the particles having two phases, one that is pure liquid OL, the other being a semi-solid mixture of OL and the alkanoic acid and diffusion impeded in these regions leading to a slower reaction rate (Knopf et al., 2005).

Using the results of Case 2, Ziemann calculated uptake coefficients for OL/DOS, OL/C16 and $\mathrm{OL} / \mathrm{C} 17$ at $(1.1 \pm 0.4) \times 10^{-3},(0.13 \pm 0.1) \times 10^{-3}$ and $(0.25 \pm 0.2) \times 10^{-3}$ (Ziemann, 2005). Notice that the OL/DOS uptake coefficient is very similar to that of pure OL, $(1.3 \pm 0.2) \times 10^{-3}$. Conversely, for the mixed particles with alkanoic acids, the values are about one order of magnitude lower than the uptake coefficient of pure OL, which is attributed to the trapping of OL. This is quite different from the value of $\gamma_{o}$ determined by Katrib et al. (2005a) for the corresponding composition of OL/SA; the OL/SA particles with $90 \%$ OL had an estimated $\gamma_{o}$ of $\sim 1 \times 10^{-3}$. However, the mixed particles of OL and $\mathrm{C} 16$ or $\mathrm{C} 17$ are very similar to the value of $\gamma_{o}$ for OL/SA particles with $50 \%$ or less OL content, $(0.15 \pm 0.10) \times 10^{-3}$.

In summary:

- $\gamma$ decreases by about one order of magnitude (to $\sim$ $10^{-4}$ ) in mixed particles that may have semi-solid phases

4.4.3.4 Reactive uptake of mixed particles: single-particle mass spectrometry

Nash et al. (2006) have recently applied single-particle MS to investigate the ozonolysis of $2 \mu \mathrm{m}$ diameter mixed particles of OL and C14. They accounted for secondary reactions from the stabilized CI (denoted SCI in the following discussion) in their calculations of $\gamma$, with the following mechanism used to analyze their data: 
1. $\mathrm{OL}+\mathrm{O}_{3} \stackrel{k_{1}}{\longrightarrow} \mathrm{SCI}$

2. $\mathrm{OL}+\mathrm{SCI} \stackrel{k_{0}}{\longrightarrow}$ products

3. $\mathrm{C} 14+\mathrm{SCI} \stackrel{k_{m}}{\longrightarrow}$ products

In the second and third steps above the products are assigned as hydroperoxy esters by the authors (i.e. AAHP). The steady state (SS) approximation was made for the SCI:

$[\mathrm{SCI}]_{s s}=\frac{k_{1}[\mathrm{OL}]}{k_{o}[\mathrm{OL}]+k_{m}[\mathrm{C} 14]}$

Since this method explicitly accounts for secondary chemistry in calculating the reactive ozone uptake coefficient, we shall present some of the details for the formulation. The above expression for $[\mathrm{SCI}]_{s s}$ was used to show the reaction rates for OL and $\mathrm{C} 14$ loss:

$$
\begin{aligned}
& \frac{-d[\mathrm{OL}]}{d t}=k_{1}[\mathrm{OL}]+\frac{k_{1} k_{0}[\mathrm{OL}]^{2}}{k_{0}[\mathrm{OL}]+k_{m}[\mathrm{C} 14]} \\
& -\frac{d[\mathrm{C} 14]}{d t}=\frac{k_{1} k_{m}[\mathrm{C} 14][\mathrm{OL}]}{k_{o}[\mathrm{OL}]+k_{m}[\mathrm{C} 14]}
\end{aligned}
$$

Solving the above equations for the ratio $k_{o} / k_{m}$ then assuming this ratio was $\sim 1$, based on the assumption that the rate of reaction of the SCI with OL and C14 is about the same Nash et al. showed:

$n_{\mathrm{OL}, \text { avail }}=\left(1-\frac{\left(1-\chi_{\mathrm{C} 14}\right)}{2}\right) n_{\mathrm{OL}, \text { particle }}$

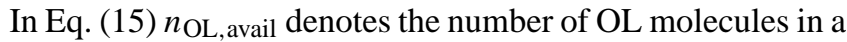
particle available for ozonolysis; $n_{\mathrm{OL}}$, particle is the total number of OL molecules in a particle of a given composition; and $\chi_{\mathrm{C} 14}$ is the mole fraction of $\mathrm{C} 14$ relative to OL. The derivation of the equation is based on the prior mechanism and their finding that $100 \%$ of the SCI reacted with the carboxylic acid groups (Nash et al., 2006). As noted by the authors (Nash et al., 2006), this contrasts the results of Hearn et al. (2005) of only $36 \%$ of the SCI reacting with the acid groups.

Nash et al. then calculated the ozone uptake coefficient in terms of $n_{\mathrm{OL} \text {, avail }}$

$\gamma=\frac{\text { reaction rate }}{\text { collision rate }}=\frac{k_{1} n_{\mathrm{OL}, \text { avail }}}{\left(\pi \bar{c} d^{2} / 4\right) \rho_{\mathrm{O}_{3}}}$

In Eq. (16) $k_{1}$ is the observed pseudo first order rate constant $\left(\mathrm{s}^{-1}\right), \bar{c}$ is the mean kinetic speed of $\mathrm{O}_{3}$ molecules in the gas-phase $\left(\mathrm{cm} \mathrm{s}^{-1}\right), d$ is the particle diameter $(\mathrm{cm})$, and $\rho_{\mathrm{O}_{3}}$ is the number density of ozone (molecules $\mathrm{cm}^{-3}$ ).

For pure OL the uptake coefficient was calculated to be 3.4 $( \pm 0.3) \times 10^{-4}$ after taking the secondary reactions into account (Nash et al., 2006); however, at the C14 crystallization point, where only $2.5 \%$ of the particle was in the solid-phase, the uptake coefficient was reduced to $9.7( \pm 1.0) \times 10^{-5}$.
Nash et al. attributed this dramatic drop in $\gamma$ to the presence of a crystalline monolayer of $\mathrm{C} 14$, which reduces $\mathrm{O}_{3}$ diffusion by several orders of magnitude, relative to liquid OL. Scanning electron microscopy was used to confirm that the particles surface is crystalline for $\mathrm{C} 14$ mole fractions greater than 0.125 (Nash et al., 2006).

\subsubsection{Reactive uptake of mixed coatings}

Knopf et al. (2005) have applied a rotating-wall flow tube reactor to study the ozonolysis of lauric acid/OL (C12/OL) and myristic acid/OL (C14/OL) mixtures. Also investigated by this method were multicomponent mixtures that were proxies to meat-cooking aerosols similar to those observed in field studies (Hildemann et al., 1994; Rogge et al., 1991; Schauer et al., 1999). A key difference in this methodology as compared to the AFT experiments is that in the former less than $3 \%$ of the film is oxidized, as compared to the aerosol based experiments where most or all of the particle is often subjected to longer exposures. Further, Knopf et al. (2005) used atmospherically relevant ozone concentrations (on the order of $10^{12}$ molecules $\mathrm{cm}^{-3}$ (Fenger, 1999)), which are several orders of magnitude lower than those used in most of the AFT experiments.

The authors varied the $\mathrm{C} 12$ and $\mathrm{C} 14$ concentrations relative to OL such that they had completely liquid mixtures as well as solid-liquid mixtures that, in the latter case, had liquid OL and the alkanoic acid as a solid. Additionally, films were prepared by two different methods to investigate the effects of preparation on uptake of ozone. The "slow cooling method" involved melting a solid-liquid mixture and crystallizing it on the wall of the tube and slowly cooling, while in the "fast cooling method", a preheated tube was rapidly immersed in liquid $\mathrm{N}_{2}$ to prepare a solid film. It should be noted that the films appear as wax-like solids with different overt morphology, but, as the authors note, although solids in appearance, the films must contain liquid by the lever rule.

By monitoring ozone loss, $\gamma$ of liquid OL (at T $286-$ $298 \mathrm{~K}$ ) and solid OL (at T 278-285 K) were determined to be $(7.9 \pm 0.3) \times 10^{-4}$ and $(0.64 \pm 0.05) \times 10^{-4}$, respectively (Knopf et al., 2005). As shown in Table 2, these values are in good agreement with other studies employing CFT (Moise and Rudich, 2002; Thornberry and Abbatt, 2004), and somewhat smaller than $\gamma$ measured in most aerosol based studies that do not employ corrections accounting for secondary chemistry (Katrib et al., 2005a; Morris et al., 2002; Smith et al., 2002; Ziemann, 2005). As in the case of the coatedwall studies by Moise and Rudich (2002), the solid-phase OL coatings have an uptake approximately one order of magnitude smaller than the liquid. Unlike the uptake of pure solid and liquid OL, the uptake of C12/OL and C14/OL are not continuous functions (Knopf et al., 2005) of the mixture ratio. As the authors note: "When a small amount of (C12) or (C14) is added to (OL), there appears to be a step change in 
the uptake coefficient, after which the uptake follows a continuous function."

The values of $\gamma$ for the liquid and solid-liquid binary mixtures are given in Table 2. Notice that the value of $\gamma$ for the C12/OL and C14/OL liquid mixtures is very similar, ranging from (4-7.2) $\times 10^{-4}$, decreasing with increasing concentration of the alkanoic acid and of similar order of magnitude of pure liquid OL. The uptake coefficient for the mixed phase coatings decreases by up to an order of magnitude, compared to the liquid mixtures. As noted by Knopf et al. this decrease in $\gamma$ probably originates from "the solid (forming) an interconnected network by dendritic growth, aggregation of crystals, or eutectic solidification, which can result in lamellar or rod microstructures." These structures slow the diffusion of ozone and OL, trap OL, and/or have other effects that cause the uptake of ozone to be smaller than the liquidphase. The slow-cooled solid-liquid mixtures generally had a smaller value of $\gamma$ than the corresponding fast-cooled mixtures (Knopf et al., 2005) with the authors proposing that the slow cooling structure trapped more OL than the fast cooling one.

$\mathrm{OA}$ in the troposphere are far more complex than proxies investigated to date in the laboratory. In this regard, films with compositions resembling meat-cooking aerosols (Rogge et al., 1991; Schauer et al., 1999) have been prepared (Knopf et al., 2005) and subjected to ozonolysis. Mixed particles with 5, 9, and 15 components were prepared, with OL as the major component in all cases, followed in order of mass by other FA, then by the other classes of organics i.e. dicarboxylic acids, alkanes, alkanones, and amides. These mixtures may represent the most realistic organic mixture found in aerosol particles with respect to identified mass. The phase behavior of these complex mixtures is not well-known, but the authors evoked thermodynamic arguments to speculate that OL should remain in the liquid state, while the alkanoic acids may be solids (Knopf et al., 2005). The value of $\gamma$ ranged from (1.6-6.9) $\times 10^{-5}$ for these mixtures, less than their $\gamma$ for liquid OL by at least one order of magnitude, with the upper-limit similar to solid OL with the slower-cooled films having smaller values of $\gamma$. The differences in $\gamma$ of the slow- and fast-cooling systems probably stem from the trapping of OL and morphological differences in the coatings as a function of preparative procedure.

The trapping of OL suggested from studies on these these proxies is in accord with a very recent report on complex particle analysis employing aerosol CIMS that included an investigation of real meat-cooking aerosols (Hearn and Smith, 2006). In that study, polydisperse meat-cooking aerosols were generated by pan frying ground hamburger that was followed by ozonolysis in a flow reactor (Hearn and Smith, 2006). The authors showed that $\sim 35 \%$ of the OL remained trapped in the particle even after an ozone exposure of $\sim 5 \times 10^{-4}$ atm s. Meat-cooking proxies of OL/C16 $\left(\chi_{\mathrm{OL}}=0.3\right)$ investigated in that study also showed OL trapping at the same ozone exposure, as opposed to pure OL that reacted to completion (Hearn and Smith, 2006).

In summary:

- Morphological differences can lead to significant changes in $\gamma$ which, compared to pure OL, decrease by about one order of magnitude when a medium is frozen or is a complex mixture

\subsection{Supercooling in mixed particles}

Hearn and Smith have described the uptake of ozone by OL/C14 with CIMS (Hearn and Smith, 2005), revealing that mixed particles can exist in a supercooled, non-equilibrium state. Particles were formed by homogeneous nucleation of heated vapors $\left(100-150^{\circ} \mathrm{C}\right)$, without solvent, as simple proxies to meat-cooking aerosols. At room temperature, the rate of decay of OL to completion in OL/C14 mixtures was approximately the same as for pure OL, indicating a supercooled mixture. This was not the expected result since C14 is a solid at room temperature and should slow the rate of decay (Knopf et al., 2005). The authors estimated that mixtures with the most $\mathrm{C} 14$ enrichment had the largest supercooling $\left(32^{\circ} \mathrm{C}\right)$ at room temperature. This estimate was based on the assumption that the complete loss of OL in the ozonized particles corresponded with completely liquid particles, giving the lower-limit of supercooling for the C14/OL particles.

The possibility of supercooling in these particles was tested by further cooling the particles to $-2^{\circ} \mathrm{C}$, then allowing them to warm back up to room temperature before performing ozonolysis. These pre-cooled particles reacted significantly more slowly than the particles which were not precooled, e.g. by a factor of 12 more slowly for particles with a mole fraction of $0.25 \mathrm{OL}$. Moreover, even with long ozone exposure $\left(>6.0 \times 10^{-4} \mathrm{~atm} \mathrm{O}_{3} \mathrm{~s}\right)$ there was still evidence of OL in the pre-cooled particles while the supercooled particles that did not undergo the pre-cooling cycle had all the OL consumed by ozone at less than half this exposure. The supercooling was further supported by FTIR analysis as detailed by the authors (Hearn and Smith, 2005).

As noted by the authors (Hearn and Smith, 2005), the presence of supercooled OA in the troposphere and the implications on ozone loss is an unexplored area, which we will elaborate on further in the Discussion.

\section{Discussion}

The $\mathrm{OL}-\mathrm{O}_{3}$ HRS continues to serve as a proxy to aid in elucidating themes of processing of HRS consisting of condensedphase organics by gas-phase trace oxidants. The following sections discuss the atmospheric implications of oxidative processing, especially by ozone, of OA, based upon what has been learned from OL and related proxies. The most important implications regard atmospheric lifetime, $\mathrm{CCN}$ ability of $\mathrm{OA}$, and subsequently the effects on radiative forcing. 
5.1 Lifetime of unsaturated organics in particulate in the troposphere

There is clearly an enhancement in the rate of loss of unsaturated organics, such as OL, from ozone, when the organic is in the form of particulate or a coating as compared to the gasphase (Hearn and Smith, 2004b; Moise and Rudich, 2001; Morris et al., 2002; Thornberry and Abbatt, 2004; Wadia et al., 2000). For example, the uptake coefficient of pure liquid OL is on the order of $10^{-3}$ (Hearn and Smith, 2004b; Katrib et al., 2005a; Knopf et al., 2005; Moise and Rudich, 2002; Morris et al., 2002; Smith et al., 2002; Thornberry and Abbatt, 2004; Ziemann, 2005), which corresponds to approximately one reaction (oxidative cleavage of OL) per 1000 collisions. For comparison, analogous homogeneous gasphase reactions have rate constants on the order of $10^{-15}$ $10^{-17} \mathrm{~cm}^{3}$ molecule $\mathrm{s}^{-1}$ (Atkinson, 1997; Atkinson et al., 1997; Finlayson-Pitts and Pitts Jr., 1999), which corresponds to approximately one reaction per $10^{5}-10^{7}$ collisions (Hearn and Smith, 2004b).

There is an anomaly in the atmospheric half-life (and lifetime) of OL, regarding loss to ozone, between laboratory based kinetic measurements and field measurements. This was noted by Morris et al. (2002) who used their experimental value of $\mathrm{H}\left(\mathrm{Dk}_{2}\right)^{1 / 2}$ to estimate an atmospheric half-life on the order of minutes for submicron OL with $100 \mathrm{ppb} \mathrm{O}_{3}$, while field measurements suggested lifetimes on the order of days (Rogge et al., 1991). Experimentally based calculations by Smith et al. support the estimate by Morris and coworkers; at $\left[\mathrm{O}_{3}\right]=100 \mathrm{ppb}$, a $50 \mathrm{~nm}$ particle of OL would take less than two minutes for $99 \%$ of the OL to react (Smith et al., 2002). Similarly, Hearn and Smith (2004b) estimated that for the same concentration of ozone, particulate OL would have a lifetime of a few minutes.

This anomaly in OL half-life between laboratory and field studies probably arises from the OL in the latter case being part of a multicomponent viscous, semi-solid particle (Morris et al., 2002). For example, in the urban environment, meat-cooking aerosols contain not only OL but SA and palmitic acid as well as many other components (Schauer et al., 1999). Smith et al. (2002), using an organic aerosol density of $1.5 \times 10^{5}$ particles $\mathrm{cm}^{-3}$ typical of an urban setting (Heintzenberg, 1989), estimated that for particles with radii of $25 \mathrm{~nm}$ and an average OL content of $1 \%$, the OL lifetime with respect to ozonolysis is $36 \mathrm{~h}$. This is also demonstrated by Ziemann (2005), who calculated OL lifetimes of $\sim 30 \mathrm{~min}$ for pure OL particles vs. $15 \mathrm{~h}$ for OL in mixed particles with alkanoic acids.

The diffusion of OL would most likely be impeded in a viscous multicomponent particle, such as meat-cooking aerosol, which would increase the OL lifetime compared to that of pure OL particulate. Moreover, in multicomponent particles with liquid and solid-phases, OL could be trapped in the solid-phase (Katrib et al., 2005a). For example, this was demonstrated in SA-OL mixed particles: OL in liquid regions reacts quickly, while OL trapped in the solid SA is "essentially unavailable for reaction" (Katrib et al., 2005a). Katrib et al. (2005a) noted this second effect may impact quantitative source apportionment, where OL is used to apportion the contribution of meat-cooking to urban particulate. The OL in the solid fraction would be detected and used in quantitative source apportionment, with the amount of OL in the liquid portion diminished due to ozonolysis; hence, meat-cooking would suffer from a negative bias in quantitative source apportionment assessment (Katrib et al., 2005a).

The coated-wall studies of multicomponent proxies of meat-cooking aerosols by Knopf et al. (2005) indicate that the lifetime of OL is not significantly affected by the addition of a second component, such as an alkanoic acid if there is no corresponding change in phase, the presence of a solidphase can cause the lifetime of OL to increase by more than an order of magnitude. They estimated that the lifetime of OL in their 15 component proxy to meat-cooking aerosol was $\sim 75 \mathrm{~min}$ as opposed to simpler proxies (OL/C12 or C14) that had lifetimes $\sim 3.5-5 \mathrm{~min}$ for the liquid solutions (Knopf et al., 2005).

The recent report by Hearn and Smith (2006) appears to be the first study to show OL trapping in an authentic meatcooking aerosol (i.e. pan fried ground hamburger) and is in accord with the results of Knopf et al. (2005) using multicomponent proxies. Hearn and Smith (2006) noted in their report: "Extrapolation of these results to a polluted atmosphere (i.e. $100 \mathrm{ppb} \mathrm{O}_{3}$ ) suggests that some of the oleic acid will have a short half-life (i.e. several minutes), while the rest will have a much longer half-life (i.e. several hours to days)."

The physical state of the FA in the condensed-phase medium has a significant impact on the uptake of ozone. Moise and Rudich (Moise and Rudich, 2002) showed the uptake of ozone by OL and LA decreased by approximately an order of magnitude upon freezing. Changes in temperature without a corresponding change in phase probably have less of an impact on reactive uptake, as shown for the case of OL, LA, and LN, which all have a small positive temperature dependency as liquids (Thornberry and Abbatt, 2004).

Uptake has also been shown to be affected by the microstructure of the organic medium (Knopf et al., 2005). With multicomponent coatings, slow cooled solid-liquid mixtures generally had a smaller uptake coefficient than fast cooled mixtures with similar composition. This was attributed to the microstructure of the solid (Knopf et al., 2005), with the film produced by slow cooling having a microstructure that either more effectively traps OL or reduces diffusion compared to its congener prepared by fast cooling. Moreover, aging of the semi-solid films affects the uptake of ozone, with older films having an increased $\gamma$, and a maximum value at $\sim 10 \mathrm{~h}$. The authors attributed this affect to either the relaxation of a non-equilibrium phase to a stable phase, or to Ostwald's ripening (Chou and Hong, 2004).

As noted earlier, Hearn and Smith (2005) demonstrated for the first time that mixed organic particles (OL/C14) can exist 


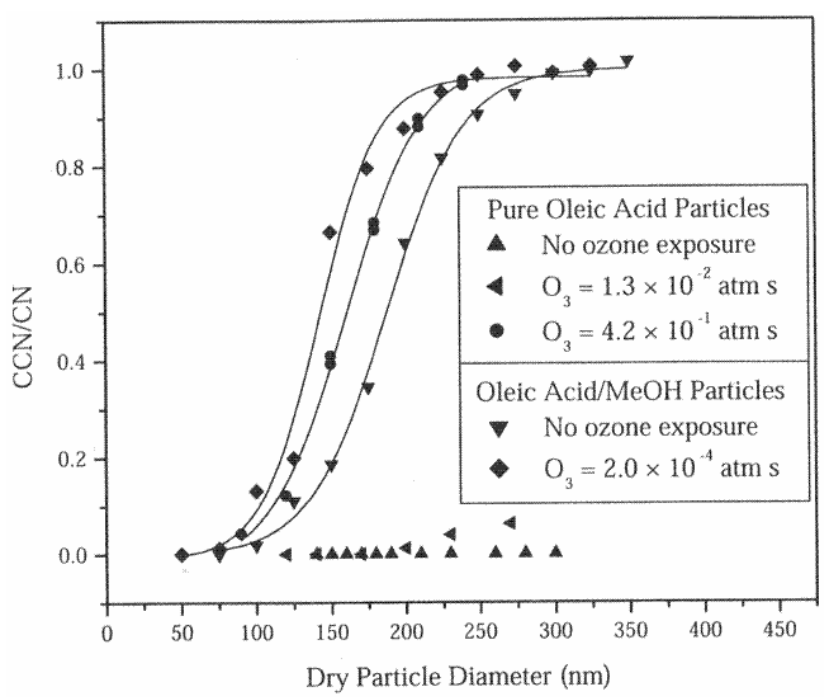

Fig. 12. $\mathrm{CCN} / \mathrm{Condensation} \mathrm{nuclei}(\mathrm{CN})$ ratio as a function of initial dry particle diameter at a supersaturation of $0.6 \%$ for several ozone exposures. All dry diameters represent the diameter after oxidation. Results for both pure OL and OL/methanol mixed particles are shown (from Broekhuizen et al., 2004).

as supercooled droplets. OL in a $200 \mathrm{~nm}$ solid-liquid particle exposed to $100 \mathrm{ppb} \mathrm{O}_{3}$ would have a lifetime of $60 \mathrm{~min}$ from the noted reaction of solid OL/C14; however in the supercooled droplet this lifetime would be only $\sim 5 \mathrm{~min}$. The different reactive uptake by supercooled OA may have atmospheric implications, particularly for the urban environment. In the experiments by Hearn and Smith (2005), organic particulate was generated by homogeneous nucleation of heated vapors, at a similar temperature of real meat-cooking aerosols (Rogge et al., 1991) suggesting these aerosols might be supercooled. To our knowledge, there have been no field studies to confirm the presence of supercooled mixed OA in the troposphere. The observation of the longer lifetime of OL in urban particulate (Rogge et al., 1991) than that of OL in laboratory measurements, would appear to indicate that supercooling of OA does not persist under atmospheric conditions; however, the OL may react quickly with ozone, increasing $\gamma$, while the particle is supercooled prior to achieving equilibrium and having a solid-phase form (Hearn and Smith, 2005).

Little is known about the thermodynamics of real atmospheric organic particulate and these experimental observations from HRS featuring relatively simple OA and coatings elucidate many of the challenges faced by researchers needed to understand the processing of organic particulate in the troposphere. Factors including aging, temperature, and motif of particulate formation, composition, and phase equilibrium all appear to affect the uptake and need further, more progressive consideration.
5.2 Oxidatively processed organic aerosols as cloud condensation nuclei

Ozonolysis results in an oxygen enriched OA containing hydrophilic species including monocarboxylic acids, dicarboxylic acids, and a variety of peroxides, including HMW polymers that are formed by secondary reactions. Oxygen enrichment has been demonstrated to be concomitant with an increase of particle density. This effect is significant, with density increasing from $0.89 \mathrm{~g} \mathrm{~cm}^{-3}$ to $1.12 \mathrm{~g} \mathrm{~cm}^{-3}$ and continuing to increase along with oxygen enrichment with prolonged exposure, even after all the OL has reacted (Katrib et al., 2005b). This is most likely due to secondary chemistry in the system. Oxygen enrichment generally corresponds to greater hygroscopicity (Asad et al., 2004; Broekhuizen et al., 2004; Hung et al., 2005) and the presence of more water soluble components and is a good indicator of $\mathrm{CCN}$ activation (Cruz and Pandis, 1997; Moise and Rudich, 2000; Novakov and Corrigan, 1996). The enhanced hygroscopicity afforded by ozonolysis of OL was shown by Asad at al. (2004) in the four-fold increase in the water-sorbing capacity of a highly processed film compared to an unprocessed one. Hung et al. (2005) also showed that the critical RH at which OL droplets took on water was reduced from over $99 \%$ to $91 \%$ after exposure to ozone, which is indicative of increased hygroscopicity.

Another consequence of increased oxygen enrichment of OA by ozonolysis is a decreased contact angle with water (Moise and Rudich, 2000, 2001), again leading to an enhancement of the CCN ability (Raymond and Pandis, 2002). Typical FA have relatively large activation diameters as predicted from Köhler theory (Köhler, 1936); for example, palmitic acid and SA have experimental activation diameters of over $200 \mathrm{~nm}$ at supersaturations of 0.3 and $1 \%$ (Raymond and Pandis, 2002) and OL has been shown not to activate ( $0.6 \%$ supersaturation) with a dry diameter up to $140 \mathrm{~nm}$ (Kumar et al., 2003). In short, the low solubility of water in HMW FA renders them particularly poor $\mathrm{CCN}$; however, studies on submicron OL and LA particles, employing a tandem differential mobility analyzer coupled to a flow reactor, showed that high exposure to ozone $(0.42 \mathrm{~atm} \mathrm{~s})$ had an effect on the CCN activity of OL and the critical activation diameter (Broekhuizen et al., 2004). At low ozone exposures $\left(<1 \times 10^{-4} \mathrm{~atm} \mathrm{~s}\right)$, there was a loss of about $25 \%$ of the original particle volume for OL, due to volatilization of nonanal; however, there was no increased $\mathrm{CCN}$ activity. However, at the higher ozone exposure, pure OL became $\mathrm{CCN}$ active with a critical activation diameter of $161 \mathrm{~nm}$ at $0.6 \%$ supersaturation. This appeared to be a direct effect of the oxidation of OL, since its saturated congener, SA, showed no activation at $0.6 \%$ supersaturation with an ozone exposure of $0.5 \mathrm{~atm} \mathrm{~s}$ and particle sizes up to $300 \mathrm{~nm}$. It should be noted that the doubly unsaturated LA never became activated even at high exposures. The inability of the unsaturated LA to activate is not as clear cut as for the saturated SA and the authors 
suggested that this might be due to the reactivity of the CI with the double bonds of LA, with a faster rate of polymer formation (than OL) and these products being more highly branched and complex (Broekhuizen et al., 2004). Clearly, the nuances of the oxidative processing of specific FA and the implications to the troposphere, including the ability to act as $\mathrm{CCN}$, need further investigation.

Mixed particulate shows a markedly different behavior than pure FA aerosol in terms of activation (Broekhuizen et al., 2004). As shown in Fig. 12, mixed OL/methanol particles became activated by ozone under atmospherically relevant exposures. This is an important result in that not only are organic particles in the troposphere composed of many components (Alves et al., 2001; Duce et al., 1983; Guo et al., 2003; Hahn, 1980; Huang et al., 2006; Pio et al., 2001; Simoneit et al., 1988) but alcohols are commonly observed in biogenic particulate (Alves et al., 2001; Pio et al., 2001; Rogge et al., 1993b; Simoneit et al., 1988, 1991; Simoneit and Mazurek, 1982).

More detailed studies need to be engaged similar to that of Broekhuizen et al. (2004) that look at the role of oxidative processing on activation of more realistically formulated multicomponent organic particulates that are better proxies for actual aerosols of the troposphere.

As noted throughout this review, the ozonolysis of OL produces a variety of peroxidic products; the possible role of these species in the CCN activation of OA needs to be thoroughly investigated. One upcoming report (Shilling et al., $2007^{1}$ ) strongly suggests that small changes in particle composition can increase the CCN activity of tropospheric OA. In this study, the $\mathrm{CCN}$ activity and the chemical composition of fine OL particulate undergoing ozonolysis was simultaneously monitored. Notably, Shilling et al. show that the oxidation of aldehyde groups to the corresponding carboxylic acids was responsible for $\mathrm{CCN}$ activation. As detailed in this work, for the ozonolysis of OL, the experimental observations and Köhler modeling indicate that the production of surface-active species, which reduce surface tension, is probably more important than the formation of more soluble species for CCN activation (Shilling et al., 2007 ${ }^{1}$ ).

5.3 Radiative forcing by oxidatively processed organic particulate

There are broad implications of oxidatively processed OA on forcing mechanisms that affect the energy budget of the Earth-atmosphere system. The most important of these implications probably stem from the enhancement of the processed OA to act as $\mathrm{CCN}$. As summarized in a recent review (Lohmann and Feichter, 2005), aerosols affect the global climate by scattering both solar and thermal radiation, as well as acting as $\mathrm{CCN}$ and ice nuclei. The first two mechanisms are considered direct forcing effects (Haywood and Boucher, 2000), while the formation of CCN and ice nuclei are considered indirect aerosol effects (Haywood and Boucher, 2000;
Lohmann and Feichter, 2005) and are perhaps the greatest source of uncertainty in understanding radiative forcing in the atmosphere (McFiggans et al., 2006). Oxidative processing of OA forms more hygroscopic particulate and may promote the Twomey effect by an increase in small droplets in clouds. The Twomey effect is a negative forcing due to scattering of solar radiation by smaller droplets in clouds with constant water content (Lohmann and Feichter, 2005; Twomey, 1959).

The role that oxidative processing of OA has in contributing to the radiative forcing is a complicated problem and still in the early stages of description. To fully describe radiation budgeting in the Earth-atmosphere system we have to develop a better description of the contribution of OA to cloud albedo and CCN mediated indirect effects from OA. Understanding these roles is imperative in light of current uncertainties in our predictions of global warming trends and climate sensitivity, which depend in part on radiation budgeting by OA.

\section{Conclusions}

The OL-O 3 HRS is a proxy system that has been used to improve our understanding of the oxidative processing of OA that occurs in the troposphere. More complex multicomponent systems are being investigated, but these aerosols and films are in most cases still far simpler than real OA. In this paper we have tried to present a key theme emerging from these experiments - heterogeneous processing by ozone, even with simple proxies, is complicated by secondary chemistry, phase equilibria and other thermodynamic effects such that to accurately access the details of reactive uptake and product formation presents a formidable task.

\section{What have we learned and what are the implications?}

- In most studies, the measured uptake coefficient of ozone by $\mathrm{OL}$ is $\sim\left(0.7-1 \times 10^{-3}\right)$, with the smaller value probably being more accurate for atmospheric OA:

(a) Direct measure of ozone loss by CFT tends towards the lower-limit

(b) Methods that correct for secondary chemistry tend towards the lower-limit

- Implication: The uptake of ozone by particle-phase unsaturates is probably more significant per unit mass than corresponding gas-phase organics, being enhanced by 2-4 orders of magnitude. However, tropospheric OA is probably not a significant sink of ozone compared to gas-phase unsaturates because of the much higher loading of unsaturated gas-phase species (e.g. isoprene) (Calvert et al., 2000) 
- The uptake coefficient may decrease significantly $(\sim 1$ order of magnitude) in mixed-particles and coatings, especially when a solid- or semi-solid phase is present

- Implication: OL lifetime in the troposphere may be extended by the morphology of real OA and could bias quantitative source apportionment

- The formation of peroxides through the secondary reactions of CI appears to be significant, and high yields are possible

1. A diversity of peroxidic have been observed including :
(a) Secondary ozonides
(b) Geminal diperoxides
(c) $\alpha$-Acyloxyalkyl Hydroperoxides
(d) $\alpha$-acyloxyalkyl alkyl peroxides
(e) bis(acyloxy-1-alkyl) peroxides

2. These products are generally HMW, low volatility, and hydrophilic

- Implication: The formation of these products may correspond with increases in CCN ability, including lowering the activation radius of the particle. Tropospheric OA may contain protic species, such as water, that may promote the formation of peroxides, enhancing these effects further.

- Implication: Ozonolysis of OA may enhance the negative forcing associated with indirect aerosol effects that are largely mediated by $\mathrm{CCN}$

What are some important questions and topics that must be addressed?

- We need to establish whether the resistor model represents an accurate physical description of the heterogeneous microphysical processing or if it is just a convenient method to fit data. Although this model gives values for $\gamma$ that are reasonably close to those determined by coated-wall tubes, there are some problems:

(a) There is a linear dependence of $\gamma$ on the particulate radius in some experiments but this is not observed in other experiments (cf. Hearn et al., 2005; Smith et al., 2002)

(b) There is no direct accounting for secondary chemistry by the model

- We need to perform multiple quantitative assessments of the total peroxides yielded by ozonolysis of OL and other unsaturated organics, especially in multicomponent proxies
- We need to accurately describe the types and yield of peroxides formed and under what conditions they are formed. Notably, we need to do more experiments that use concentrations of ozone (as opposed to "ozone exposure") similar to tropospheric levels and compare the yields of peroxidic and other products to extant data

- We need to understand how peroxide yields and the types formed vary with the addition of ubiquitous protic species, most notably water

- We need to accurately measure the lifetime of these peroxides in oxidatively processed aerosol

- We need to understand the role of these peroxides in the activation of $\mathrm{OA}$ to $\mathrm{CCN}$

- Is there a significant enough yield of these products that they contribute significantly to HULIS?

- Proxies that specifically model atmospheric aerosol types need to be developed. This includes proxies for both biogenic and anthropogenic emission.

- A better thermodynamic description of multicomponent $\mathrm{OA}$ is needed to understand the potential roles of phase equilibria, supercooling and other effects that may affect reactive uptake and chemical kinetics, lifetime of specific analytes, and other processes

- We need to look at the effects of more complicated (realistic) processing by multiple gas-phase species, including systems with multiple oxidants

- We need to place emphasis on studies at elevated humidity that exam all of points noted

\section{Addendum}

At the time of submission of the final version of this review several breaking reports have come to our attention and though we cannot address them in detail we would like to make members of our community aware of them.

The recent results of Shilling et al. (2007) ${ }^{1}$ were noted in Sect. 5.2 and are significant in that it suggests that small changes in chemical composition from oxidative processing can increase $\mathrm{CCN}$ activity of tropospheric aerosol.

Hung and Ariya (2007) have recently reported results on experiments on the heterogeneous processing of OL and $\mathrm{OL} / \mathrm{NaCl}$ (aq) droplets by ozone at two relative humidities. High molecular weight peroxidic products (up to $\mathrm{C} 45$ ) were evidenced and possibly formed from secondary reactions initiated by SCI. While at high $\mathrm{RH}(87 \pm 5 \%)$ ozonized OL droplets only take up water slightly, internally mixed particles of $\mathrm{OL} / \mathrm{NaCl}(\mathrm{aq})$ had complex water uptake behavior. The hygroscopic properties or growth factors of the internally mixed particles are altered as the oxidation products of the OL exist concurrently with $\mathrm{NaCl}$ (aq). 
McNeill et al. (2007) have recently reported on the oxidation of submicron aqueous aerosols consisting of internal mixtures of sodium oleate, sodium dodecyl sulfate and inorganic salts $\left(\mathrm{NaCl}, \mathrm{Na}_{2} \mathrm{SO}_{4}\right)$ by $\mathrm{O}_{3}, \mathrm{NO}_{3} / \mathrm{N}_{2} \mathrm{O}_{5}$, and $\mathrm{OH}$. The oxidation of oleate by $\mathrm{O}_{3}$ follows Langmuir-Hinshelwood kinetics, with $\gamma^{\mathrm{O}_{3}} \sim 10^{-5}$. Langmuir-Hinshelwood parameters are also given for the ozonolysis of oleate and appear to have no dependence on the ionic composition of the particulate or presence of alkyl surfactants. $\mathrm{OH}$ appears to efficiently oxidize oleate, and the reactive uptake coefficient was estimated: $0.1 \leq \gamma^{\mathrm{OH}} \leq 1$. There was no detectable oxidation of oleate by $\mathrm{NO}_{3} / \mathrm{N}_{2} \mathrm{O}_{5}$ at $100 \mathrm{ppb} \mathrm{NO}_{3}$ for the timescales of their experiments and they estimate $\gamma^{\mathrm{NO}_{3}}<10^{-3}$ as a conservative upper limit to the reaction probability for $\mathrm{NO}_{3}$ loss to oleate in their particles.

\section{Appendix A}

List of abbreviations

$\alpha$ AAHP-type $\alpha$-Acyloxyalkyl Hydroperoxide(s) $+\alpha$ acyloxyalkyl hydroxyalkyl peroxides + bis(acyloxy-1-alkyl) peroxides

AAHP $\quad \alpha$-Acyloxyalkyl Hydroperoxide(s)

AFT

AMS

Aerosol flow tube(s)

Aerosol Mass Spectrometer (Spectrometry)

ATR-IR Attenuated Total Internal Reflectance Infrared Spectroscopy

$\mathrm{CCN}$

CFT

CI

CIMS

$\mathrm{C} 12$

C14

C16

C17

DOA

DOS

E- $-\mathrm{O}_{3} \mathrm{RS}$

FA

FIDI

FT-IR

GC

HMW

HULIS

HRS

IGAC

\begin{tabular}{|c|c|}
\hline IGBP & $\begin{array}{l}\text { International Geosphere Biosphere } \\
\text { Programme }\end{array}$ \\
\hline iLEAPS & $\begin{array}{l}\text { Integrated Land Ecosystem Atmo- } \\
\text { sphere Process Study }\end{array}$ \\
\hline IR & Infrared \\
\hline LA & Linoleic Acid \\
\hline LC-MS & $\begin{array}{l}\text { Liquid Chromatography Mass Spec- } \\
\text { trometry }\end{array}$ \\
\hline $\mathrm{LN}$ & Linolenic Acid \\
\hline MOL & Methyl Oleate \\
\hline MS & Mass Spectrometer (Spectrometry) \\
\hline MW & Molecular Weight \\
\hline $\mathrm{OA}$ & Organic Aerosol \\
\hline OL & Oleic Acid \\
\hline $\mathrm{OL}-\mathrm{O}_{3} \mathrm{HRS}$ & $\begin{array}{l}\text { Oleic Acid-Ozone Heterogeneous Re- } \\
\text { action System }\end{array}$ \\
\hline OOA & 9-Oxooctadecanoic Acid \\
\hline PERCI-AMS & $\begin{array}{l}\text { Photoelectron Resonance Capture Ion- } \\
\text { ization Aerosol Mass Spectrometry }\end{array}$ \\
\hline $\mathrm{PO}$ & Primary Ozonide \\
\hline RH & Relative Humidity \\
\hline SA & Stearic Acid \\
\hline SCI & Stabilized Criegee Intermediate(s) \\
\hline SMPS & Scanning Mobility Particle Sizer \\
\hline SO & Secondary Ozonide(s) \\
\hline SOA & Secondary Organic Aerosol \\
\hline SOLAS & $\begin{array}{l}\text { Surface Ocean-Lower Atmosphere } \\
\text { Study }\end{array}$ \\
\hline SS & Steady State (approximation) \\
\hline TDPBMS & $\begin{array}{l}\text { Thermal Desorption Particle Beam } \\
\text { Mass Spectrometry }\end{array}$ \\
\hline TOF & Time-of-Flight \\
\hline TPTD & $\begin{array}{l}\text { Temperature Programmed Thermal } \\
\text { Desorption }\end{array}$ \\
\hline
\end{tabular}

Acknowledgements. The authors thank the referees, S. Martin and A. Tuck, for their insightful and helpful comments. The authors also gratefully acknowledge the financial support of the National Science Foundation (ATM-0440074).

Edited by: Y. Rudich

\section{References}

Abbatt, J. P. D. and Nowak, J. B.: Heterogeneous interactions of $\mathrm{HBr}$ and $\mathrm{HOCl}$ with cold sulfuric acid solutions: Implications for Arctic boundary layer bromine chemistry, J. Phys. Chem. A, 101, 2131-2137, 1997.

Agranovski, V. and Ristovski, Z. D.: Real-time monitoring of viable bioaerosols: capability of UVAPS to predict the amount of individual microorganisms in aerosol particles, J. Aerosol Sci., 36, 665-676, 2005.

Ahern, H. E., Walsh, K. A., Hill, T. C. J., and Moffett, B. F.: Ice-nucleation negative fluorescent pseudomonads isolated from Hebridean cloud and rain water produce biosurfactants, Biogeosciences Discuss., 3, 1561-1586, 2006, http://www.biogeosciences-discuss.net/3/1561/2006/. 
Alves, C., Pio, C., and Duarte, A.: Composition of extractable organic matter of air particles from rural and urban Portuguese areas, Atmos. Environ., 35, 5485-5496, 2001.

Ariya, P. A., Sander, R., and Crutzen, P. J.: Significance of $\mathrm{HO}_{x}$ and peroxides production due to alkene ozonolysis during fall and winter: A modeling study, J. Geophys. Res., 105, 17 721$17738,2000$.

Asad, A., Mmereki, B. T., and Donaldson, D. J.: Enhanced uptake of water by oxidatively processed oleic acid, Atmos. Chem. Phys., 4, 2083-2089, 2004, http://www.atmos-chem-phys.net/4/2083/2004/.

Aschmann, S. M., Arey, J., and Atkinson, R.: OH radical formation from the gas-phase reactions of $\mathrm{O}_{3}$ with a series of terpenes, Atmos. Environ., 36, 4347-4355, 2002.

Atkinson, R.: Gas-phase tropospheric chemistry of volatile organic compounds: 1. Alkanes and alkenes, J. Phys. Chem. Ref. Data, 26, 215-290, 1997.

Atkinson, R., Baulch, D. L., Cox, R. A., Hampson Jr., R. F., Kerr, J. A., Rossi, M. J., and Troe, J.: Evaluated kinetic, photochemi$\mathrm{cal}$, and heterogeneous data for atmospheric chemistry. 5. IUPAC subcommittee on gas kinetic data evaluation for atmospheric chemistry, J. Phys. Chem. Ref. Data, 26, 521-1011, 1997.

Atkinson, R., Tuazon, E. C., and Aschmann, S. M.: Products of the gas-phase reactions of $\mathrm{O}_{3}$ with alkenes, Environ. Sci. Technol., 29, 1860-1866, 1995.

Bailey, P. S.: The reactions of ozone with organic compounds, Chem. Rev., 58, 925-1010, 1958.

Bailey, P. S.: Ozonation in Organic Chemistry, 1: Olefinic Compounds, Academic Press, New York, 1978.

Bailey, P. S. and Ferrell, T. M.: Mechanism of Ozonolysis. A more flexible stereochemical concept, J. Am. Chem. Soc., 100, 899905, 1978

Bailey, P. S., Ward, J. W., Potts III, F. E., Chang, Y.-G., and Hornish, R. E.: Ozonation of hindered vinyl alcohols. Production of free radicals by ozonation, J. Am. Chem. Soc., 96, 7228-7232, 1974.

Barger, W. R. and Garrett, W. D.: Surface active organic material in the marine atmosphere, J. Geophys. Res., 75, 4561-4566, 1970.

Barger, W. R. and Garrett, W. D.: Surface active organic material in the air over the Mediterranean and over the eastern equatorial Pacific, J. Geophys. Res., 81, 3151-3157, 1976.

Bernatek, E., Hagen, H., and Ledaal, T.: Acidolysis of some stable ozonides, Acta Chem. Scand., 21, 1555-1557, 1967.

Bernatek, E. and Ledaal, T.: Solvolysis of ozonides, Tetrahedton Lett., 1, 30-34, 1960.

Bertram, A. K., Ivanov, A. V., Hunter, M., Molina, L. T., and Molina, M. J.: The reaction probability of $\mathrm{OH}$ on organic surfaces of tropospheric interest, J. Phys. Chem. A, 105, 9415-9421, 2001.

Bezdek, H. F. and Carlucci, A. F.: Concentration and removal of liquid microlayers from a seawater surface by bursting bubbles, Limnol. Oceanogr., 19, 126-132, 1974.

Blanchard, D. C.: The electrification of the atmosphere by particles from bubbles in the sea, Prog. Oceanogr., 1, 73-112, 1963.

Blanchard, D. C.: Sea-to-air transport of surface active material, Science, 146, 396-397, 1964.

Broekhuizen, K. E., Thornberry, T., Kumar, P. P., and Abbatt, J. P. D.: Formation of cloud condensation nuclei by oxidative processing: unsaturated fatty acids, J. Geophys. Res., 109, D24206, doi:10.1029/2004JD0005298, 2004.
Bunnelle, W. H.: Preparation, properties, and reactions of carbonyl oxides, Chem. Rev., 91, 335-362, 1991.

Calvert, J. G., Atkinson, R., Kerr, J. A., Madronich, S., Moortgat, G. K., Wallington, T. J., and Yarwood, G.: The Mechanism of Atmospheric Oxidation of Alkenes, Oxford University Press, Oxford, 2000.

Charpy-Roubaud, C. and Sournia, A.: The comparative estimation of phytoplanktonic, microphytobenthic and macrophytobenthic primary production in the oceans, Mar. Microb. Food Webs, 4, 31-57, 1990.

Cheng, Y., Li, S.-M., Leithead, A., Brickell, P. C., and Leaitch, W. R.: Characterizations of cis-pinonic acid and n-fatty acids on fine aerosols in the Lower Fraser Valley during Pacific 2001 Air Quality Study, Atmos. Environ., 38, 5789-5800, 2004.

Chou, C.-M. and Hong, P.-D.: Nucleation, growth, fractal aggregation, and late-stage coarsening on structural development of polymer physical gels, Macromolecules, 37, 5596-5606, 2004.

Colthup, N. B., Daly, L. H., and Wiberly, S. E.: Introduction to Infrared and Raman Spectroscopy, Academic Press, New York, 1975.

Cooper, P. L. and Abbatt, J. P. D.: Heterogeneous interactions of $\mathrm{OH}$ and $\mathrm{HO}_{2}$ radicals with surfaces characteristic of atmospheric particulate matter, J. Phys. Chem., 100, 2249-2254, 1996.

Crank, J.: The Mathematics of Diffusion, Clarendon Press, Oxford, 1975.

Criegee, R.: Mechanism of ozonolysis, Agnew. Chem. internat. Edit., 14, 745-752, 1975.

Criegee, R. and Wenner, G.: Ozonization of 1,2,3,4,5,6,7,8octahydronaphthalene, Liebigs Ann. Chem., 564, 9-15, 1949.

Cruz, C. N. and Pandis, S. N.: A study of the ability of pure secondary organic aerosol to act as cloud condensation nuclei, Atmos. Environ., 31, 2205-2214, 1997.

Danckwerts, P. V.: Gas-Liquid Reactions, McGraw-Hill, New York, 1970.

Davidovits, P., Jayne, J. T., Duan, S. X., Worsnop, D. R., Zahniser, M. S., and Kolb, C. E.: Uptake of gas molecules by liquids: A model, J. Phys. Chem., 95, 6337-6340, 1991.

de Gouw, J. A. and Lovejoy, E. R.: Reactive uptake of ozone by liquid organic compounds, Geophys. Res. Lett., 25, 931-934, 1998.

Demou, E., Visram, H., Donaldson, D. J., and Makar, P. A.: Uptake of water by organic films: the dependence on the film oxidation state, Atmos. Environ., 37, 3529-3537, 2003.

Diehl, K., Matthias-Maser, S., Jaenicke, R., and Mitra, S. K.: The ice nucleating ability of pollen: Part 2. Laboratory studies in immersion and contact freezing modes, Atmos. Res., 61, 125-133, 2002.

Diehl, K., Quick, C., Matthias-Maser, S., Mitra, S. K., and Jaenicke, R.: The ice nucleating ability of pollen Part 1: Laboratory studies in deposition and condensation freezing modes, Atmos. Res., 58, 75-87, 2001.

Docherty, K. S. and Ziemann, P. J.: Reaction of oleic acid particles with $\mathrm{NO}_{3}$ radicals: Products, mechanism, and implications for radical-initiated organic aerosol oxidation, J. Phys. Chem. A, 110, 3567-3577, 2006.

Donaldson, D. J., Ravishankara, A. R., and Hanson, D. R.: Detailed study of $\mathrm{HOCl}+\mathrm{HCl} \rightarrow \mathrm{Cl}_{2}+\mathrm{H}_{2} \mathrm{O}$ in sulfuric acid, J. Phys. Chem. A, 101, 4717-4725, 1997.

Donaldson, D. J. and Vaida, V.: The influence of organic films at the air-aqueous boundary on atmospheric processes, Chem. Rev., 
106, 1445-1461, 2006.

Duarte, C. M. and Cebrián, J.: The fate of marine autotrophic production, Limnol. Oceanogr., 41, 1758-1766, 1996.

Duce, R. A., Mohnen, V. A., Zimmerman, P. R., Grosjean, D., Cautreels, W., Chatfield, R., Jaenicke, R., Ogren, J. A., Pellizzari, E. D., and Wallace, G. T.: Organic material in the global troposphere, Rev. Geophys. Space Phys., 21, 921-952, 1983.

Elbert, W., Taylor, P. E., Andreae, M. O., and Pöschl, U.: Contribution of fungi to primary biogenic aerosols: active discharge of spores, carbohydrates, and inorganic ions by Asco- and Basidiomycota, Atmos. Chem. Phys. Discuss., 6, 11317-11355, 2006.

Eliason, T. L., Aloisio, S., Donaldson, D. J., Cziczo, D. J., and Vaida, V.: Processing of unsaturated organic acid films and aerosols by ozone, Atmos. Environ., 37, 2207-2219, 2003.

Eliason, T. L., Gilman, J. B., and Vaida, V.: Oxidation of organic films relevant to atmospheric research, Atmos. Environ., 38, 1367-1378, 2004.

Ellison, G. B., Tuck, A. F., and Vaida, V.: Atmospheric processing of organic aerosols, J. Geophys. Res., 104, 11 633-11 641, 1999.

Fang, J., Kawamura, K., Ishimura, Y., and Matsumoto, K.: Carbon isotope composition of fatty acids in the marine aerosols from the Western North Pacific: Implication for the source and atmospheric transport, Environ. Sci. Technol., 62, 2598-2604, 2002.

Feng, J., Hu, M., Chan, C. K., Lau, P. S., Fang, M., He, L., and Tang, X.: A comparative study of the organic matter in $\mathrm{PM}_{2.5}$ from three Chinese megacities in three different climatic zones, Atmos. Environ., 40, 3983-3994, 2006.

Fenger, J.: Urban air quality, Atmos. Environ., 33, 4877-4900, 1999.

Fenske, J. D., Hasson, A. S., Paulson, S. E., Kuwata, K. T., Ho, A., and Houk, K. N.: The pressure dependence of the $\mathrm{OH}$ radical yield from ozone-alkene reactions, J. Phys. Chem. A, 104, 78217833, 2000.

Finlayson-Pitts, B. J. and Pitts Jr., J. N.: Chemistry of the Upper and Lower Atmosphere: Theory, Experiments, and Applications, Academic Press, New York, 1999.

Fliszár, S., Gravel, D., and Cavalieri, E.: Étude quantitative des réactions d'ozonolyse II. Ozonation du trans-stilbène, Can J. Chem, 44, 1013-1019, 1966.

Fraser, M. P., Cass, G. R., and Simoneit, B. R. T.: Particulate organic compounds emitted from motor vehicle exhaust and in the urban atmosphere, Atmos. Environ., 33, 2715-2724, 1999.

Fuzzi, S., Andreae, M. O., Huebert, B. J., Kulmala, M., Bond, T. C., Boy, M., Doherty, S. J., Guenther, A., Kanakidou, M., Kawamura, K., Kerminen, V.-M., Lohmann, U., Russell, L. M., and Pöschl, U.: Critical assessment of the current state of scientific knowledge, terminology, and research needs concerning the role of organic aerosols in the atmosphere, climate, and global change, Atmos. Chem. Phys., 6, 2017-2038, 2006, http://www.atmos-chem-phys.net/6/2017/2006/.

Gill, P. S., Graedel, T. E., and Weschler, C. J.: Organic films on atmospheric aerosol particles, fog droplets, cloud droplets, raindrops, and snowflakes, Rev. Geophys. Space Phys., 21, 903-920, 1983.

Goddard III, W. A., Dunning Jr., T. H., Hunt, W. J., and Hay, P. J.: Generalized valence bond desription of bonding in low-lying states of molecules, Acc. Chem. Res., 6, 368-378, 1973.

Gong, H., Matsunaga, A., and Ziemann, P. J.: Products and mech- anism of secondary organic aerosol formation from reactions of linear alkenes with $\mathrm{NO}_{3}$ radicals, J. Phys. Chem. A, 109, 4312 4324, 2005.

Graber, E. R. and Rudich, Y.: Atmospheric HULIS: how humic-like are they? A comprehensive and critical review, Atmos. Chem. Phys., 6, 729-753, 2006,

http://www.atmos-chem-phys.net/6/729/2006/.

Greenwood, F. L.: Studies in ozonolysis. I. Action of ozone on solvents used in ozonation, J. Org. Chem., 10, 414-418, 1945.

Grimm, R. L. and Beauchamp, J. L.: Field-induced droplet ionization mass spectrometry, J. Phys. Chem. B, 107, 14 161-14 163, 2003.

Grimm, R. L., Hodyss, R., and Beauchamp, J. L.: Probing interfacial chemistry of single droplets with field-induced droplet ionization mass spectrometry: Physical adsorption of polycyclic aromatic hydrocarbons and ozonolysis of oleic acid and related compounds, Anal. Chem., 78, 3800-3806, 2006.

Guo, Z. G., Sheng, L. F., Feng, J. L., and Fang, M.: Seasonal variation of solvent extractable organic compounds in the aerosols in Qingdao, China, Atmos. Environ., 37, 1825-1834, 2003.

Gutbrod, R., Kraka, E., Schindler, R. N., and Cremer, D.: Kinetic and theoretical investigation of the gas-phase ozonolysis of isoprene: carbonyl oxides as an important source of $\mathrm{OH}$ radicals in the atmosphere, J. Am. Chem. Soc., 119, 7330-7342, 1997.

Gutbrod, R., Schindler, R. N., Kraka, E., and Cremer, D.: Formation of $\mathrm{OH}$ radicals in the gas phase ozonolysis of alkenes: the unexpected role of carbonyl oxides, Chem. Phys. Lett., 252, 221-229, 1996.

Hahn, J.: Organic constituents of natural aerosols, Ann. NY Acad. Sci., 338, 359-376, 1980.

Hanson, D. R.: Surface-specific reactions on liquids, J. Phys. Chem. B, 101, 4998-5001, 1997.

Hanson, D. R.: Reaction of $\mathrm{ClONO}_{2}$ with $\mathrm{H}_{2} \mathrm{O}$ and $\mathrm{HCl}$ in sulfuric acid and $\mathrm{HNO}_{3} / \mathrm{H}_{2} \mathrm{SO}_{4} / \mathrm{H}_{2} \mathrm{O}$ mixtures, J. Phys. Chem. A, 102, 4794-4807, 1998.

Hanson, D. R. and Lovejoy, E. R.: The reaction of $\mathrm{ClONO}_{2}$ with submicrometer sulfuric acid aerosol, Science, 267, 1326-1328, 1995.

Hanson, D. R. and Ravishankara, A. R.: Uptake of $\mathrm{HCi}$ and $\mathrm{HOCl}$ onto sulfuric acid: solubilities, diffusivities, and reaction, J. Phys. Chem., 97, 12 309-12 319, 1993.

Hanson, D. R., Ravishankara, A. R., and Lovejoy, E. R.: Reaction of $\mathrm{BrONO}_{2}$ with $\mathrm{H}_{2} \mathrm{O}$ on submicron sulfuric acid aerosol and the implications for the lower stratosphere, J. Geophys. Res., 101, 9063-9069, 1996.

Harding, L. B. and Goddard III, W. A.: Mechanisms of gas-phase and liquid-phase ozonolysis, J. Am. Chem. Soc., 100, 7180 7188, 1978.

Haywood, J. and Boucher, O.: Estimates of the direct and indirect radiative forcing due to tropospheric aerosols: A review, Rev. Geophys. Space Phys., 38, 513-543, 2000.

He, L.-Y., Hu, M., Huang, X.-F., Yu, B.-D., Zhang, Y.-H., and Liu, D.-Q.: Measurement of emissions of fine particulate organic matter from Chinese cooking, Atmos. Environ., 38, 6557-6564, 2004.

Hearn, J. D., Lovett, A. J., and Smith, G. D.: Ozonolysis of oleic acid particles: evidence for a surface reaction and secondary reactions involving Criegee intermediates, Phys. Chem. Chem. Phys., 7, 501-511, 2005. 
Hearn, J. D. and Smith, G. D.: A chemical ionization mass spectrometry method for the online analysis of organic aerosols, Anal. Chem., 76, 2820-2826, 2004a.

Hearn, J. D. and Smith, G. D.: Kinetics and product studies for the ozonolysis reactions of organic particles using aerosol CIMS, J. Phys. Chem. A, 108, 1019-1029, 2004b.

Hearn, J. D. and Smith, G. D.: Measuring rates of reaction in supercooled organic particles with implications for atmospheric aerosol, Phys. Chem. Chem. Phys., 7, 2549-2551, 2005.

Hearn, J. D. and Smith, G. D.: Reactions and mass spectra of complex particles using Aerosol CIMS, Int. J. Mass Spectrom., 258, 95-103, 2006.

Heintzenberg, J.: Fine particles in the global troposphere, Tellus, 41B, 149-160, 1989.

Herron, J. T. and Huie, R. E.: Stopped-flow studies of the mechanisms of ozone-alkene reactions in the gas phase. Ethylene, J. Am. Chem. Soc., 99, 5430-5435, 1977.

Herron, J. T., Martinez, R. I., and Huie, R. E.: Kinetics and energetics of the Criegee intermediate in the gas phase.1. The Criegee intermediate in ozone-alkene reactions, Int. J. Chem. Kinet., 14, 201-224, 1982.

Hiberty, P. C.: Mechanism of ozonolysis. Ab initio study of the primary ozonide and its cleavage to the Criegee intermediate, J. Am. Chem. Soc., 98, 6088-6092, 1976.

Hildemann, L. M., Klinedinst, D. B., Klouda, G. A., Currie, L. A., and Cass, G. R.: Sources of urban contemporary carbon aerosol, Environ. Sci. Technol., 28, 1565-1576, 1994.

Hoffman, E. J. and Duce, R. A.: Organic carbon in the marine atmospheric particulate matter: Concentration and particle size distribution, Geophys. Res. Lett., 4, 449-452, 1977.

Horie, O. and Moortgat, G. K.: Decomposition pathways of the excited Criegee intermediates in the ozonolysis of simple alkenes, Atmos. Environ., 25A, 1881-1896, 1991.

Hou, X., Zhuang, G., Sun, Y., and An, Z.: Characterization and sources of polycyclic aromatic hydrocarbons and fatty acids in $\mathrm{PM}_{2.5}$ aerosols in dust season in China, Atmos. Environ., 40, 3251-3262, 2006.

Huang, X.-F., He, L.-Y., Hu, M., and Zhang, Y.-H.: Annual variation of particulate organic compounds in $\mathrm{PM}_{2.5}$ in the urban atmosphere of Beijing, Atmos. Environ., 40, 2449-2458, 2006.

Hung, H.-M. and Ariya, P.: Oxidation of oleic acid and oleic acid/sodium chloride(aq) mixture droplets with ozone: Changes of hygroscopicity and role of secondary reactions, J. Phys. Chem. A, 111, 620-632, 2007.

Hung, H.-M., Katrib, Y., and Martin, S. T.: Products and mechanisms of the reaction of oleic acid with ozone and nitrate radical, J. Phys. Chem. A, 109, 4517-4530, 2005.

Inoue, T., Motoda, I., Hiramatsu, N., Suzuki, M., and Sato, K.: Phase behavoir of binary mixtures of cis-monounsaturated fatty acids with different $\omega$-chain length Chem. Phys. Lipids, 63, 243250, 1992.

Inoue, T., Hisatsugu, Y., Ishikawa, R., and Suzuki, M.: Solid-liquid phase behavior of binary fatty acid mixtures 2 . Mixtures of oleic acid with lauric acid, myristic acid, and palmitic acid, Chem. Phys. Lipids, 127, 161-173, 2004a.

Inoue, T., Hisatsugu, Y., Yamamoto, R., and Suzuki, M.: Solidliquid phase behavior of binary fatty acid mixtures 1 . Oleic acid/stearic acid and oleic acid/behenic acid mixtures, Chem. Phys. Lipids, 127, 143-152, 2004b.
Inoue, T., Hisatsugu, Y., Suzuki, M., Wang, Z., and Zheng, L.: Solid-liquid phase behavior of binary fatty acid mixtures 3. Mixtures of oleic acid with capric acid (decanoic acid) and caprylic acid (octanoic acid), Chem. Phys. Lipids, 132, 225-234, 2004c.

Iwahashi, M., Kasahara, Y., Matsuzawa, H., Yagi, K., Nomura, K., Terauchi, H., Ozaki, Y., and Suzuki, M.: Self-diffusion, dynamical molecular conformation, and liquid structures of $n$-saturated and unsaturated fatty acids, J. Phys. Chem. B, 104, 6186-6194, 2000.

Iwahashi, M., Suzuki, M., Czarnecki, M. A., Liu, Y., and Ozaki, Y.: Near-IR molar absorption coefficient for the $\mathrm{OH}$-stretching mode of cis-9-octadecenoic acid and dissociation of the acid dimers in the pure liquid state, J. Chem. Soc. Faraday Trans., 91, 697-701, 1995.

Iwahashi, M., Takebayashi, S., Umehara, A., Kasahara, Y., Minami, H., Matsuzawa, H., Inoue, T., and Takahashi, H.: Dynamical dimer structure and liquid structure of fatty acids in their binary liquid mixture: dodecanoic acid and 3-phenylpropionic acids system, Chem. Phys. Lipids, 129, 195-208, 2004.

Iwahashi, M., Yamaguchi, Y., Kato, T., Horiuchi, T., Sakurai, I., and Suzuki, M.: Temperature dependence of molecular conformation and liquid structure of cis-9-octadecenoic acid, J. Phys. Chem., 95, 445-451, 1991.

Jacobson, M. C., Hansson, H.-C., Noone, K. J., and Charlson, R. J.: Organic atmospheric aerosols: review and state of the science, Rev. Geophys. Space Phys., 38, 267-294, 2000.

Kanakidou, M., Seinfeld, J. H., Pandis, S. N., Barnes, I., Dentener, F. J., Facchini, M. C., Van Dingenen, R., Ervens, B., Nenes, A., Nielson, C. J., Swietlicki, E., Putaud, J. P., Balkanski, Y., Fuzzi, S., Horth, J., Moortgat, G. K., Winterhalter, R., Myhre, C. E. L., Tsigaridis, K., Vignati, E., Stephanou, E. G., and Wilson, J.: Organic aerosol and global climate modelling: a review, Atmos. Chem. Phys., 5, 1053-1123, 2005,

http://www.atmos-chem-phys.net/5/1053/2005/.

Katrib, Y., Biskos, G., Buseck, P. R., Davidovits, P., Jayne, J. T., Mochida, M., Wise, M. E., Worsnop, D. R., and Martin, S. T.: Ozonolysis of mixed oleic-acid/stearic-acid particles: Reaction kinetics and chemical morphology, J. Phys. Chem. A, 109, 10910-10919, 2005a.

Katrib, Y., Martin, S. T., Hung, H.-M., Rudich, Y., Zhang, H., Slowik, J. G., Davidovits, P., Jayne, J. T., and Worsnop, D. R.: Products and mechanisms of ozone reactions with oleic acid for aerosol particles having core-shell morphologies, J. Phys. Chem. A, 108, 6686-6695, 2004.

Katrib, Y., Martin, S. T., Rudich, Y., Davidovits, P., Jayne, J. T., and Worsnop, D. R.: Density changes of aerosol particles as a result of chemical reaction, Atmos. Chem. Phys., 5, 275-291, $2005 \mathrm{~b}$.

Kawamura, K. and Gagosian, R. B.: Implications of $\omega$ oxocarboxylic acids in the remote marine atmosphere for photooxidation of unsaturated fatty acids, Nature, 325, 330-332, 1987.

Ketseridis, G. and Eichmann, R.: Organic compounds in aerosol samples, Pure Appl. Geophys., 116, 274-282, 1978.

Knopf, D. A., Anthony, L. M., and Bertram, A. K.: Reactive uptake of $\mathrm{O}_{3}$ by multicomponent and multiphase mixtures containing oleic acid, J. Phys. Chem. A, 109, 5579-5589, 2005.

Knopf, D. A., Mak, J., Gross, S., and Bertram, A. K.: Does atmospheric processing of saturated hydrocarbon surfaces by $\mathrm{NO}_{3}$ lead to volatilization?, Geophys. Res. Lett., 33, L17816, doi:10.1029/2006GL026884, 2006. 
Köhler, H.: The nucleus in and the growth of hygroscopic particles, Trans. Faraday Soc., 32, 1152-1161, 1936.

Kolb, C. E., Davidovits, P., Jayne, J. T., Shi, Q., and Worsnop, D. R.: Kinetics of trace gas uptake by liquid surfaces, Prog. React. Kinet. Mec., 27, 1-46, 2002.

Kumar, P. P., Broekhuizen, K., and Abbatt, J. P. D.: Organic acids as cloud condenstaion nuclei: Laboratory studies of highly soluble and insoluble species, Atmos. Chem. Phys., 3, 509-520, 2003, http://www.atmos-chem-phys.net/3/509/2003/.

LaFranchi, B. W. and Petrucci, G. A.: Photoelectron resonance capture ionization (PERCI): A novel technique for the softionization of organic compounds, J. Am. Soc. Mass Spectrom., 15, 424-430, 2004.

LaFranchi, B. W. and Petrucci, G. A.: A comprehensive characterization of photoelectron resonance capture ionization aerosol mass spectrometry for the quantitative and qualitative analysis of organic particulate matter, Int. J. Mass Spectrom., 258, 120-133, 2006.

LaFranchi, B. W., Zahardis, J., and Petrucci, G. A.: Photoelectron resonance capture ionization mass spectrometry: a soft ionization source for mass spectrometry of particle-phase organic compounds, Rapid Commun. Mass Spectrom., 18, 2517-2521, 2004.

Ledea, O., Díaz, M., Molerio, J., Jardines, D., Rosado, A., and Correa, T.: ${ }^{1}$ H-NMR spectroscopy study of oleic acid and methyl oleate ozonation in different reaction conditions, Revista CENIC Ciencias Químicas, 34, 3-8, 2003.

Lee, A. K. Y., Lau, A. P. S., Cheng, J. Y. W., Fang, M., and Chan, C. K.: Source identification analysis for the airborne bacteria and fungi using a biomarker approach, Atmos. Environ., in press, 2007.

Lewin, A. G., Johnson, D., Price, D. W., and Marston, G.: Aspects of the kinetics and mechanism of the gas-phase reactions of ozone and conjugated dienes, Phys. Chem. Chem. Phys., 3, 1253-1261, 2001.

Limbeck, A. and Puxbaum, H.: Organic acids in continental background aerosols, Atmos. Environ., 33, 1847-1852, 1999.

Lohmann, U. and Feichter, J.: Global indirect aerosol effects: a review, Atmos. Chem. Phys., 5, 715-737, 2005, http://www.atmos-chem-phys.net/5/715/2005/.

Lovejoy, E. R., Huey, L. G., and Hanson, D. R.: Atmospheric fate of $\mathrm{CF}_{3} \mathrm{OH}$ 2: Heterogeneous reaction, J. Geophys. Res., 100, 18 775-18 780, 1995.

Mag, T.: Canola and Rapeseed. Production, Chemistry, Nutrition, and Processing Technology, Van Nostrand Reinhold, New York, 1990.

Marks, R., Kruczalak, K., Jankowska, K., and Michalska, M.: Bacteria and fungi in air over the Gulf of Gdansk and Baltic Sea, J. Aerosol Sci., 32, 237-250, 2001.

Martin, S. T.: Interactive comment on "The oleic acid-ozone heterogeneous reaction system: products, kinetics, secondary chemistry, and atmospheric implications of a model system - a review," Atmos. Chem. Phys. Discuss., 6, S4979-S4980, 2006 a.

Martin, S. T.: Interactive comment on "The oleic acid-ozone heterogeneous reaction system: products, kinetics, secondary chemistry, and atmospheric implications of a model system - a review," Atmos. Chem. Phys. Discuss., 6, S4975-S4978, 2006 b.

Martinez, R. I., Herron, J. T., and Huie, R. E.: The mechanism of ozone-alkene reactions in the gas phase. A mass spectrometric study of the reactions of eight linear and branched-chain alkenes,
J. Am. Chem. Soc., 103, 3807-3820, 1981.

Marty, J. C., Saliot, A., Buat-Ménard, P., Chesselet, R., and Hunter, K. A.: Relationship between the lipid compositions of marine aerosols, the sea surface mircolayer, and subsurface water, J. Geophys. Res., 84, 5707-5716, 1979.

Maßling, A., Wiedensohler, A., Busch, B., Neusüß, C., Quinn, P., Bates, T., and Covert, D.: Hygroscopic properties of different aerosol types over the Atlantic and Indian Oceans, Atmos. Chem. Phys., 3, 1377-1397, 2003,

http://www.atmos-chem-phys.net/3/1377/2003/.

Matthias-Maser, S. and Jaenicke, R.: The size distribution of primary biological aerosol particles with radii $>0.2 \mu \mathrm{m}$ in an urban/rural influenced region, Atmos. Res., 39, 279-286, 1995.

McFiggans, G., Artaxo, P., Baltensperger, U., Coe, H., Facchini, M. C., Feingold, G., Fuzzi, S., Gysel, M., Laaksonen, A., Lohmann, U., Mentel, T. F., Murphy, D. M., O’Dowd, C. D., Snider, J. R., and Weingartner, E.: The effect of physical and chemical aerosol properties on warm cloud droplet activation, Atmos. Chem. Phys., 6, 2593-2649, 2006,

http://www.atmos-chem-phys.net/6/2593/2006/.

McNeill, V. F., Wolfe, G. M., and Thorton, J. A.: The oxidation of oleate in submicron aqueous salt aerosols: Evidence of a surface process, J. Phys. Chem. A, 111, 1073-1083, 2007.

Mmereki, B. T. and Donaldson, D. J.: Direct observation of the kinetics of an atmospherically important reaction at the air-aqueous interface, J. Phys. Chem. A, 107, 11 038-11 042, 2003.

Mochida, M., Katrib, Y., Jayne, J. T., Worsnop, D. R., and Martin, S. T.: The relative importance of competing pathways for the formation of high-molecular-weight peroxides in the ozonolysis of organic aerosol particles, Atmos. Chem. Phys., 6, 4851-4866, 2006, http://www.atmos-chem-phys.net/6/4851/2006/.

Mochida, M., Kitamori, Y., and Kawamura, K.: Fatty acids in the marine atmosphere: Factors governing their concentrations and evaluation of organic films on sea-salt particles, J. Geophys. Res., 107, 4325, doi:10.1029/2001JD001278, 2002.

Moise, T. and Rudich, Y.: Reactive uptake of ozone by proxies for organic aerosols: Surface versus bulk processes, J. Geophys. Res., 105, 14 667-14 676, 2000.

Moise, T. and Rudich, Y.: Uptake of $\mathrm{Cl}$ and $\mathrm{Br}$ by organic surfaces - a perspective on organic aerosols processing by tropospheric oxidants, Geophys. Res. Lett., 28, 4083-4086, 2001.

Moise, T. and Rudich, Y.: Reactive uptake of ozone by aerosolassociated unsaturated fatty acids: kinetics, mechanism, and products, J. Phys. Chem. A, 106, 6469-6476, 2002.

Moise, T., Talukdar, R. K., Frost, G. J., Fox, R. W., and Rudich, Y.: Reactive uptake of $\mathrm{NO}_{3}$ by liquid and frozen organics, J. Geophys. Res., 107, AAC6/1-AAC6/9, 2001.

Moise, T., Talukdar, R. K., Frost, G. J., Fox, R. W., and Rudich, Y.: Reactive uptake of $\mathrm{NO}_{3}$ by liquid and frozen organics, J. Geophys. Res., 107, 4014, doi:10.1029/2001JD000334, 2002.

Molina, M. J., Ivanov, A. V., Trakhtenberg, S., and Molina, L. T.: Atmospheric evolution of organic aerosol, Geophys. Res. Lett., 31, L22104, doi:10.1029/2004GL020910, 2004.

Morris, J. W., Davidovits, P., Jayne, J. T., Jimenez, J. L., Shi, Q. Kolb, C. E., Worsnop, D. R., Barney, W. S., and Cass, G.: Kinetics of submicron oleic acid aerosols with ozone: a novel mass spectrometric technique, Geophys. Res. Lett., 29, 71/71-71/74, 2002. 
Murray, R. W.: The mechanism of ozonolysis, Acc. Chem. Res., 1, 313-320, 1968.

Murray, R. W. and Williams, G. J.: Ozonolysis. Steric effects in the aldehyde, J. Org. Chem., 34, 1891-1895, 1969.

Mysak, E. R., Wilson, K. R., Jimenez-Cruz, M., Ahmed, M., and Baer, T.: Synchrotron radiation based aerosol time-of-flight mass spectrometry for organic constituents, Anal. Chem., 77, 59535960, 2005.

Nash, D. G., Liu, F., Mysak, E. F., and Baer, T.: Aerosol particle mass spectrometry with low photon energy laser ionization, Int. J. Mass Spectrom., 241, 89-97, 2005.

Nash, D. G., Tolocka, M. P., and Baer, T.: The uptake of $\mathrm{O}_{3}$ by myristic acid - oleic acid mixed particles: evidence for solid surface layers, Phys. Chem. Chem. Phys., 8, 4468-4475, 2006.

Neeb, P., Horie, O., and Moortgat, G. K.: The nature of the transitory product in the gas-phase ozonolysis of ethene, Chem. Phys. Lett., 246, 150-156, 1995.

Neeb, P., Horie, O., and Moortgat, G. K.: Gas-phase ozonolysis of ethene in the presence of hydroxylic compounds, Int. J. Chem. Kinet., 28, 721-730, 1996.

Neeb, P., Horie, O., and Moortgat, G. K.: The ethene - ozone reaction in the gas phase, J. Phys. Chem. A, 102, 6778-6785, 1998.

Nishikawa, A., Yamada, K., Matsutani, S., Higo, M., Kigawa, H., and Inagaki, T.: Structure of ozonolysis products of methyl oleate obtained in a carboxylic acid medium, JAOCS, 72, 735$740,1995$.

Novakov, T. and Corrigan, C. E.: Cloud condensation nucleus activity of the organic component of biomass smoke particles, Geophys. Res. Lett., 23, 2141-2144, 1996.

O'Dowd, C. D., Facchini, M. C., Cavalli, F., Ceburnis, D., Mircea, M., Decesari, S., Fuzzi, S., Yoon, Y. J., and Putaud, J.-P.: Biogenically driven organic contribution to marine aerosol, Nature, 431, 676-680, 2004.

Parrondo, R. M., Karafiloglou, P., Pappalardo, R. R., and Marcos, E. S.: Calculation of the weights of resonance structures of molecules in solution, J. Phys. Chem., 99, 6461-6467, 1995.

Pio, C., Alves, C., and Duarte, A.: Organic components of aerosols in a forested area of central Greece, Atmos. Environ., 35, 389401, 2001.

Pryde, E. H., Moore, D. J., and Cowan, J. C.: Hydrolytic, reductive and pyrolytic decomposition of selected ozonolysis products. Water as an ozonization medium, J. Am. Oil Chem. Soc., 45, 888-894, 1968.

Putaud, J.-P., Van Dingenen, R., Mangoni, M., Virkkula, A., Raes, F., Maring, H., Prospero, J. M., Swietlicki, E., Berg, O. H., Hillamo, R., and Mäkelä, T.: Chemical mass closure and assessment of the origin of the submicron aerosol in the marine boundary layer and the free troposphere at Tenerife during ACE2, Tellus, 52B, 141-168, 2000.

Quinn, J. G. and Wade, T. L.: Lipid measurements in the marine atmosphere and the sea surface microlayer, National Science Foundation, Washington, D.C., 1972.

Raymond, T. M. and Pandis, S. N.: Cloud activation of single-component organic aerosol particles, J. Geophys. Res., 107(D24), 4787, doi:10.1029/2002JD002159, 2002.

Rebrovic, L.: The peroxidic species generated by ozonolysis of oleic acid or methyl oleate in a carboxylic acid medium, J. Am. Oil Chem. Soc., 69, 159-165, 1992.

Reynolds, J. C., Last, D. J., McGillen, M., Nijs, A., Horn, A. B.,
Percival, C., Carpenter, L. J., and Lewis, A. C.: Structural analysis of oligomeric molecules formed from the reaction products of oleic acid ozonolysis, Environ. Sci. Technol., 40, 6674-6681, 2006.

Robinson, A. L., Subramanian, R., Donahue, N. M., BernardoBricker, A., and Rogge, W. F.: Source apportionment of molecular markers and organic aerosol. 3. Food cooking emissions, Environ. Sci. Technol., 40, 7820-7827, 2006.

Rogge, W. F., Hildemann, L. M., Mazurek, M. A., and Cass, G. R.: Sources of fine organic aerosol. 1. Charbroilers and meat cooking operations, Environ. Sci. Technol., 25, 1112-1125, 1991.

Rogge, W. F., Hildemann, L. M., Mazurek, M. A., and Cass, G. R.: Sources of fine organic aerosol. 2. Noncatalyst and catalystequipped automobiles and heavy-duty diesel trucks, Environ. Sci. Technol., 27, 636-651, 1993a.

Rogge, W. F., Hildemann, L. M., Mazurek, M. A., Cass, G. R., and Simoneit, B. R. T.: Sources of fine organic aerosol. 4. Particulate abrasion products from leaf surfaces of urban plants, Environ. Sci. Technol., 27, 2700-2711, 1993 b.

Rogge, W. F., Mazurek, M. A., Hildemann, L. M., Cass, G. R., and Simoneit, B. R. T.: Quantification of urban organic aerosols at a molecular level: identification, abundance and seasonal variation, Atmos. Environ., 27A, 1309-1330, 1993c.

Rudich, Y.: Laboratory perspectives on the chemical transformations of organic matter in atmospheric particles, Chem. Rev., 103, 5097-5124, 2003.

Rudich, Y., Donahue, N. M., and Mentel, T. F.: Aging of organic aerosol: Bridging the gap between laboratory and field studies, Ann. Rev. Phys. Chem., 58, 321-352, 2007.

Sander, W.: Carbonyl oxides: Zwitterions or diradicals?, Agnew. Chem. internat. Edit., 29, 344-354, 1990.

Schauer, J. J., Kleeman, M. J., Cass, G. R., and Simoneit, B. R. T.: Measurement of emissions from air pollution sources. 1. $\mathrm{C}_{1}$ through $\mathrm{C}_{29}$ organic compounds from meat charbroiling, Environ. Sci. Technol., 33, 1566-1577, 1999.

Schauer, J. J., Rogge, W. F., Hildemann, L. M., Mazurek, M. A., and Cass, G. R.: Source apportionment of airborne particulate matter using organic compounds as tracers, Atmos. Environ., 30, 3837-3855, 1996.

Schwartz, J., Dockery, D. W., and Neas, L. M.: Is daily mortality associated specifically with fine particles?, J. Air Waste Manage. Assoc., 46, 927-939, 1996.

Schwartz, J. and Neas, L.: Fine particles are more strongly associated than coarse particles with acute respiratory health effects in schoolchildren, Epidemiology, 11, 6-10, 2000.

Seinfeld, J. H. and Pandis, S. N.: Atmospheric Chemistry and Physics: From Air Pollution to Climate Change, WileyInterscience, NY, 1998.

Selçuki, C. and Aviyente, V.: A DFT study of carbonyl oxide and its methyl-substituted analogues in solution, Chem. Phys. Lett., 288, 669-676, 1998.

Shi, Q., Davidovits, P., Jayne, J. T., Worsnop, D. R., and Kolb, C. E.: Uptake of gas-phase ammonia. 1. Uptake by aqueous surfaces as a function of pH, J. Phys. Chem. A, 103, 8812-8823, 1999.

Simoneit, B. R. T.: Application of molecular marker analysis to vehicular exhaust for source reconciliations, Intern. J. Environ. Anal. Chem., 22, 203-233, 1985.

Simoneit, B. R. T.: Characterization of organic constituents in aerosols in relation to their origin and transportation: A review, 
Intern. J. Environ. Anal. Chem., 23, 207-237, 1986.

Simoneit, B. R. T., Cox, R. E., and Standley, L. J.: Organic matter of the troposphere - IV. Lipids in Harmattan aerosols of Nigeria, Atmos. Environ., 22, 983-1004, 1988.

Simoneit, B. R. T., Crisp, P. T., Mazurek, M. A., and Standley, L. J.: Composition of extractable organic matter of aerosols from the Blue Mountains and southeast coast of Australia, Environ. Int., 17, 405-419, 1991.

Simoneit, B. R. T. and Mazurek, M. A.: Organic matter of the troposphere - II. Natural background of biogenic lipid matter in aerosols over the rural western United States, Atmos. Environ., 16, 2139-2159, 1982.

Sin, D. W. M., Fung, W. H., Choi, Y. Y., Lam, C. H., Louie, P. K. K., Chow, J. C., and Watson, J. G.: Seasonal and spatial variation of solvent extractable organic compounds in fine suspended particulate matter in Hong Kong, J. Air Waste Manage. Assoc., 55, 291-301, 2005.

Smith, G. D., Woods III, E., DeForest, C. L., Baer, T., and Miller, R. E.: Reactive uptake of ozone by oleic acid aerosol particles: Application of single-particle mass spectrometry to heterogeneous reaction kinetics, J. Phys. Chem. A, 106, 8085-8095, 2002.

Sodeman, D. A., Toner, S. M., and Prather, K. A.: Determination of single particle mass spectral signatures from light-duty vehicle emissions, Environ. Sci. Technol., 39, 4569-4580, 2005.

Stephanou, E. G. and Stratigakis, N.: Oxocarboxylic and $\alpha, \omega-$ dicarboxylic acids: Photooxidation products of biogenic unsaturated fatty acids present in urban aerosols, Environ. Sci. Technol., 27, 1403-1407, 1993.

Sturrock, M. G., Cline, E. L., and Robinson, K. R.: The ozonation of phenanthrene with water as participating solvent, J. Org. Chem., 28, 2340-2343, 1963.

Su, F., Calvert, J. G., and Shaw, J. H.: A FT IR spectroscopic study of the ozone-ethene reaction mechanism in $\mathrm{O}_{2}$-rich mixtures, $\mathrm{J}$. Phys. Chem., 84, 239-246, 1980.

Sun, J. and Ariya, P. A.: Atmospheric organic and bio-aerosol as cloud condensation nuclei (CCN): A review, Atmos. Environ., 40, 795-820, 2006.

Sykes, D. C., Woods III, E., Smith, G. D., Baer, T., and Miller, R. E.: Thermal vaporization-vacuum ultraviolet laser ionization timeof-flight mass spectrometry of single aerosol particles, Anal. Chem., 74, 2048-2052, 2002.

Tervahattu, H., Hartonen, K., Kerminen, V.-M., Kupiainen, K., Aarnio, P., Koskentalo, T., Tuck, A. F., and Vaida, V.: New evidence of an organic layer on marine aerosols, J. Geophys. Res., 107, AAC1/1-AAC1/9, doi:10.1029/2000JD000282, 2002.

Tervahattu, H., Juhanoja, J., and Kupiainen, K.,: Identification of an organic coating on marine aerosol particles by TOF-MS, J. Geophys. Res., 107, ACH18-11-18-17, doi:10.1029/2001JD001403, 2002.

Tervahattu, H., Juhanoja, J., Vaida, V., Tuck, A. F., Niemi, J. V., Kupiainen, K., Kulmala, M., and Vehkamäki, H.: Fatty acids on continental sulfate aerosol particles, J. Geophys. Res., 110, D06207, doi:10.1029/2004JD005400, 2005.

Thornberry, T. and Abbatt, J. P. D.: Heterogeneous reaction of ozone with liquid unsaturated fatty acids: detailed kinetics and gas-phase product studies, Phys. Chem. Chem. Phys., 6, 84-93, 2004.

Tobias, H. J. and Ziemann, P. J.: Compound identification in organic aerosols using temperature-programmed thermal desorp- tion particle beam mass spectrometry, Anal. Chem., 71, 34283435, 1999.

Twomey, S.: The nuclei of natural cloud formation, part II: The supersaturation in natural clouds and the variation of cloud droplet concentration, Geofis. Pure Appl., 43, 243-248, 1959.

Utter, R. G., Burkholder, J. B., Howard, C. J., and Ravishankara, A. R.: Measurement of the mass accomodation coefficient of ozone on aqueous surfaces, J. Phys. Chem. , 96, 4973-4979, 1992.

Wadia, Y., Tobias, D. J., Stafford, R., and Finlayson-Pitts, B. J.: Real-time monitoring of the kinetics and gas-phase products of the reaction of ozone with an unsaturated phosopholipid at the air-water interface, Langmuir, 16, 9321-9330, 2000.

Wadt, W. R. and Goddard III, W. A.: The electronic structure of the Criegee intermediate. Ramifications for the mechanism of ozonolysis, J. Am. Chem. Soc., 97, 3004-3021, 1975.

Wang, G., Kawamura, K., Lee, S., Ho, K., and Cao, J.: Molecular, seasonal, and spatial distributions of organic aerosols from fourteen Chinese cities, Environ. Sci. Technol., 40, 4619-4625, 2006.

Woods III, E., Smith, G. D., Dessiaterik, Y., Baer, T., and Miller, R. E.: Quantitative detection of aromatic compounds in single aerosol particle mass spectrometry, Anal. Chem., 73, 2317-2322, 2001.

Woods III, E., Smith, G. D., Miller, R. E., and Baer, T.: Depth profiling of heterogeneously mixed aerosol particles using singleparticle mass spectrometry, Anal. Chem., 74, 1642-1649, 2002.

Worsnop, D. R., Morris, J. W., Shi, Q., Davidovits, P., and Kolb, C. E.: A chemical kinetic model for reactive transformations of aerosol particles, Geophys. Res. Lett., 29, 57/51-57/53, 2002.

$\mathrm{Yu}, \mathrm{S}$.: Role of organic acids (formic, acetic, pyruvic and oxalic) in the formation of cloud condensation nuclei (CCN): a review, Atmos. Res., 53, 185-217, 2000.

Zahardis, J., LaFranchi, B. W., and Petrucci, G. A.: Photoelectron resonance capture ionization-aerosol mass spectrometry of the ozonolysis products of oleic acid particles: Direct measure of higher molecular weight oxygenates, J. Geophys. Res., 110, D08307, doi:10.1029/2004JD005336, 2005.

Zahardis, J., LaFranchi, B. W., and Petrucci, G. A.: Direct observation of polymerization in the oleic acid - ozone heterogeneous reaction system by photoelectron resonance capture ionization aerosol mass spectrometry, Atmos. Environ., 40, 16611670, 2006a.

Zahardis, J., LaFranchi, B. W., and Petrucci, G. A.: The heterogeneous reaction of particle-phase methyl esters and ozone elucidate by photoelectron resonance capture ionization: Direct products of ozonolysis and secondary reactions leading to the formation of ketones, Int. J. Mass Spectrom., 253, 38-47, $2006 \mathrm{~b}$.

Zahardis, J., LaFranchi, B. W., and Petrucci, G. A.: Photoelectron resonance capture ionization mass spectrometry of fatty acids in olive oil, Eur. J. Lipid Sci. Technol., 108, 925-935, 2006c.

Zelikman, E. S., Yur'ev, Y. N., Berezova, L. V., and Tsyskovskii, V. K.: Ozonolysis of olefins in the presence of aliphatic alcohols and acids, Zh. Organ. Khim., 7, 633-636, 1971.

Zhao, Y., Hu, M., Slanina, S., and Zhang, Y.: Chemical compositions of fine particulate organic matter emitted from Chinese cooking, Environ. Sci. Technol., 41, 99-105, 2007.

Zheng, M., Wan, T. S. M., Fang, M., and Wang, F.: Characterization of non-volatile organic compounds in the aerosols of Hong Kong - Identification, abundance and origin, Atmos. Environ., 
31, 227-237, 1997.

Zheng, M., Fang, M., Wang, F., and To, K. L.: Characterization of the solvent extractable organic compounds in PM2.5 aerosols in Hong Kong, Atmos. Environ., 34, 2691-2702, 2000.
Ziemann, P. J.: Aerosol products, mechanisms, and kinetics of heterogeneous reactions with oleic acid in pure and mixed particles, Faraday Discuss., 130, 469-490, 2005. 